Cahiers Charlevoix

Études franco-ontariennes
Cahiers Charlevoix Études franco-ontariennes

or Crevenerix of

\title{
1910. Une première prise de parole collective en Ontario français
}

\section{René Dionne}

Volume 1, 1995

URI : https://id.erudit.org/iderudit/1039461ar

DOI : https://doi.org/10.7202/1039461ar

Aller au sommaire du numéro

\section{Éditeur(s)}

Société Charlevoix

Presses de l’Université d’Ottawa

\section{ISSN}

1203-4371 (imprimé)

2371-6878 (numérique)

Découvrir la revue

Citer cet article

Dionne, R. (1995). 1910. Une première prise de parole collective en Ontario français. Cahiers Charlevoix, 1, 15-124. https://doi.org/10.7202/1039461ar

\section{Résumé de l'article}

René Dionne, pionnier des études littéraires franco-ontariennes à l'Université d'Ottawa, se penche sur un texte fondateur de l'identité franco-ontarienne : les actes du Congrès d'éducation des Canadiens-Français d'Ontario tenu à Ottawa en 1910. Par le compte rendu fidèle et détaillé qu'il en donne, il réaffirme le long passé littéraire franco-ontarien, dont la prise de parole actuelle n'est qu'un épisode, puisqu'il a dénombré plus de deux cents oeuvres écrites par vingt-quatre écrivains outaouais qui prirent individuellement la parole entre 1865 et 1909. Puis il compare ce congrès aux grandes conventions nationales (la franco-américaine, les québécoises et les acadiennes) pour mieux marquer l'originalité du congrès franco-ontarien qui, bien que tardif, fut, observe l'auteur, démocratique, provincial, national, loyal, optimiste et littéraire. Devant les conflits politiques et religieux qui menaçaient de dégénérer, l'heure était à la vigilance et à la cohésion; la prise de parole de 1910 se devait d'être collective.
Ce document est protégé par la loi sur le droit d'auteur. L'utilisation des services d'Érudit (y compris la reproduction) est assujettie à sa politique d'utilisation que vous pouvez consulter en ligne.

https://apropos.erudit.org/fr/usagers/politique-dutilisation/ 


\title{
1910. \\ UNE PREMIĖRE PRISE DE PAROLE COLLECTIVE EN ONTARIO FRANÇAIS
}

\author{
René Dionne
}

Département des lettres françaises

Université d'Ottawa, Ottawa

Cahiers Charlevoix 1, 1995, pp. 15-124. 
I -1865-1909: LES DÉBuTS D'UNE INSTITUTION LITTÉRAIRE

FRANCO-ONTARIENNE

Les auteurs et leurs œuvres

La presse périodique

Les sociétés littéraires et leurs activités

Les imprimeurs et les éditeurs

II - 1865-1909: LA NAISSANCE ET LE DÉVELOPPEMENT D'UNE CONSCIENCE FRANCO-ONTARIENNE

Les préoccupations religieuses et politiques

Les prolégomènes d'un conflit

L'appel au rassemblement

Les préparatifs du congrès

III - 1910: LE CONGRÈS DE FONDATION DE L'ACFÉO.

UNE PREMIERE PRISE DE PAROLE COLLECTIVE

Un plaidoyer pour l'éducation chrétienne

Les buts du congrès

Entre le passé et l'avenir

L'éducation de la volonté fait l'homme

L'enseignement professionnel

École séparée et école publique

La lutte contre l'intempérance

Les francophones de l'Est ontarien

Les francophones du Nouvel Ontario

Le droit à une éducation canadienne-française complète

Les francophones de l'Ouest ontarien

La mutualité, un remède

La nécessité de fonder une association nationale

L'accès aux charges publiques

Le mal des chantiers

Le banquet de clôture

Les francophones de la région de Pembroke

IV - 1910: LE CONGRÈS DE FONDATION DE L'ACFÉO.

UNE PIĖCE D'IDENTITÉ

Une convention tardive

Une convention franco-ontarienne

Une convention démocratique

Une convention provinciale

Une convention nationale

Une convention loyale

Une convention optimiste

Une convention littéraire 


\section{0.}

UNE PREMIËRE PRISE DE PAROLE COLLECTIVE EN ONTARIO FRANÇAIS

\section{INTRODUCTION}

Quand cessera-t-on de nous rebattre les oreilles avec des phrases comme les suivantes: "la littérature franco-ontarienne est jeune», "il n'y a pas eu de prise de parole en Ontario français avant la décennie de 1970", "l'institution littéraire est chose récente en Ontario français», «il n'y a pas eu d'éditeur francoontarien avant $1972 »$, etc.?

Il y a vingt ans, on pouvait excuser l'ignorance qui se cache derrière ces affirmations gratuites. Aujourd'hui, après les études qui ont été publiées, les nombreux articles qui ont paru, les cours qui ont été donnés depuis 1976 à des centaines d'étudiants dans plusieurs universités et l'enseignement d'œuvres ou de textes choisis au niveau du collégial et du secondaire, il est difficile d'accepter en silence de telles affirmations.

Que beaucoup d'œuvres publiées ces dernières années manquent de maturité, nous en convenons 
tous, mais cela ne fait pas du corpus de plusieurs centaines d'œuvres qui ont été écrites et publiées par les francophones de l'Ontario depuis un siècle et demi une littérature jeune. Affirmer que les FrancoOntariens n'ont pas pris la parole en Ontario avant 1970 , c'est faire une insulte aux générations antérieures qui ont lutté avec succès, par la parole et par l'action, pour établir et faire croître en Ontario la communauté francophone à laquelle nous appartenons et qui leur doit jusqu'à présent la conservation de sa langue et de sa culture françaises.

Nous n'avons pas l'intention de réfuter ici toutes les affirmations gratuites qui ont cours actuellement dans le domaine littéraire franco-ontarien. Nous voulons simplement réaffirmer que les Franco-Ontariens ont un long passé littéraire, qu'ils ont pris la parole avec force et fierté depuis plus d'un siècle et que leur première prise de parole collective eut lieu dès 1910 . Il y en eut d'autres par la suite, mais l'espace pour les raconter nous fait défaut ici; nous affirmerons seulement qu'il n'y en a pas eu de plus démocratique ni de plus collective depuis, et que celle-là fut substantielle et littéraire au point de marquer nettement la transition entre deux périodes d'histoire.

Pour mieux situer cette prise de parole dans l'histoire littéraire de l'Ontario français, nous consacrerons la première partie de notre étude à la période de 1865-1909, qui vit les débuts d'une institution littéraire franco-ontarienne (I) ainsi que la naissance et le développement d'une prise de conscience francoontarienne (II). Dans la seconde partie, nous présenterons le contenu de la prise de parole collective que fut, en 1910, le Congrès d'éducation des Canadiens français de l'Ontario (III), puis nous comparerons 
cette convention nationale à celle qui eut lieu à Québec en 1880 et aux conventions acadiennes de 1881,1884 et 1890 (IV). De cette comparaison ressortiront comme particulières aux Franco-Ontariens un certain nombre de manières de penser et de faire que nous considérerons comme autant de composantes ou de traits particuliers d'une identité collective qui en compte déjà bien d'autres et qui va s'affirmer plus fermement que jamais à compter de 1912 et jusqu'en 1927, sous la pression du Règlement 17.

\section{1865-1909: LES DÉBuTS D'UNE INSTTTUTION LTTÉRAIRE FRANCO-ONTARIENNE}

Il importe de rappeler ici que, en Ontario français, la littérature a précédé l'institution. En effet, dès les premières années du régime français (1610-1760) ${ }^{1}$, puis sous la domination anglaise $(1760-1865)^{2}$, il s'est trouvé des francophones pour écrire en Ontario et sur l'Ontario. Découvreurs, explorateurs, aventuriers, missionnaires, voyageurs, administrateurs ou historiens, ces auteurs, sauf quelques-uns au début du XIX siècle, s'adressèrent la plus grande partie du temps à un public européen. Leurs œuvres n'en constituent pas moins un corpus important, pierre d'assise de l'histoire ontarienne et source d'inspiration encore trop peu exploitée par les écrivains francoontariens, alors que leurs compatriotes québécois, et même les Canadiens anglais, y ont beaucoup puisé.

\footnotetext{
${ }^{1}$ Voir René Dionne, «La Littérature franco-ontarienne. Esquisse historique (1610-1987)", dans les Franco-Ontariens, sous la direction de Cornelius J. Jaenen, coll. "Ontario Historical Studies», Ottawa, les Presses de l'Université d'Ottawa, 1993, pp. 343-347.

2 Ibid., pp. 347-350.
} 
LES AUTEURS ET LEURS CEUVRES

Cependant, ce n'est qu'avec l'arrivée à Ottawa, en 1865-1866, des fonctionnaires et des parlementaires fédéraux que commence la littérature moderne de l'Ontario français ${ }^{3}$. Quelques-uns de ces arrivants, dont le romancier Antoine Gérin-Lajoie ${ }^{4}$, le conteur Joseph-Charles Taché5, le poète Alfred Garneau ${ }^{6}$, le chansonnier et critique littéraire EmmanuelMarie Blain de Saint-Aubin ${ }^{7}$ et le journaliste Stanislas Drapeau $^{8}$, avaient participé au mouvement littéraire du début de la décennie 1860 à Québec. Ils avaient

${ }^{3}$ Ibid., pp. 350-356.

${ }^{4}$ Voir R. Dionne, Antoine Gérin-Lajoie, homme de lettres, coll. «Études», Sherbrooke, Éditions Naaman, 1978, 434[1] p. — Adjoint au directeur de la Bibliothèque du Parlement, Gérin-Lajoie avait habité Toronto de 1856 à 1859; il y avait publié en 1857-1858 les deux tomes du Catalogue de la Bibliothèque du Parlement, imprimé par ordre de la Législature, Toronto, John Lovell, vili, 1895 p. [pagination continue]. ${ }^{5}$ Voir Jean-Guy Nadeau, «Taché, Joseph-Charles (baptisé CharlesJoseph)", dans Dictionnaire biographique du Canada [désormais: $D B C$ ], sous la direction de Francess G. Halpenny et Jean Hamelin, Québec, les Presses de l'Université Laval, vol. 12, pp. 1103-1106; Éveline Bossé, Joseph-Charles Taché (1820-1894). Un grand représentant de l'élite canadienne-française, Québec, Éditions Garneau, 1971, 324 p. - Député du comté de Rimouski, Taché avait fait de longs séjours à Toronto en 1850 et 1851 et de 1856 à 1859; pendant ce dernier séjour, il avait publié le Canada et l'Exposition universelle de 1855, Toronto, des presses à vapeur de John Lovell, 1856, 477[2] p., et Des provinces de l'Amérique du Nord et d'une union fédérale, Québec, J.-T. Brousseau, $1858,252 \mathrm{p}$.

"Voir Suzanne Prince, «Alfred Garneau. Édition critique de son œuvre», thèse présentée à l'École des études supérieures de l'Université d'Ottawa en vue de l'obtention du Ph. D. en littérature française, 1974, vil, 734 f.; Paul Wyczynski, «Poésies», dans Dictionnaire des œuvres littéraires du Québec [désormais: DOLQ], sous la direction de Maurice Lemire, $2^{\text {e }}$ édition revue, corrigée et mise à jour, Montréal, Fides, 1980, vol. 1, pp. 598-603.

7 Voir Philippe Sylvain, «Blain de Saint-Aubin, Emmanuel-Marie», dans $D B C$, vol. 11 , pp. 90-92.

8 Voir Elzéar Lavoie, «Drapeau, Stanislas (baptisé Jean-BaptisteStanislas)», dans DBC, vol. 12, pp. 292-296. 
écrit dans la vieille capitale; ils écriraient aussi dans la nouvelle. Ils s'étaient imaginé qu'ils allaient être exilés dans les bois; ils se retrouvèrent avec leur excellente bibliothèque (celle du Parlement) au milieu d'une population francophone qui avait déjà mis en place des institutions scolaires, dont l'Université d'Ottawa, issue du Collège Saint-Joseph fondé par les Oblats en $1848^{\circ}$, et des sociétés à la fois nationales et littéraires, telles la Société Saint-Jean-Baptiste et l'Institut canadien-français qui dataient des années 1852 et $1853^{10}$.

S'établirent aussi à Ottawa entre 1865 et 1910 , les écrivains suivants: le généalogiste et historien Cyprien Tanguay ${ }^{11}$ (1865), le poète Jean-Amable Bélanger (1865), le dramaturge Augustin Laperrière ${ }^{12}$ (1865), le polygraphe Benjamin Sulte ${ }^{13}$ (1866), le journaliste

\footnotetext{
${ }^{9}$ Volr Roger Guindon, Coexistence difficile. La Dualité linguistique d l'Université d'Ottawa, vol. 1: 1848-1898, Ottawa, les Presses de l'Université d'Ottawa, 1989, xil[vili], 209 p.; Coexistence menacée. La Dualité linguistique d l'Université d'Ottawa, vol. 2: 1898-1936, 1992, xvili, 235 p.

${ }^{10}$ Madeleine Charlebois-Dirschauer, «La Naissance des sociétés sœurs: l'Institut canadien-français et la Société Saint-Jean-Baptiste de Bytown (1852-1856)", dans Solitude rompue, textes réunis par Cécile CloutierWojciechowska et Réjean Robidoux en hommage à David M. Hayne, coll. "Cahiers du CRCCF», 23, Ottawa, Éditions de l'Université d'Ottawa, 1986, pp. 38-46.

${ }^{11}$ Voir Noël Bélanger, "Tanguay, Cyprien», dans $D B C$, vol. 13, pp. 1094-1097. [Ramsay Cook remplace Francess Halpenny comme directeur général de ce volume.]

${ }^{12}$ Voir Marcel Fortin, «Le Théâtre d'expression française dans l'Outaouais, des origines à 1967", thèse de $\mathrm{Ph}$. D. (lettres françaises) présentée à l'Université d'Ottawa en 1985, 2 vol., Ottawa, Marcel Fortin, 1986, vol. 1, ff. 380-381.

${ }^{13}$ Voir Gérard Malchelosse, Cinquante-six Ans de vie littéraire. Benjamin Sulte et son cuvre, essai de bibliographie des travaux historiques et littéraires (1860-1916) de ce polygraphe canadien, précédé d'une notice biographique par Gérard Malchelosse [...] d'un poème inédit par Albert Ferland [...] et d'une préface par Casimir Hébert [...], Montréal, «Le Pays laurentien», 1916, [iv], 78 p.
} 
et essayiste Joseph Tassé ${ }^{14}$ (1867), l'orateur Wilfrid Laurier $^{15}$ et le chroniqueur Alphonse Lusignan ${ }^{16}$ (1874), le journaliste Rémi Tremblay ${ }^{17}$ et le biographe et historien Alfred-Duclos De Celles ${ }^{18}$ (1880), le romancier Joseph Marmette ${ }^{19}$ (1882), le dramaturge Stanislas Brault ${ }^{20}(1883)$, le critique littéraire Charles Savary ${ }^{21}$ (1888), l'historien Alexis de Barbezieux (1890), le poète William Chapman ${ }^{22}$ (1898), l'économiste et essayiste Errol Bouchette ${ }^{23}$ (1898), le linguiste et conteur Sylva Clapin ${ }^{24}$ (1900), le dramaturge Sylvio Corbeil ${ }^{25}$ (1902), le romancier

${ }_{14}$ Voir Jean-Marie Lebel, «Tassé, Joseph», dans DBC, vol. 12, pp. 1116-1118; Geo[rge] Maclean Rose, A Cyclopcedia of Canadian Biography: Being Chiefly Men of the Time, a collection of persons distinguished in professionnal and political life; leaders in the commerce and industry of Canada, and successful pioneers, "Rose's National Biographical Series», 1, Toronto, Rose Publishing Company, 1886, pp. 484-485.

${ }^{15}$ Voir L[ouis] Le Jeune, Dictionnaire général de biographie, histoire, littérature, agriculture, commerce, industrie et des arts, sciences, maurs, coutumes, institutions politiques et religieuses du Canada [désormais: DGC], Ottawa, Université d'Ottawa, 1931, vol. 2, pp. 99-101.

${ }^{16}$ Voir ibid., p. 195.

17 Voir Dictionnaire des auteurs de langue française en Amérique du Nord [désormais: DALFAN], [par] Réginald Hamel, John Hare [et] Paul Wyczynski, Montréal, Fides, 1989, p. 1305.

${ }^{18}$ Voir L. Le Jeune, DGC, vol. 1, pp. 480-481.

${ }^{19}$ Voir Roger Le Moine, Joseph Marmette. Sa vie, son $\propto u v r e$, suivi de À travers la vie, roman de mœurs canadiennes de Joseph Marmette, coll. "Vie des lettres canadiennes», 5, Québec, les Presses de l'Université Laval, 1968, 250[1] p.

${ }^{20}$ Voir M. Fortin, «Le Théâtre d'expression française dans l'Outaouais, des origines à 1967», vol. 1 , ff. 356-357.

21 Voir En collaboration, "Savary, Charles», $D B C$, vol. 11, pp. 888889.

${ }^{22}$ Voir Jean Ménard, La Vie littéraire au Canada français, coll. «Cahiers du Centre de recherche en civilisation canadienne-française», 5, Ottawa, Éditions de l'Université d'Ottawa, 1971, pp. 15-34, 125-130.

${ }^{23}$ Voir L. Le Jeune, DGC, Ottawa, Université d'Ottawa, 1931, vol. 1, p. 217. ${ }^{24}$ Voir ibid., pp. 391-392.

${ }^{25}$ Voir M. Fortin, «Le Théâtre d'expression française dans l'Outaouais, des origines à 1967», vol. 1, ff. 361-362. 
et dramaturge Rodolphe Girard ${ }^{26}$ (1904).

Dix-neuf de ces auteurs étaient originaires du Québec et trois, Savary, de Barbezieux et Blain de Saint-Aubin, étaient venus de France, ainsi qu'un quatrième peut-être, Laperrière. À côté d'eux ne se trouvèrent que deux écrivains nés à Ottawa: le poète Rodolphe Chevrier ${ }^{27}$ et le romancier et dramaturge Régis Roy ${ }^{28}$. En 1909, vingt-quatre de ces vingt-cinq auteurs avaient fait paraître 201 ouvrages, soit 154 depuis qu'ils résidaient en Ontario, et douze d'entre eux 47 du temps qu'ils habitaient le Québec; les douze autres n'avaient publié que comme résidants de l'Ontario. Le vingt-cinquième, Blain de SaintAubin, n'avait pas recueilli en volumes les nombreux poèmes, chansons, contes ${ }^{29}$ et articles de critique littéraire qu'il avait publiés dans les journaux du Québec, puis de l'Ontario.

\section{LA PRESSE PERIODIQUE}

Ses confrères outaouais ont collaboré à des journaux et à des revues du Québec, mais ils ont aussi fondé ou nourri des périodiques en terre ontarienne ${ }^{30}$.

\footnotetext{
${ }^{26}$ Voir M. Charlebois-Dirschauer, Rodolphe Girard (1879-1956). Sa vie, son œuvre, Montréal, Fides, 1986,159 p.

27 Voir DALFAN, p. 301.

${ }^{28}$ Voir ibid., pp. 1199-1200.

${ }^{29}$ Voir Aurélien Boivin, Le Conte littéraire québécois au XIX' siècle, essai de bibliographie critique et analytique, préface de Maurice Lemire, Montréal, Fides, 1975, pp. 68-69.

${ }^{30}$ Voir Francis-J. Audet, Historique des journaux d'Ottawa, Ottawa, A. Bureau, 1896, 45 p.; Paul-François Sylvestre, Les Journaux de l'Ontario français, 1858-1983, coll. "Documents historiques», 81, Sudbury, Société historique du Nouvel-Ontario (Université de Sudbury), 1984, [iv], 1, 55 p.; Gaétan Gervais, "L'Ontario français (1821-1910)», dans les Franco-Ontariens, sous la direction de Cornelius J. Jaenen, pp. 6263.
} 
De 1858 à 1909, une trentaine de journaux ont vu le jour à Ottawa. Plusieurs furent éphémères, mais, à partir de 1861, la capitale n'a jamais été sans journal. La plupart des journaux de cette époque ont consacré des colonnes à la littérature et la majorité d'entre eux ont fait une large place aux feuilletons. Le Journal pour tous (1878-1880) et Nouvelle Publication populaire (1896) furent fondés dans un but littéraire et quelque quatre cents articles concernant la vie littéraire (histoire et critique) ont été repérés dans les périodiques suivants: la Gazette des familles canadiennes et acadiennes (1877), la Gazette des familles (1878), le Foyer domestique (1876-1879), l'Album des familles (1880-1884), la Lyre d'or (18871889) et les Mémoires et comptes rendus de la Société royale du Canada, (1882-1909) ${ }^{31}$. À ce nombre, il faut ajouter quelques milliers ${ }^{32}$ de textes de création littéraire qui ont paru dans ces périodiques et dans les vingt-cinq autres (ou plus) qui ont existé à Ottawa avant 1910.

On trouve aussi des textes littéraires dans les périodiques des autres régions, mais dans une propor-

${ }^{31}$ René Dionne et Plerre Cantin, Bibliographie de la critique de la littérature québécoise et canadienne-française dans les revues canadiennes (1760-1899), coll. "Histoire littéraire du Québec et du Canada français», 18, Ottawa, les Presses de l'Université d'Ottawa, 1992, [vii], 308 p.; Bibliographie de la critique de la littérature française et étrangère dans les revues canadiennes (1760-1899), environ 120 pages une fois imprimées (manuscrit inédit, en quête d'une aide financière à la publication).

${ }^{32}$ Cette estimation se fonde sur la récolte que nous avons faite avec Pierre Cantin en dépouillant, au complet (quand ce fut possible) ou en partie, les périodiques cités et quelques autres, dont les quotidiens suivants: le Courrier d'Outaouais (1870-1875), le Courrier fédéral (18871888), le Canada (1879-1896) et le Temps (1894-1896); nous conservons les résultats de ces dépouillement sur fiches en attendant d'avoir l'alde qui nous permettrait de les compléter et de les publier pour les besoins des chercheurs et des professeurs. 
tion moindre que dans ceux d'Ottawa. Il est intéressant de constater, même si on ne peut les qualifier de franco-ontariens, que trois journaux imprimés à Détroit (É.-U.) ont circulé très tôt $(1825,1843,1850)$, mais moins d'une année chacun, dans le Sud-ouest avant que ne naissent le Progrès (1858), premier journal outaouais, et l'Étoile du Nord (1870) de Sandwich, qui semble avoir été le premier journal francoontarien de sa région; sept se succédèrent à Windsor et deux à Chatham. Dans l'Est, c'est Plantagenet qui prendra l'initiative (1885); Alfred, Clarence-Creek, L'Orignal et Hawkesbury suivront. En 1894, SturgeonFalls donne au Nord son premier journal; Mattawa aura le sien l'année suivante, et Cobalt, en $1907^{33}$.

\section{LES SOCIETTES LITTÉRAIRES ET LEURS ACTTVITÉS}

Les journaux outaouais de l'époque font état régulièrement des travaux des nombreuses sociétés littéraires de la région. L'Institut canadien-français a généré plusieurs d'entre elles: le Cercle dramatique d'Ottawa ${ }^{34}$ (1853), le Cercle littéraire de la jeunesse catholique d'Ottawa (1862), le Cercle des familles, qui organise des soirées littéraires (1870), le Club des débats (1875-1878), le Club des discussions (1880), le Cercle littéraire et scientifique (1894). En 1909, naît l'Alliance française d'Ottawa. Les écrivains participent aux activités de ces sociétés; certaines ont même été fondées par l'un ou l'autre d'entre eux. Ils

${ }^{33}$ P.-F. Sylvestre, Les Journaux de l'Ontario français, 1858-1983, pp. 14-15; "Cent Ans de presse francophone dans le Sud-ouest ontarien", dans Propos sur la littérature outaouaise et franco-ontarienne, IV, introduction et choix de textes par R. Dionne, Ottawa, le Centre de recherche en civilisation canadienne-française (Université d'Ottawa), 1983, pp. 100-110.

${ }^{34}$ Voir M. Fortin, «Le Théâtre d'expression française dans l'Outaouais, des origines à 1967", vol. 1, ff. 206-210. 
en créent aussi deux qui sont réservées à des littérateurs et à des savants choisis: la Société royale du Canada ${ }^{35}$ (1882) et le Club des Dix ${ }^{36}$ (1884). À l'Université d'Ottawa, on fonde en 1887. la Société des débats français ${ }^{37}$ et, vers 1900 , le Club littéraire canadien-français.

Certaines de ces Sociétés littéraires ont des activités théâtrales régulières, tels le Cercle dramatique d'Ottawa (soixante-cinq productions de 1858 à 1907) et la Société des débats français (quatorze productions de 1898 à 1909). D'autres ne produisent que quelques pièces; c'est le cas de deux cercles paroissiaux: le Cercle dramatique de La Salle (1886) et le Cercle dramatique Saint-Jean-Baptiste (1888). La salle de l'Institut canadien-français et les salles paroissiales Sainte-Anne et Saint-Jean-Baptiste sont les principaux lieux de spectacles amateurs, mais il arrive que l'on utilise les salles plus spacieuses et plus confortables de la communauté anglophone dont les activités théâtrales sont beaucoup plus nombreuses et plus institutionnalisées. Nous n'avons pas de statistiques précises sur le nombre de représentations françaises qui ont eu lieu avant 1910 à Ottawa, mais Marcel Fortin en a compté 489 avant 1913 sur les deux rives outaouaises, soit 379 par des groupes d'amateurs, 64 dans les collèges, 27 par des troupes canadiennes (montréalaises surtout) et 19 par des troupes de France. Fortin note que son recensement est incomplet pour le $\mathrm{XIX}^{\mathrm{e}}$ siècle et il ne nous a pas

\footnotetext{
${ }^{35}$ Voir L. Lejeune, DGC, vol. 1, p. 657.

${ }^{36}$ Voir Louyse de Bienville, Figures et paysages, préface de Édouard Montpetit, Montréal, Éditions Beauchemin, 1931, pp. 65-85; R. Le Moine, Joseph Marmette. Sa vie, son auvre, pp. 77-83.

${ }^{37}$ Voir M. Fortin, «Le Théâtre d'expression française dans l'Outaouais, des origines à 1967", vol. 1, ff. 108-115.
} 
été possible, à partir de ses statistiques, de préciser le nombre de représentations qui ont eu lieu à Ottawa, mais nous croyons pouvoir affirmer que ce fut plus de la moitié. Quoi qu'il en soit, la thèse de Fortin confirme la tradition qui veut que, bien avant 1910 , Ottawa ait été une ville où l'activité théâtrale ne le cédait en rien à celle d'une ville de même grandeur, telle Québec. Elle possédait même ses dramaturges: Augustin Laperrière (3 pièces), Régis Roy (9), Stanislas Brault (2), Sylvio Corbeil (1), Rodolphe Girard (4) et Rémi Tremblay (une opérette) ${ }^{38}$.

\section{LES IMPRIMEURS ET LES EDITEURS}

Il y eut aussi des éditeurs et des imprimeurs de livres français en Ontario avant 1910. Si nous laissons de côté l'imprimeur Louis Roy ${ }^{39}$, qui imprima en anglais à Toronto, du 18 avril 1793 au 31 juillet 1794 , le premier journal ontarien, et l'éditeur GeorgeÉdouard Desbarats ${ }^{40}$, dont les ateliers fonctionnèrent sur la rue Sparks à Ottawa de 1865 à 1869, et ne considérons que les éditeurs et imprimeurs qui publièrent des livres des auteurs franco-ontariens de 1851 à 1909, nous comptons quatre éditeurs à Toronto: John Lovell ( 3 volumes), The Canada History Company (1), Morang (1), J. C. Winston (1), et à

\footnotetext{
${ }^{38}$ Nous avons puisé la plus grande partie des renseignements contenus dans ce paragraphe dans les deux volumes de la thèse de $M$. Fortin; le second volume, sous-titré «Appendices documentaires» (214 f.), contient des chronologies des troupes de tournées en langue française et des créations dramatiques outaouaises ainsi que des répertoires des représentations théâtrales et des théâtres radiophonique et télévisuel en Outaouais.

${ }^{39}$ Voir John E. Hare, «Roy, Louls», dans $D B C$, vol. 4, pp. 746-748.

${ }^{40}$ Voir Claude Galarneau, «Desbarats, George-Édouard», dans $D B C$, vol. 12, pp. 268-272; «Les Desbarats. Une dynastie d'imprimeurséditeurs (1794-1893)", Cahiers des Dix, n 46, 1991 , pp. 125-149.
} 
Ottawa trois éditeurs: J. Durie (1), le Bureau de l'agriculture et des statistiques (1), Mortimer (1); et onze imprimeurs ${ }^{41}$ ( 23 volumes) à Ottawa. Les auteurs ne leur confièrent donc que 32 de leurs 160 volumes; à ce nombre s'ajoutent six ouvrages d'Ottawa qui ne mentionnent ni éditeur ni imprimeur. La plupart des 122 autres ont été publiés à Québec ou à Montréal (110), et dans d'autres villes québécoises: Hull (1), Arthabaska (1), Trois-Rivières (1), Lévis (2); quelquesuns ont été publiés à Paris (4 et une troisième édition) et aux États-Unis (3).

Comme l'indiquent assez bien les statistiques sur les lieux de publication et les célébrations, en 1877, du vingt-cinquième anniversaire de fondation de l'Institut canadien-français ${ }^{42}$, auxquelles participèrent plusieurs écrivains québécois, les auteurs franco-ontariens d'avant 1910 gardent encore des liens avec l'institution littéraire québécoise, mais il

${ }^{41}$ A. Bureau, Imprimeur (4 volumes), Imprimerie Joseph Bureau (5), Imprimerie du journal "Le Canada» (5), Cie d'imprimerie d'Ottawa (2), «Le Courrier d'Ottawa» (1), Imprimerie du «Foyer domestique» (1), Des Ateliers du “Free Press» (1), L'Imprimerie générale (1), Printed by MacLean, Roger (1), Imprimerie W. T. Mason (1), Imprimerie des R. R. Sœurs du Bon Pasteur (1).

${ }^{42}$ Voir Institut canadien-français d'Ottawa, Célébration du $25^{\circ}$ anniversaire, 1852-1877, Ottawa, Imprimerie du «Foyer domestique», 1879, xxxii, 120 p.; voir aussi les textes signalés dans R. Dionne et P. Cantin, Bibliographie de la critique de la littérature québécoise et canadiennefrançaise dans les revues canadiennes (1760-1899), $\mathrm{n}^{05} 118,119,333-$ $334,337-347,527$. - Cette "convention littéraire" aurait été «le premier congrès du genre au Canada», selon Gaétan Gervais ( «L'Ontario français (182 1-1910)", dans les Franco-Ontariens, sous la direction de Cornelius J. Jaenen, p. 61). P.-J.-O. Chauveau avait émis la même opinion le 25 juin 1880 en rangeant parmi les plus solennelles des "grandes manifestations» nationales cet événement de 1877, «première convention des littérateurs canadiens». (Dans H[onoré]-J[ulien]Ilean]-B[aptiste] Chouinard, Fête nationale des Canadiens-Français célébrée d Québec en 1880 [désormats: FNCF], Québec, de l'Imprimerie A. Côté et Cie, éditeurs, 1881, pp. 274-275.) 
est visible que, en 1910, existe bel et bien une institution littéraire franco-ontarienne. Ses fondements reposent principalement (1) sur des auteurs qui ont vraiment pris la parole en Ontario et pour un Ontario français ainsi qu'en témoignent leurs livres ou leurs écrits dans les journaux et (2) sur des animateurs littéraires qui ont créé et développé, à Ottawa du moins, un milieu culturel qui satisfait ses intellectuels grâce à ses sociétés littéraires et nationales et offre à la communauté francophone en général des divertissements de qualité par ses activités théâtrales.

\section{1865-1909: LA NAISSANCE ET LE DÉVELOPPEMENT D'UNE CONSCIENCE FRANCO-ONTARIENNE}

Cette institution littéraire en est encore à ses débuts, cependant, parce que ceux qui l'ont créée et développée n'ont pas encore pris conscience suffisamment de leur appartenance à l'ensemble de la collectivité franco-ontarienne. Tout au long de la période, leur prise de parole demeure jusqu'à un certain point individuelle et locale, c'est-à-dire principalement outaouaise. Mais les difficultés que ces francophones rencontrent de plus en plus à mesure qu'ils se répandent sur le territoire ontarien vont les forcer à communiquer entre eux et à prendre en compte peu à peu le fait que, s'ils sont toujours des Canadiens français, il n'en reste pas moins que c'est en Ontario qu'ils vivent, et que, pour y vivre en français et sauvegarder leur culture, ils ont besoin d'unir leurs forces, car leur destin est spécifique, en ce sens qu'il se réalisera dans des conditions particulières, celles qui proviennent d'une situation de minoritaires dans un ensemble anglophone et protestant. 
LES PREOCCUPATIONS RELIGIEUSES ET POLITIQUES

De 1865 à 1909, les auteurs et les animateurs littéraires font œuvre de pionniers. Immigrants québécois et français en très grande partie, ils ont non seulement à s'adapter à un nouveau milieu social et linguistique, mais encore à protéger et à développer, sinon à créer presque de toutes pièces, un espace littéraire et culturel français dans un milieu majoritairement anglais. Dans ces conditions, chacun procède au gré de son initiative personnelle, soit en participant aux sociétés existantes comme le fait si bien Benjamin Sulte, qui anime et préside avec succès l'Institut canadien-français pendant des dizaines d'années, soit en fondant des journaux comme Stanislas Drapeau le fait à plusieurs reprises ou en les dirigeant tel Joseph Tassé, soit en publiant des livres ou en écrivant dans les périodiques.

C'est dans ceux-ci beaucoup plus que dans les livres que l'on découvre les préoccupations religieuses et politiques propres aux Franco-Ontariens de la seconde moitié du XIX $\mathrm{X}^{\mathrm{e}}$ siècle. Plusieurs journaux affichent leurs couleurs à travers leur appellation ou leur devise: «Les peuples se déplacent quelquefois, mais ne s'anéantissent jamais» (Le Courrier d'Ottawa, 1861), "Foi et patriotisme» (La Gazette des familles, 1871), "Notre religion, notre langue» (Le Courrier d'Essex, 1884), «Dieu, le Pape, la Patrie» (La Nation, Plantagenet, 1885), "L'Unité du pays en vue» (Le Courrier fédéral, Ottawa, 1887), etc. Sauf dans les journaux humoristiques qui ont pour but d'amuser leurs lecteurs et les journaux politiques qui ne durent que le temps d'une campagne électorale, l'éditorialiste qui définit le programme du journal fait généralement état d'une volonté bien arrêtée de ser- 
vir les intérêts des Canadiens français catholiques, que ce soit en toute indépendance ou de connivence avec un parti politique: indépendant, le Courrier d'Ottawa (1861) se propose "par dessus tout" de «propag(er) la vérité religieuse vivante dans la foi chrétienne»; le Canada (Ottawa, 1865 et 1879) «servir(a) la cause nationale» selon la politique du parti conservateur tandis que, libéral, et bilingue pendant les trois premières semaines de sa parution, le Courrier d'Outaouais (1870) «travailler(a) à l'entente cordiale des deux peuples».

On ne retrouve pas explicitement le même militantisme dans les ouvrages publiés en Ontario français entre 1865 et 1909. La perspective de la plupart d'entre eux est canadienne-française avant que d'être franco-ontarienne. Écrits en très grande partie par des immigrants québécois qui se souviennent encore de leurs origines, les ouvrages de l'époque se greffent sur un fonds culturel commun à tous les francophones du Canada: une tradition française qui est devenue proprement canadienne au cours de trois siècles d'exploration et d'appropriation d'un territoire qui, même partagé avec un conquérant, ne cesse d'être considéré comme une patrie de l'Atlantique au Pacifique. Et cette patrie, on ne l'a pas quittée en s'installant en Ontario: on n'a fait que se réapproprier une autre partie de son territoire à une époque où les Canadiens français s'emploient à coloniser la vallée de l'Outaouais et le Nord ontarien; aussi est-elle toujours à défendre ou à étudier dans son ensemble. La plupart du temps national, c'est-à-dire canadienfrançais, le point de vue des historiens et généalogistes de l'époque inclut implicitement l'Ontario; il en va de même des romanciers comme Antoine Gérin-Lajoie et Errol Bouchette, qui situent l'action de leurs 
romans au Québec principalement, et des poètes qui chantent, tel William Chapman, la foi catholique, la langue française, la patrie canadienne et la grande nature du Canada. Bien plus, rares sont ceux d'entre eux qui ne participent pas par quelques écrits ou par leurs activités culturelles et politiques à la lutte quotidienne pour la préservation et la promotion de la langue et de la culture françaises en Ontario.

Cette lutte apparaissait facile, mais importante et courageuse, dans le premier recueil de poésie francoontarienne, les Laurentiennes ${ }^{43}$ de Benjamin Sulte, en 1870. Conscients du danger qui les guettait, les francophones recherchaient la bonne entente avec les Anglo-Ontariens, mais ne s'en laissaient point imposer. On pouvait croire que l'harmonie serait possible entre les deux groupes. Peu à peu, cependant, au fur et à mesure que les francophones grandirent en nombre et qu'ils occupèrent une place de plus en plus importante dans la société ontarienne, voire prédominante en certains lieux de pouvoir comme le diocèse d'Ottawa et la Commission des écoles séparées d'Ottawa, les anglophones, craintifs, prirent des mesures pour contrecarrer l'influence de ces papistes et de ces étrangers.

\section{LES PROLEGOMENES D'UN CONFLIT}

La francophobie et l'anticatholicisme qui se développèrent alors auraient eu pour «toile de fond»,

\footnotetext{
${ }^{43}$ Montréal, Eusèbe Senécal, imprimeur-éditeur, 208 p. Voir, entre autres, les pages 125 à 128: "Le Canada français à l'Angleterre»; ce poème daté de juin 1867 fut écrit «à la suite d'une conversation un peu vive avec un Anglais d'un rang assez élevé, quil refusait de reconnaître a la race française du Canada le droit incontestable de conserver ce qui constitue aujourd'hui sa nationalité».
} 
selon l'historien Robert Choquette ${ }^{44}$, un «darwinisme social ${ }^{45}$ » nourri principalement par le "progressisme $^{46}$ " et la "manifest destiny ${ }^{47}$ ». Les attitudes

${ }^{44}$ Dans Equal Rights: The Jesuits' Estates Act Controversy (Montréal, McGill-Queen's University Press, 1979, pp. 175-201: «The Agitation in Contexty), l'historien J. R. Miller a étendu cette toile de fond a l'ensemble de la situation politique canadienne; d'après lui, les antagonismes nationaux des années 1880 avaient pour sources profondes les querelles et conflits anciens que la Confédération de 1867 n'avaient pas réussi à régler: les deux nations qu'elle devait unir étalent toujours divisées.

${ }^{45}$ Cette doctrine selon laquelle les sociétés évoluent et survivent tout comme les espèces, en luttant pour leur existence, a été soutenue aux États-Unis par des sociologues et des économistes, entre autres par William Graham Sumner, Andrew Carnegie et John D. Rockfeller. Voir "Social Darwinism" in A Documentary History of American Thought and Society, edited by Charles Crowe, Boston, Allyn and Bacon, Inc., 1965, pp. 222-239; Mary T. Bush, «Representative Nineteenth Century New England Historians View Manifest Destinym, thesis presented to the Faculty of Arts of the University of Ottawa through the Department of History as partial fulfillment of the requirements for the degree of Doctor of Philosophy, Rochester (New York), 1963, 1. 133-180: «John Fiske Exponent of Darwinian Manifest Destiny".

${ }^{46}$ Pour Robert Choquette, le progressisme «est une version sécularisée de la vieille doctrine chrétienne de la catholicité de l'Église, à l'effet que le monde progresse toujours vers le royaume de Dieu». L'Ontario français. Historique, coll. "L'Ontario français", Montréal, Éditions Études vivantes, 1980 , p. 163. - "Our cause is based on the eternal principle of rigtheousness; and even though we who now lead may for the time fail, in the end the cause itself shall triumph.... To you who strive in a spirit of brotherhood for the betterment of our nation, to you who gird yourselves for this great new fight in the never-ending warfare for the good of mankind, I say in closing... We stand at Armageddon, and we battle for the Lord.» Theodore Roosevelt, "We Stand at Armageddon and Battle for the Lord", in A Documentary History of American Thought and Society, edited by Charles Crowe, p. 283.

${ }^{47}$ On doit l'expression à l'Américain John L. O'Sullivan. Comme plusieurs de ses concitoyens, il croyait que Dieu avait choisi sa nation non seulement pour occuper l'Amérique du Nord, mais aussi pour éclairer le monde et le dominer. Voir John L. O'Sullivan, «Nationalism and Manifest Destiny" $(1839,1845)$, in A Documentary History of American Thought and Society, edited by Charles Crowe, pp. 175-176; Josiah Strong, "A Religious Justification for Anglo-Saxon Domination of the World (1885), ibid., pp. 252-254.

«In viewing their history, Americans have often described themselves 
anticanadiennes-françaises auraient été activées surtout par les orangistes ${ }^{48}$ et les membres de la Protestant Protective Association ${ }^{49}$, une société secrète d'origine américaine. Elles furent attisées par des

as agents of destiny - as a new chosen people ordained by God to guide the rest of the world out of the wilderness and into a new promised land. This destiny has been described as the American dream, or the American mission, or a national idealism. It has meant a basic belief in the innate goodness of the country.

One way by which the nation has tried to reach the fulfillment ot its dream is through expansion." Mary T. Bush, "Representative Nineteenth Century New England Historians View Manifest Destiny», 1. 2.

"America's incorporation of all adjacent lands was the virtually inevitable fulfillment of a moral mission delegated to the nation by Providence itself." Albert Weinberg, Manifest Destiny: A Study of Nationalist Expansionism in American History, Gloucester, Peter Smith, 1958, pp. 1-2.

${ }^{48}$ Membres de la Loyal Orange Institution. Cette société fut fondée dans le nord de l'Irlande en 1795 par les protestants qui s'opposaient, pour conserver leur pouvoir sur cette partie du pays, à l'émancipation des catholiques. Les fondateurs empruntèrent le nom de la société au roi d'Angleterre William III (né Guillaume d'Orange); défenseur du protestantisme et adversaire de toute hégémonie catholique française, il avait assuré sa domination sur l'Écosse et l'Irlande en remportant, le 12 juillet 1690 , contre le roi catholique Jacques II, la fameuse bataille de la rivière Boyne, près de Drogheda, en Irlande. - La Grande Loge de l'Amérique du Nord britannique fut fondée à Brockville (Ontario) en 1830. Pour un bref résumé de son histoire, de son rôle et de son influence au Canada, voir Hereward Senior, "Orange Order», in the Canadian Encyclopedia, second edition, Edmonton, Hurtig Publishers, 1988, Vol. 3, pp. 1582-1583. Pour plus de renseignements sur le rôle

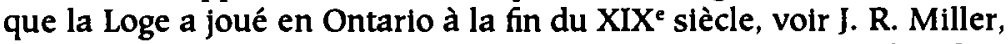
Equal Rights: The Jesuits' Estates Act Controversy, passim (cf. index, pp. 220-221).

${ }_{49}$ "Fondé aux États-Unis, ce club anti-patriotique est importé au Canada, à Windsor, en 1891. Le P.P.A. s'oppose aux catholiques Individuellement, en boycottant leurs commerces et en cherchant à les éliminer de la vie publique. Il croit que les catholiques ne sont pas habilités à occuper des postes politiques ou militaires puisqu'ils sont les sujets d'une puissance étrangère (le pape) et sont ainsi des subversifs. Un catholique est un étranger dans tous les sens du mot. L'association se développe graduellement et sans tapage jusqu'à l'automne 1893 quand l'un de ses candidats sort vainqueur d'une élection par- 
événements qui réveillèrent le nationalisme canadienfrançais et provoquèrent l'agressivité des AngloCanadiens: entre autres, la révolte et la pendaison de Louis Riel $(1885)^{50}$, la décision prise par Honoré Mercier $^{51}$, premier ministre du Québec, de consulter

tielle provinciale. À la fin de 1893 , elle fait élire plusieurs candidats lors des élections municipales. [...]

"Durant la campagne électorale provinciale de 1894 , le P.P.A. prêche que la seule question à trancher est celle de savoir si le pape gouvernera le Canada. [...] L'association réussit à faire élire quelques candidats en plus d'une douzaine de députés, tant conservateurs que libéraux, qui avaient endossé sa politique. Au lendemain des élections de juin 1894 , la discorde et les querelles internes mènent à la désagrégation du P.P.A. Il disparaît de la scène provinciale avant la fin du siècle, à la même époque où le parti conservateur devient moins anticatholique et plus modéré.» R. Choquette, L'Ontario français. Historique, pp. 167170. Voir aussi J. R. Miller, Equal Rights: The Jesuits' Estates Act Controversy, pp. 171-172, 176 et 191; J[ames] D[avid] Edgar, The P.P.A. in Ontario: Being Extracts from Speeches and Two Letters, of Mr. J. D. Edgar, M.P., [Toronto, 1893-1894], 14 p. [au sujet de J.D. Edgar (1841-1899), qui aurait été «le premier homme politique protestant de l'Ontario à dénoncer le fanatisme et l'intolérance" de la P.P.A., voir Paul D. Stevens, «Edgar, Sir James David», dans DBC, vol. 12, pp. 316-320; Geo[rgel Maclean Rose, Ed., A Cyclopæedia of Canadian Biography: Being Chiefly Men of the Time, a collection of persons distinguished in professionnal and political life; leaders in the commerce and industry of Canada, and successful pioneers, "Rose's National Biographical Series», 2, Toronto, Rose Publishing Company, 1888, Vol. 2, p. 594]; [J. D. Edgar(?)], P.P.A. in Ontario: History and Principles of the Organization, [Ottawa, 1894], 15 p.; Petronilla, "Political Religionism" and the P.P.A. [a letter to the Editor of the Catholic Register], 4 p.

${ }^{50}$ J. R. Miller, Equal Rights: The Jesuits' Estates Act Controversy, pp. 13, 33, 179; Chad Gaffield, Language, Schooling, and Cultural Conflict: The Origins of the French-Language Controversy in Ontario, Kingston and Montreal, McGill-Queen's University Press, 1987, pp. 148-151: «The Hanging of Louis Riel»; J[oseph-]O[ctave] Pelland, [éditeur], Biographie, discours, conférences, etc. de l'Hon. Honoré Mercier, Montréal, 1890, pp. 234-327: "Question Riel» [discours à l'Assemblée législative du Québec le 7 mal 1886] et pp. 328-333: [discours prononcé sur le Champ-de-Mars (Montréal) le 22 novembre 1885 à la suite de la pendaison de Riel à Régina le 16 novembre].

${ }^{51}$ Voir Pierre Dufour et Jean Hamelin, «Mercier, Honoré", dans DBC, vol. 12, pp. 783-793. 
le pape sur la distribution entre les catholiques des 400000 \$ que le Parlement avait décidé de leur donner ${ }^{52}$ en restitution des biens des jésuites que la Couronne britannique s'était appropriés en 1763 , 1774 et 1800 , puis avait attribués au gouvernement canadien qui les avait abandonnés au gouvernement du Québec en $1867^{53}$, et l'abolition, au Manitoba, en 1890 , à la fois du réseau d'écoles catholiques qui existait depuis 1871 et de l'usage de la langue française au Parlement et dans les tribunaux ${ }^{54}$.

Précédée, puis accompagnée, de la "guerre ecclésiastique" que se livrèrent les évêques anglophones et francophones pour la direction des diocèses ${ }^{55}$, la

${ }^{52}$ Cette décision de Mercier souleva la colère des orangistes qui y virent une intrusion du pape dans les affaires canadiennes. (D'après Philippe Sylvain, «Biens des jésuites, Lol sur les», dans l'Encyclopédie du Canada, Montréal, Stanké, 1987, tome 1, p. 220.) - Votée à l'unanimité par le Parlement québécois le 12 juillet 1888 , la lol sur les biens des jésuites provoqua, en juin 1889 , la naissance à Toronto de l'Equal Rights Association for the Province of Ontario. Cette association protestait contre ce qu'elle jugeait une intrusion du pape dans les affaires canadiennes et un geste de soumission à l'égard de l'Église catholique romaine. Elle ne parvint pas à faire désavouer la loi québécoise, mais elle s'en prit aux écoles séparées et aux écoles des Territoires du Nord-Ouest et du Manitoba tout comme à celles de l'Ontario. Elle ne fit élire qu'un député en 1890 , mais réussit à faire adopter des pièces de son programme par les deux partis politiques de l'époque. (D'après J. R. Miller, «Equal Rights Association» in the Canadian Encyclopedia, second edition, Vol. 2, p. 715.) Pour plus de précisions, voir id., Equal Rights: The Jesuits' Estates Act Controversy, pp. 77-174. ${ }^{53}$ Voir ibid., pp. 1-23: «The Jesuits' Estates Problem and Its Solution»; Philippe Sylvain, «Biens des jésuites, Lol sur les», dans l'Encyclopédie du Canada, tome 1, p. 220; J. O. Pelland, [éditeur], Biographie, discours, conférences, etc. de l'Hon. Honoré Mercier, pp. 334-341: «Incorporation de la Compagnie de Jésus» [discours à l'Assemblée législative du Québec le 2 mai 1887], et pp. 342-397: "Les Biens des Jésuites» [discours à l'Assemblée législative du Québec le 28 juin 1888].

${ }_{54}$ Voir Lionel Groulx, L'Enseignement français au Canada, II: les Écoles des minorités, Montréal, Librairie Granger Frères limitée, 1933, pp. 71-137: «Les Écoles du Manitoba».

${ }^{55} \mathrm{R}$. Choquette, L'Église catholique dans l'Ontario français du dix- 
lutte ontarienne se fit principalement dans le champ de l'éducation et, à compter de 1910, férocement, entre deux groupes catholiques: aux Canadiens français, pour qui, la langue française et la foi catholique étant gardiennes l'une de l'autre, l'école française était un instrument de survivance indispensable, les Irlandais catholiques demandaient, tout simplement pensaient-ils, de faire le sacrifice de leur langue sur l'autel de la foi, valeur supérieure et suprême ${ }^{56}$; ils se

neuvième siècle, coll. "Cahiers d'histoire», 13, Ottawa, Éditions de l'Université d'Ottawa, 1984, pp. 251-280: «Duhamel vs Lynch: les conflits de frontières ecclésiastiques».

${ }^{56} \mathrm{Ce}$ point de vue sera exprimé lors du XXI ${ }^{e}$ Congrès eucharistique international, à Montréal, le 10 septembre 1910, par Mgr Francis Bourne, archevêque de Westminster. Voici les passages les plus percutants de son discours: "The early history of Canada is part of the history of the Catholic Church. [...] the power and influence of the Catholic Church throughout all the earlier history of the colony were due largely to the fact that the whole influence of the language and literature of the country was on the side of the Catholic Church. The French tongue, with which all progress in every department of life was identified, gave forth but one note when it expounded to the people the mysteries of religion, whether they were preached to those who had come from their ancestral home in France, or had in turn to be translated to the various races to whom the land once belonged.

Now the circumstances have vastly altered. With slow increase at first, and now with an incalculable rapidity, another language is gaining for Itself a paramount importance in the ordinary things of life. [...] [...] if the mighty nation that Canada is destined to become in the future is to be won for and held to the Catholic Church, this can only be done for making known to a great part of the Canadian people in succeeding generations, the mysteries of our faith through the medium of our English speech. In other words, the future of the Church in this country, and its consequent re-action upon the older countries in Europe, will depend to an enormous degree upon the extent to which the power, influence and prestige of the English language and literature can be definitely placed upon the side of the Catholic Church.

[...]

[...], I should like to make a suggestion whereby all may be united in prayer that the influence of the English language may at last, in spite of all the harm that it has wrought in religious matters in days gone by, be brought by God to be a mighty force for the support and spread of religious unity and truth. [...] It is only by bringing the English tongue 
heurtèrent à un mur vivant. Sans cesse croissant à partir de 1885 , le conflit atteignit un niveau de crise

to render service to the cause of truth that Canada can be made in the full sense a Catholic nation; and the spectacle of a united Canada, enunciating in French and English alike the same religious truths, would be for the whole Church of God a power of irresistible force. I trust that my proposal will not appear to you too bold, and that it will meet with your generous and whole-hearted acceptance.

Let me sum what I mean. God has allowed the English tongue to be widely spread over the civilized world, and it has acquired an influence which is ever growing. Until the English language, English habits of thought, English literature - in a word the entire English mentality is brought into the service of the Catholic Church, the saving work of the Church is impeded and hampered. Each English-speaking nation can help in this great work; [...]. But the Dominion of Canada can at the present moment, owing to her long and deeply rooted Catholic traditions and to the magnificent opportunities now presented to her, render the greatest service of them all. And in accomplishing her part of the work the Catholic Church in Canada will not only advance her own sacred cause, but at the same time she will bring renewed courage to English-speaking Catholics all the world over, and become a source of ever increasing and unfailing strength to the Universal Church. It is an opportunity now given which may never come again. Humanly speaking, if it is lost, the loss will be immeasurable and irretrievable." XXI ${ }^{e}$ Congrès eucharistique international. Montréal, Montréal, Librairie Beauchemin limitée, 1911, pp. 151-153.

Certains, tel Paul Racine dans Henri Bourassa a Notre-Dame (coll. «Frangipani», 11, Montréal, Aux Éditions de l'Entr'aide, 1942), ont émis l'hypothèse que l'archevêque avait orienté son discours d'après les avis des Irlandais qui l'avaient accueilli et logé à Saint Patrick (Montréal); ses hôtes lui auraient fait valoir l'occasion favorable que présentait le Congrès eucharistique «pour lancer et réaliser un projet entrevu depuis longtemps: la reconnaissance de l'anglais comme langue officielle de l'Église catholique au Canada» (p. 23). Une note de Bourassa à la rédaction de l'ouvrage (p. 30) contient une opinion différente: «c'est en Angleterre même qu'on aurait demandé à Mgr Bourne de promouvoir l'anglicisation du Canada pour le bienfait du catholicisme. Si bien que l'archevêque aurait rédigé son discours sur le paquebot" qui l'amenait au Canada.

Racine fait aussi état (p. 21 ) de l'influence de la «Church Extension» qui «travaillait bruyamment (cf[.] "La Croix", journal montréalais, des années 1907-08-09-10) à l'unification linguistique des pays pour mieux assurer la conversion du bloc protestant». Selon Racine (p. 23), à en juger par les applaudissements avec lesquels les auditeurs anglais avaient accueilli les propos de Mgr Bourne, il $y$ avait bien eu 
en 1910, culmina de 1912 à 1917 , puis s'estompa à compter de 1927.

\section{Robert Choquette a fait l'historique de ces quarante}

«manœuvre» de la part de la "Church Extension". Ce mouvement connaissait du succès aux États-Unis. Louis Madelin en avait pris la mesure lors d'une rencontre qu'on lul avait fortement conseillé d'avoir avec Mgr John Ireland, le célèbre archevêque de Saint Paul (Minnesota). L'historien français avait ensuite livré ses «Impressions d'outre-mer. Le Catholicisme» à la République française, et le Canada de Montréal avait reproduit l'article le $1^{\text {er }}$ août 1908 . Le paragraphe sulvant fait connaître une facette d'un certain clergé américain: "C'est un clergé patriote. Je ne sais si j'ai trouvé ailleurs plus d'orgueil américain. Et je ne sais si aucune force agit plus efficacement pour l' "américanisation" des immigrants. Jamais les prélats américains - même ceux dont les parents sont venus d'Irlande ou d'Italie - n'ont admis l'existence de groupes catholiques nationaux. Pas d'Église canadienne, pas d'Église italienne, pas d'Église irlandaise dans l'Église catholique américaine. "C'était un grand danger pour la discipline", me disait Ireland. On prêche en anglais, on confesse en anglais - sauf au début, et on enseigne en anglais. Qui n'aperçoit le service rendu dès lors par l'Église catholique à la nationalité américaine.» Né en Irlande en 1838, John Ireland avait immigré aux États-Unis en 1849 avec sa famille, puis était allé étudier en France avant d'être ordonné prêtre à Saint-Paul en 1861. Dans l'importante notice biographique que lui a consacrée the New Encyclopedia Britannica, on lit ce qui suit (Fifteenth Edition, 1984, Vol. 5, p. 422): "head of the liberal Roman catholic clergy who promoted the integration of predominantly immigrant parishes into the life of the U.S. Church (and society as a whole) - in opposition to the separatist tendency of many ethnic groups to preserve their European-style churches, with priests of their own nationalities. [...] Ireland's liberal views also give him a wide influence and reputation outside of the church. Many Europeans considered him the chief Catholic intellectual leader in the U.S. His ideas on social reform and the relation of the church to a democratic society were prophetic.» Dans the New Columbia Encyclopedia (edited by William H. Harris and Judith S. Levey, New York and London, Columbia University Press, 1975, p. 1362), on dit aussi de lui: «Bishop Ireland was an energetic spokesman for liberal American Catholicism. He gained many enemies by advocating state support and inspection of Catholic schools and by opposing the use of foreign languages in American Catholic churches, except in extreme need, and in parochial schools under any circumstances. [...] He continually made public statements on political matters, and he was a close personal friend of Presidents William McKinley and Theodore Roosevelt.» 
années ${ }^{57}$. Il a situé le point de départ du conflit dans les mesures régressives par lesquelles le gouvernement ontarien restreignit progressivement l'enseignement en langue française. De 1786 à 1885, les Franco-Ontariens avaient profité de la liberté laissée à chaque groupe ethnique d'administrer et de faire fonctionner ses écoles dans la langue de son choix. En 1885, le Ministère de l'éducation rend l'enseignement de l'anglais obligatoire pendant un certain nombre d'heures et exige des futurs enseignants qu'ils réussissent des examens qui attesteront de leur connaissance de cette langue. En 1889 , il supprime les autorisations que le Conseil de l'instruction publique avait données en 1868 pour l'utilisation de certains manuels scolaires en français et, en 1879, pour l'utilisation de manuels québécois; les enseignants devront utiliser les «French-English Readers» du ministère. Le 4 avril 1890, l'Assemblée législative rend obligatoire l'usage de l'anglais comme langue de communication dans les écoles, "excepté où ce serait impossible en raison de l'ignorance de l'anglais par l'écolier». "Cet[te] échappatoire», commente Robert Choquette, allait permettre «aux écoles des FrancoOntariens de continuer d'enseigner en français ${ }^{58}$.

Plus encore que ces restrictions et obligations nou-

\footnotetext{
${ }^{57}$ Language and Religion: A History of English-French Conflict in Ontario, coll. "Cahiers d'histoire de l'Université d'Ottawa», 5, [Foreword by Mason Wade], Ottawa, University of Toronto Press, 1975, xil[ii], 264 p.; Langue et religion. Histoire des conflits anglo-français en Ontario, [avant-propos de Mason Wade], Ottawa, les Éditions de l'Université d'Ottawa, 1977, 268 p. Voir aussi Lionel Groulx, L'Enseignement français au Canada, II: les Écoles des minorités, pp. 194-239: «Les Écoles franco-ontariennes"; C. Gaffield, Language, Schooling, and Cutural Conflict: The Origins of the French-Language Controversy in Ontario, xvili, 249 p.

${ }^{58} \mathrm{R}$. Choquette, L'Ontario français, historique, pp. 170-173.
} 
velles, ce sont les enquêtes répétées sur la qualité de l'enseignement en français dans les écoles françaises qui firent mal aux Franco-Ontariens. Suscitées par les critiques des Anglo-Ontariens qui se plaignaient de l'ignorance des francophones et de l'incompétence de leurs instituteurs, elles furent instituées par le ministre de l'éducation. Celle de 1889 déplora le manque de formation de presque tous les enseignants francophones de Prescott et de Russell; la suivante, en 1893, constata un progrès certain, mais pas aussi rapide que le ministre l'avait souhaité. Une troisième enquête, en 1893, demandée celle-là par la Commission des écoles séparées d'Ottawa, amena les Frères des écoles chrétiennes, dont on avait blâmé les méthodes pédagogiques, à quitter toutes leurs écoles ontariennes l'année suivante. Ils revinrent à Ottawa en 1902, mais, deux ans plus tard, on contesta leur droit d'enseigner en Ontario sans posséder un certificat d'aptitude de cette province; les tribunaux donnèrent raison à la poursuite et, en 1907, une loi ontarienne rendit obligatoire la possession dudit certificat $^{59}$.

\section{L'APPEL AU RASSEMBLEMENT}

«La situation étant devenue de plus en plus précaire», il se produisit une sorte de «réveil national ${ }^{60}$ » qui s'exprima dans une première convention géné rale

${ }^{59}$ Id., Langue et religion. Histoire des conflits anglo-français en Ontario, pp. 63-77.

${ }_{60}$ A[lexandre] Beausoleil, «Préface», p. 7, dans Congrès d'éducation des Canadiens-Français d'Ontario. 1910 [désormais: CECFO], rapport officiel des séances tenues à Ottawa, du 18 au 20 janvier 1910 (questions d'éducation et d'intérêt général), 23 gravures hors texte, Ottawa, Association canadienne-française d'éducation, $1910,363 \mathrm{p}$. 
des "Canadiens-Français ${ }^{61}$ d'Ontario" à Ottawa en 1910. Durant toutes les années antérieures de luttes, les réactions n'avaient pas fait défaut, mais elles avaient été ponctuelles et locales la plupart du temps. Ainsi il y avait eu à Windsor, le 25 juin 1883, donc deux ans avant le début des restrictions gouvernementales que nous avons mentionnées, une convention régionale; elle s'était terminée par une résolution qui laissait percer une inquiétude collective et équivalait à un appel à l'action sinon à la lutte:

Que, vu que la langue française est la langue de nos ancêtres, et que sa conservation parmi nous est une des principales sauvegardes de notre religion et de nos traditions nationales, le plus grand encouragement lui soit accordé surtout dans nos écoles et de la part de nos hommes d'Etat de notre origine ${ }^{62}$.

En 1900, à Ottawa une quarantaine de personnes s'étaient réunies, mais le secrétaire de leur assemblée étant décédé peu après, leurs résolutions ne furent jamais publiées. Quelque six ans plus tard, les officiers de la Société Saint-Jean-Baptiste d'Ottawa avaient mis sur papier un projet de «Fédération ca-

${ }^{61}$ Dans les citations, nous avons respecté, à quelques exceptions près (que nous avons signalées), la graphie utilisée par leurs auteurs, même lorsqu'elle était fautive, comme dans le cas de Canadiens-Français qui devrait s'écrire Canadiens français (nom) ou canadien-français (adjectif), puisque le Canada français ne désigne pas une unité administrative. Voir à ce sujet des autorités comme Adolphe V. Thomas, Dictionnaire des difficultés de la langue française; Jean Girodet, Pièges et difficultés de la langue française; Dupré, Encyclopédie du bon français dans l'usage contemporain; Le Robert (le grand et le petit); le Dictionnaire encyclopédique Larousse; etc. Il est intéressant de constater que, au Canada, dès les premières éditions de son célèbre Dictionnaire du bon langage, au début du XXe slècle, l'abbé Étienne Blanchard enselgnait la même règle.

${ }^{62}$ Proposition de M. F. X. Meloche, appuyée par H. Girardot et citée par $O$. L[alonde] dans "Origine, but, préparatifs et organisation", CECFO, p. 41. 
tholique et nationale des Canadiens-Français de la province d'Ontario». Leur but était le suivant:

Grouper tous les Canadiens-Français de la province d'Ontario dans une Fédération puissante, animée d'un véritable esprit d'union et guidée par des aspirations vraiment patriotiques à l'égard de tout ce qui concerne la religion et la race; disposer d'une force vivante et courageuse prête à marcher sur le terrain social et politique pour la défense du drapeau ${ }^{63}$.

Ces officiers avaient dressé un plan pour diviser l'Ontario français en districts dont les limites correspondraient à celles des archidiocèses; ces districts seraient subdivisés en comtés regroupant les paroisses. Les conseils de paroisse seraient soumis à la juridiction des conseils de comté et ceux-ci à celle des conseils de district, lesquels seraient sous l'autorité du Conseil fédéral. Les questions les plus importantes seraient débattues lors de conventions ou congrès qui réuniraient à la fois les membres du Conseil fédéral et les délégués des comtés. La mise sur pied de cette fédération se ferait en trois étapes: (1) la fondation de sociétés Saint-Jean-Baptiste dans toute la province, (2) la réunion de représentants des comtés pour établir et adopter les règlements de la fédération et «étudier toutes les questions importantes qui seraient de nature à favoriser les intérêts religieux, moraux, intellectuels et matériels» des Canadiens français de l'Ontario, (3) la création à Ottawa d'un Bureau de la fédération ou Conseil fédéral. Le projet demeura en plan, mais l'idée de réunir ce qu'on appellerait aujourd'hui les états généraux de l'Ontario français avait fait un pas de plus.

C'est tout naturellement qu'elle devait réapparaître en 1908 dans le champ le plus miné pour les Franco-

${ }^{63}$ Texte cité par id., ibid., p. 42. 
Ontariens ${ }^{64}$, celui de l'éducation. L'année précédente, les participants à un congrès pédagogique tenu à Ottawa s'étaient mis d'accord sur bien des points, dont la fusion de deux associations d'enseignants ${ }^{65}$, mais n'avaient pas cru bon de convoquer une convention nationale des Franco-Ontariens:

Ce qui manquait pour mener à bonne fin une telle entreprise, c'était l'union. Le terrible esprit de parti n'était pas étranger aux misères qui se succédaient sans laisser percer une lueur d'espérance. Malgré ces petites épreuves, l'idée du Congrès faisait son chemin ${ }^{66}$.

Elle trouva son véhicule dans le Moniteur, hebdomadaire lancé à Hawkesbury le 11 septembre 1908. Il avait pour devise "Prêchons l'union», et ses rédacteurs y furent fidèles. Ils ne cessèrent de s'en prendre à l'esprit de parti qui divisait les francophones et ils insistèrent sur la nécessité de faire changer le système d'enseignement qui faisait alors du français une «matière secondaire»:

L'avenir de notre race en Ontario dépend de l'éducation que recevront les petits Canadiens-Français, c'est là un fait certain.

L'enseignement dans les écoles fréquentées par les petits Canadiens-Français doit être bilingue; c'est une nécessité dans notre province de savoir les deux langues, mais n'allons pas conclure de là que c'est la langue anglaise qui doit être la seule apprise; non, c'est la langue française qu'il faut d'abord apprendre très bien, puis ensuite, comme perfectionnement, la langue anglaise.

\footnotetext{
64 «Tous les Canadiens-Français d'Ontario redoutalent l'avenir de notre nationalité lorsqu'lls considéralent attentivement la manière dont était traité l'enselgnement du français dans les écoles.» Id., ibid., p. 44.

${ }^{65}$ Voir R. Choquette, Langue et religion. Histoire des conflits anglofrançais en Ontario, pp. 77-78.

${ }^{66} \mathrm{O}$. L[alonde], dans CÉCFO, p. 46.
} 
Or, avec le programme actuel d'enseignement, il est impossible que les petits Canadiens-Français apprennent très bien la langue française.

$[\ldots]$

Il faut donc travailler dans le but de faire changer un pareil état de choses, et pour réussir il faut l'union, l'union de tous les Canadiens-Français d'Ontario.

Dans une question si importante, il faut bannir l'esprit de parti politique; libéraux comme conservateurs doivent n'avoir qu'un but touchant cette question: perfectionner le système scolaire actuel, exiger un programme d'enseignement distinct pour les écoles bilingues d'Ontario ${ }^{67}$.

[...]

La tâche sera belle si ce journal travaille au relèvement des nôtres. Plus que jamais, nous avons besoin de prêcher le dévouement. Le Moniteur fera l'office d'apôtre missionnaire $[\ldots]^{68}$.

Dans le même journal, trois mois plus tard, soit le 18 décembre 1908, sous le pseudonyme de J. B. Ontario, l'abbé Alexandre Beausoleil, curé de Fournier (comté de Prescott), lançait dans le public l'idée d'une convention nationale. Après avoir évoqué la dispersion des divers groupes franco-ontariens et affirmé la nécessité de créer, «sans tarder, un solide trait d'union» entre ces groupes, «afin qu'ils puissent plus facilement prendre contact entre eux, avoir conscience de leur nombre, mettre plus d'ensemble, partant plus de force, dans la revendication de leurs droits", il rappelait que, dans des situations semblables à celle des Franco-Ontariens, les Acadiens et les Franco-Américains avaient trouvé dans des «assemblées conventionnelles des trésors d'énergie et de courage qui, non seulement leur assur(ai)ent la paix

${ }^{67}$ Louis des Érables, le 11 septembre 1908, cité par id., ibid., pp. 47-49. ${ }^{68}$ Robert Desprès, le 11 septembre 1908, cité par id., ibid., p. 49. 
du présent, mais leur permett(ai)ent d'envisager l'avenir avec confiance». Alexandre Beausoleil en appelait ensuite avec émotion à ses compatriotes en deux paragraphes, dont le second fait entendre, six ans avant Louis Hémon, la voix du pays. Elle contient déjà «l'âme» d'une province, celle de l'Ontario français, dont elle exprime avec force la détermination têtue des premiers explorateurs et défricheurs:

Pourquoi, oubliant nos luttes et nos divisions, ne tiendrionsnous pas, nous aussi, nos assises nationales, où, dans une fraternelle communauté d'idées et de sentiments, nous étudierions les conditions sociales des CanadiensFrançais d'Ontario, au triple point de vue économique, politique et religieux? Pourquoi, par la grande voix d'un Congrès, ne ferions-nous pas entendre à ceux qui nous jalousent ou nous persécutent la liste de nos fières et légitimes revendications? Pourquoi, fermes sans jactance, forts des qualités résistables de notre race, ne dirionsnous pas aux races qui ourdissent notre fusion complète dans le grand tout anglo-saxon:

«Nous sommes plus de 235000 Canadiens-Français ici sur le sol d'Ontario; nous y sommes pour y rester; nous y sommes pour $y$ vivre en citoyens paisibles mais déterminés à garder le précieux héritage de nos traditions nationales, notre langue, notre foi; les luttes ne nous feront pas peur, pas plus que les tracasseries administratives n'amoindriront la ferveur de nos réclamations; nous sommes unis à tout jamais; nous formons bloc; désormais, nos sympathies et nos votes iront du côté où nous trouverons justice et bienveillance ${ }^{69} . "$

\section{LES PRÉPARATIFS DU CONGRÈS}

Le 28 décembre 1908, soit dix jours après la publication de cet article, qui fut reproduit dans l'Action sociale de Québec et dans plusieurs autres journaux, franco-ontariens surtout, eut lieu, dans une salle de

${ }^{69}$ Texte cité par id., ibid., pp. 49-51. 
l'Union Saint-Joseph, une réunion convoquée par Aurélien Bélanger ${ }^{70}$, inspecteur des écoles bilingues de l'Est ontarien, afin de discuter de la situation des Frères qui avaient réussi leurs examens de certification, mais n'avaient reçu des permis d'enseignement que pour une année, et non pour cinq ans, comme ils auraient dû. Alors que l'on se demandait quoi faire pour mettre fin à la série des embêtements et injustices, l'abbé Alexandre Beausoleil proposa de "préparer un Congrès de tous les CanadiensFrançais d'Ontario». Le juge Albert Constantineau, personnage influent dont on avait espéré qu'il pût être «l'âme dirigeante» d'un tel congrès, confessa qu'il songeait à un ralliement national de cette sorte depuis six mois; il en fit voir les difficultés, on les pesa sur-le-champ et, séance tenante, on chargea le juge Constantineau et l'abbé Beausoleil de convoquer une assemblée de citoyens pour le 10 janvier afin de «discuter de la possibilité d'un Congrès National» et, dans le cas d'une réponse affirmative, de nommer un comité qui s'assurerait du concours de tous les groupes francophones de la province.

La réunion ne put avoir lieu que le 24 janvier. On se mit d'accord pour organiser un Congrès plutôt que pour réaliser le projet de la Fédération Saint-JeanBaptiste dont nous avons parlé plus haut. Un comité fut formé qui rédigea et adressa, quelques jours plus tard, une lettre circulaire aux curés et aux personnes

${ }^{70}$ Né à Sainte-Scholastique (Québec) en 1878 et décédé à Ottawa en 1953, Aurélien Bélanger avait fait des études en droit et en philosophie à l'Université d'Ottawa avant d'y enseigner (1896-1902), puis de devenir inspecteur des écoles bilingues de l'est de l'Ontario (19081912) et directeur des écoles bilingues d'Ottawa (1919-1930). Ce "combattant de la première heure dans la lutte en faveur du français" poursuivit le combat à l'Assemblée législative de l'Ontario comme député libéral des comtés de Russell (1923-1929) et de Prescott (1934- 
influentes de la province. Cette lettre contenait un questionnaire qui permettrait de connaître l'opinion des citoyens sur l'opportunité du Congrès et sur les questions qu'on devrait $y$ traiter. Réponses favorables reçues, il fut décidé en assemblée générale, le 4 mai 1909, d'organiser le Congrès.

Dès les jours suivants, on se mit au travail et la façon dont on procéda pour engager l'ensemble de la collectivité dans les travaux du congrès manifesta, une fois de plus, la volonté des organisateurs d'unir les Canadiens français de toutes les régions de l'Ontario et de toutes les classes autour des plus influents d'entre eux. On s'occupa, d'abord, de former un comité provisoire de quatre dignitaires ecclésiastiques (deux évêques ${ }^{71}$ et deux administrateurs de diocèse ${ }^{72}$ )

1948). Voir Robert Choquette, La Foi gardienne de la langue en Ontario, 1900-1950, Montréal, les Éditions Bellarmin, 1987, pp. 220-222; DAF, p. 44; Paul-François Sylvestre, Nos parlementaires, préface de Bernard Grandmaître, Ottawa, les Éditions l'Interligne, 1986, p. 80.

${ }^{71} \mathrm{Mgr}$ Narcisse- Zéphirin Lorrain (1842-1915), né à Saint-Martin-deLaval (Québec), vicaire apostolique de Pontlac (1882-1898), évêque de Pembroke (1898-1915) [voir L. Le Jeune, DGC, vol. 2, pp. 170-171; Antonin Nantel, «Mgr Lorrain», Pages historiques et littéraires, Montréal, Arbour et Dupont, imprimeurs, 1928, pp. 185-192; R. Choquette, L'Église catholique dans l'Ontario français du dix-neuvième siècle, pp. 265-266]; Mgr Élie-Anicet Latulipe (1859-1922), né a Saint-Anicet (Québec), vicaire apostolique du Témiscamingue (1908-1915), évêque de Haileybury (1915-1922) [voir L. Le Jeune, DGC, vol. 2, pp. 9899; R. Choquette, L'Église catholique dans l'Ontario français du dix-neuvième siècle, pp. 278-279].

${ }^{72} \mathrm{Mgr}$ Joseph-Onésime Routhier (1836-1927), frère de sir AdopheBasile Routhier, né à Saint-Placide (Québec), administrateur de l'archidiocèse d'Ottawa à la suite du décès de Mgr Joseph-Thomas Duhamel le 5 juin 1909 [voir L. Le Jeune, DGC, vol. 2, pp. 545-546; R. Choquette, L'Église catholique dans l'Ontario français du dix-neuvième siecle, pp. 236-237]; Mgr Jean-Baptiste-Joseph-Edmond Meunier (18601914), né à Sainte-Rose (Laval, Québec), études au petit séminaire de Sainte-Thérèse, prêtre en 1884 , vicalre dans le diocèse de Montréal (1884-1886), en poste à l'évêché de London (1886-1891), curé de Belle-Rivière (1891-1901) puis de Saint-Alphonse de Windsor (Essex, 
et de trois notables laïques (un ex-juge ${ }^{73}$, un sénateur ${ }^{74}$ et un ministre du gouvernement ontarien ${ }^{75}$ ). Ces personnalités devinrent bientôt membres honoraires d'un comité très large, dit général, qui comprit, de plus, cinq officiers généraux (un ecclésiastique ${ }^{76}$ et quatre laïcs ${ }^{77}$ ) et soixante-deux autres membres

Ontario) (1901-1914), administrateur du diocèse de London du 13 avril 1908 au 25 avril 1910, vicaire général du même diocèse jusqu'à sa mort [voir Jean-Baptiste-Arthur Allaire, Dictionnaire biographique du clergé canadien, tome 6 , Saint-Hyacinthe, Imprimerie du «Courrier de Saint-Hyacinthe», 1934, p. 433].

${ }^{73}$ Henri-Elzéar Taschereau (1836-1911), né à Sainte-Marie-de-Beauce (Québec), il était entré à la Cour Suprême du Canada en octobre 1878 et en avait été le juge en chef de novembre 1902 à mai 1906. Voir L. Le Jeune, DGC, vol. 2, pp. 698-699; Henry James Morgan, Ed., The Canadian Men and Women of the Time: A Handbook of Canadian Biography, first edition, Toronto, William Briggs, 1898, p. 998.

${ }^{74}$ Napoléon-Antoine Belcourt (1860-1932), né à Toronto (Ontario), avocat, sénateur depuis 1907 après avoir été député d'Ottawa (18961906) et président de la Chambre des communes (1904-1906). Voir R. Choquette, La Foi gardienne de la langue en Ontario, 1900-1950, pp. 213-219; H. J. Morgan, Ed., The Canadian Men and Women of the Time: A Handbook of Canadian Biography, first edition, 1898, p. 67; id., The Canadian Men and Women of the Time: A Handbook of Canadian Biography of Living Characters, second edition, Toronto, William Briggs, 1912 , p. 84.

${ }^{75}$ Joseph-Octave Réaume (1856-1933), né à Anderton (Ontario), médecin, député d'Essex à l'Assemblée législative de l'Ontario de 1902 à 1914 et ministre des Travaux publics de 1905 à 1914. Voir DAF, p. 303; Paul-François Sylvestre, Nos parlementaires, p. 114.

${ }^{76}$ Alexandre Beausoleil (1861-1931), né à Marieville (Québec), curé de Casselman (1893-1897), de Sainte-Anne [Ottawa] (1897-1903), de Fournierville (1903-1911), de Vankleek-Hill (1911-1925), viceprésident. Voir DAF, pp. 43-44.

77 Albert Constantineau (1866-1944), né à Saint-Eugène, (Prescott, Ontario), juge, président [voir Jean-Yves Pelletier, Nos magistrats, Ottawa, les Editions L'Interligne, 1989, pp. 87-88]; Rufus H. Parent (1877-1960), né à Sainte-Anne (Essex, Ontario), médecin à Ottawa dès 1902 [voir Georgette Lamoureux, Histoire d'Ottawa et de sa population canadienne-française, tome 5: Ottawa, 1926-1950, Ottawa, G. Lamoureux, 1989, pp. 320-3211, et Charles-Avila Séguin (1883-1965), né à Montréal (Québec), avocat, député provincial de Russell (19291934) [voir id., ibid., p. 323; P.-F. Sylvestre, Nos parlementaires, pp. 117-1181, secrétaires conjoints; Emmanuel Tassé (1850-1916), né à 
(dix-sept ecclésiastiques ${ }^{78}$ et quarante-cinq laïcs de professions diverses $\left.{ }^{79}\right)$. Le Comité général s'empressa de partager sa tâche entre sept comités composés, à quelques exceptions près, de ses propres membres, et responsables devant lui de leurs activités; ce furent les comités d'éducation, des intérêts généraux, de publicité, de la statistique; des finances, d'organisation, de réception. Tous ces comités s'efforcèrent de travailler à l'échelle de la province. Ainsi, le $1^{\text {er }}$ septembre 1909, le Comité de la statistique fit tenir aux curés et à leurs paroissiens influents un long questionnaire $^{80}$ qui devait le renseigner sur la situation et l'état de la collectivité franco-ontarienne; les questions avaient été préparées sous quatre chefs principaux: la population, les écoles, l'agriculture et l'industrie (questions économiques), l'action sociale. Le Comité d'organisation, lui, envoya des représentants dans les différentes régions de la province; précédés par un mémoire ${ }^{81}$ dont des milliers d'exemplaires avaient été envoyés dans toutes les paroisses, ils allèrent de paroisse en paroisse afin de faire prendre conscience à tous les Canadiens français

Trois-Rivières (Québec), financier, trésorier.

${ }^{78}$ Dix prêtres séculiers (dont huit étalent curés de paroisse) et sept religieux (4 oblats, dont l'un était curé de paroisse; un jésuite, un dominicain et un montfortain, curés de parolsse).

${ }^{79}$ Cinq députés et trois ex-députés, quatre médecins, deux avocats, un juge, quatre inspecteurs d'écoles, un principal d'école, deux professeurs, huit fonctionnaires, un chimiste, un écrivain (l'un des médecins, Rodolphe Chevrier, et l'un des fonctionnaires, Alfred-Duclos De Celles, étaient aussi écrivains), trois journalistes, deux marchands, un comptable, un gérant de banque, trois dirigeants de l'Union SaintJoseph, un entrepreneur, deux personnes dont la profession n'est pas connue.

${ }^{80}$ "Questionnaire du Comité de la Statistique», dans CÉCFO, pp. 72 82.

${ }^{81}$ «Mémolre concernant le congrès d'éducation des CanadiensFrançais d'Ontario», dans CÉCFO, pp. 86-90. 
de l'Ontario des buts et de la nécessité du congrès et de les encourager à envoyer le plus grand nombre possible de délégués à Ottawa le 18 janvier 1910.

\section{1910: LE CONGRÈS DE FONDATION DE L'ACFÉO.}

UNE PREMIÈRE PRISE DE PAROLE COLLECTIVE

Ce fut un succès étonnant. Le 18 janvier, en effet, ce sont douze cents délégués choisis par des assemblées populaires qui se présentent aux organisateurs d'Ottawa. Ils viennent de tous les points de la province: quatre-vingt-onze de l'Ouest, une centaine du Nord et des centaines de l'Est ${ }^{82}$. La Basilique NotreDame se remplit pour la messe d'ouverture du congrès. Le délégué apostolique, Mgr Donatus Sbar[r]etti ${ }^{83}$, a accepté de la célébrer et l'abbé LéonCalixte Raymond ${ }^{84}$, curé de The Brook [Bourget] (comté de Russell), a été choisi pour prononcer le sermon.

\footnotetext{
${ }^{82}$ Voir la liste dans CÉCFO, pp. 313-344.

${ }^{83}$ Né en 1856 à Montefranco, en Ombrie (Italie), Mgr Donatus Sbarretti avait été auditeur à la délégation apostolique de Washington (18931900), puis évêque de La Havane (1900-1901), avant d'êttre nommé délégué apostolique du Canada et de Terre-Neuve, avec résidence à Ottawa, le 6 décembre 1902. Son mandat se termina le 3 novembre 1910. Il décéda en 1939. Voir L. Le Jeune DGC, vol. 2, pp. 611-612; R. Choquette, La Langue gardienne de la foi en Ontario, 1900-1950, p. 31. ${ }^{84} \mathrm{~L}$ 'abbé Léon-Calixte Raymond, né à Saint-Eugène-de-Prescott (Ontario) le 11 avril 1871, était curé de The Brook depuis 1904; 1 avait été ordonné prêtre en 1897 après des études à Ottawa, puis il avait été vicaire a Masson (1897), Buckingham (1897-1901), Saint-Eugène-dePrescott (1901), et curé a Luskville (1901-1904). (D'après Jean-BaptisteArthur Allaire, Dictionnaire biographique du clergé canadien-français, vol, 2: les Contemporains, Saint-Hyacinthe, imprimerie de «la Tribune», 1908, p. 500.)
} 
UN PLAIDOYER POUR L'ÉDUCATION CHRÉTIENNE

Son texte ${ }^{85}$ est un plaidoyer, classique par sa composition et son contenu, en faveur de l'éducation chrétienne telle qu'on la concevait et pratiquait au Canada français depuis la seconde moitié du XIX siècle.

Après avoir rappelé dans le premier paragraphe de son introduction ${ }^{86}$ que le congrès a été suscité par les dangers que la langue française, gardienne de la foi, court en Ontario, et que le but du congrès, c'est de préserver les libertés acquises et de conquérir celle qui doit «les couronner: la liberté d'enseignement supérieur», le prédicateur affirme que l'instruction sans l'éducation peut «devenir un instrument de perdition». Il expose ensuite longuement sa conception de l'éducation, puis la résume en une phrase: «éduquer une vie humaine, c'est former un honnête homme, perfectionner l'honnête homme par le chrétien, préparer le chrétien à devenir saint». C'est la plus grande œuvre qui soit et, "d'office», elle appartient «aux chefs de famille, d'une part; à l'Église, d'autre part».

Passant au premier point de son discours ${ }^{87}$, l'abbé Raymond rappelle le rôle que l'Église a joué dans la conservation de la culture occidentale après l'invasion des barbares aussi bien en éduquant les enfants pauvres qu'en fondant et dirigeant des universités. L'Église a compris que l'éducation chrétienne devait commencer dès le jeune âge et c'est elle qui a «appris au monde le respect de l'enfance». Elle «s'entend mieux que qui que ce soit en matière d'éducation".

\footnotetext{
${ }^{85}$ «Sermon de M. l'abbé L. Raymond», dans CÉCFO, pp. 102-112.

${ }^{86}$ Ibid., pp. 102-104.

${ }^{87}$ Ibid., pp. 105-110.
} 
Auguste Comte, propagandiste de l'école neutre en France, n'a-t-il pas dit que «l'Église catholique a été le promoteur le plus efficace du développement populaire de l'intelligence humaine"? C'est cette Église qui «a éduqué le peuple canadien-français et lui a conservé, avec sa langue, la religion de ses pères".

Dans son deuxième point ${ }^{88}$, le prédicateur justifie la nécessité de l'école chrétienne à partir du fait que, devenu fils de Dieu par son baptême, le petit enfant a besoin de se mettre en relation avec ce Dieu dès que s'éveillent son intelligence et son cœur; il a done droit non seulement au respect, mais à une éducation chrétienne. Aux parents, "l'autorité immédiate» voulue par Dieu, de le prendre en charge les premiers, puis de le confier à l'Église quand ils ne sont plus capables de le faire. Alors, «en principe et en fait, l'école chrétienne, telle que l'Église l'entend et l'a créée, est, à tout point de vue, supérieure à toutes les autres écoles", car, à la différence de l'école non chrétienne "où tout est sacrifié au savoir profane", elle ne se contente pas de préparer l'homme instruit: elle prépare l'homme de foi.

En troisième lieu ${ }^{89}$, l'abbé Raymond se demande s'il existe en Ontario des écoles catholiques où les petits Canadiens français peuvent être éduqués chrétiennement. Il reconnaît qu'elles existent pour les petits de cinq à quatorze ans, mais que, malheureusement, ces petits sont obligés d'y utiliser très tôt une langue étrangère au lieu de la leur, qui est «bien souvent" la gardienne de leur foi. Il faut améliorer cette situation. Les Canadiens français de l'Ontario y arriveront s'ils sont capables de «mettre le devoir en

88 Ibid., pp. 107-110.

${ }^{89}$ Ibid., pp. 110-112. 
avant des intérêts personnels» et de se convaincre que, «pour constituer un peuple», «l'unité de la foi, l'uniformité des mœurs, la communauté de langage» sont nécessaires, et s'ils peuvent, mus par l'amour de la patrie, lutter comme leurs pères et se rallier sous la devise «Dieu et notre langue!».

Le sermon se termine par un mot d'ordre: «En face d'une légion, ne nous bornons pas à n'être qu'une poignée ${ }^{90 ! . . . » ~}$

\section{LES BUTS DU CONGRES}

La plupart des séances du congrès eurent lieu au Monument National dont les dirigeants avaient mis gratuitement toutes les salles à la disposition des délégués. La première réunion débuta à deux heures et demie de l'après-midi par l'envoi de deux câblogrammes $^{91}$ : l'un à Rome, pour protester de la "soumission absolue» du Congrès au Saint-Siège et implorer la bénédiction du pape Pie X; l'autre à Londres, pour exprimer l'«inaltérable loyauté» et l' «absolu dévouement» dudit Congrès à la «Personne» du roi Édouard VII et à «l'Empire». Faut-il noter que la proposition du premier texte fut reçue avec enthousiasme et la lecture du second, accueillie par un tonnerre d'applaudissements?

Ces gestes d'une extrême prudence une fois posés, le juge Albert Constantineau prend la parole ${ }^{92}$ en sa qualité de président de la Commission constituante du congrès. Il consacre la première moitié de son

\footnotetext{
${ }^{90}$ Ibid., p. 112.

${ }^{91}$ Les textes de ces câblogrammes ont été reproduits dans CECFO, pp. 113-114.

92 "Discours de Son Honneur le Juge A. Constantineau», dans CECFO, pp. 114-123.
} 
discours $^{93}$ à un historique de la naissance et des préparatifs du congrès ainsi qu'à un rappel des buts visés et des questions à considérer: la publication d'un journal impartial qui traiterait de façon intelligente des questions d'intérêt public, la passion des chantiers qui ralentit la colonisation et retarde la fondation des foyers domestiques, l'abus des boissons enivrantes que l'on devrait contrer par la prédication et des sociétés de tempérance, l'éducation des enfants. Cette dernière question est la plus importante de toutes. Quelqu'un que l'orateur ne nomme pas n'a-t-il pas dit, en effet, qu' "une nation se juge par la puissance de son intelligence et la force de son caractère"? Le juge Constantineau prend cependant soin de préciser que, s'agissant du congrès en cours, le mot éducation ne réfère pas qu'au domaine scolaire, il "embrasse" aussi "une série de questions multiples qui intéressent "(la) foi, (la) nationalité et (la) vie sociale" des Canadiens français de l'Ontario.

Dans la seconde moitié de son discours ${ }^{94}$, le juge fait valoir l'importance de la langue française non seulement comme langue seconde dans un pays où près du tiers de la population la parle, mais aussi comme langue diplomatique de l'univers entier. Aussi regrette-t-il que les universités anglaises ne lui donnent qu' «une place facultative dans l'enseignement supérieur" et il voit le jour où les Franco-Ontariens, en plus de l'enseigner dans les écoles primaires, «la feron[t] étudier dans les établissements d'enseignement secondaire et supérieur». Il s'indigne ensuite du fait que l'on a songé à contester aux francophones de l'Ontario le droit de se réunir en congrès pour

${ }^{93}$ Ibid., pp. 114-118.

${ }^{94}$ Ibid., pp. 119-122. 
améliorer leur situation scolaire et linguistique aussi bien que sociale, économique et nationale. Leur geste n'a rien de déloyal, mais l'orateur croit bon, comble de prudence, d'ajouter aux deux câblogrammes du Congrès une déclaration qui justifie et engage toute sa nation: «Nous usons d'un droit commun à tous [...]. Inséparablement attachés à la foi de nos pères, nous demeurons les sujets féaux et loyaux de la couronne britannique. [...] pour nous, Canadiens catholiques, la maxime est sacrée: "Obéir à l'État, c'est obéir à Dieu."".

En conclusion ${ }^{95}$, le juge Constantineau décrit l'urgence et la nécessité qu'il y a pour la race canadienne-française de conserver son identité, «tout en travaillant, de concert avec les autres races, à la formation d'une grande et puissante nation canadienne». À cette fin, elle doit s'attacher à sa foi religieuse, adhérer à sa langue, demeurer fidèle à ses traditions ancestrales, présenter un front uni pour la défense et la revendication de ses droits, être fidèle à "sa mission providentielle de misères et de combats d'abord, d'accroissement et de vitalité ensuite, de développement, d'expansion, d'évangélisation, de succès et de prospérité finalement».

\section{ENTRE LE PASSÉ ET L'AVENIR}

La deuxième séance du congrès eut lieu le soir du même jour. Ce fut la plus nourrissante, car le Comité d'éducation y présenta un rapport fouillé, dont la lecture fut précédée d'un éloquent discours de son président, monsieur Pierre-Martial Côté ${ }^{96}$, du ministère de la Justice.

95 Ibid., pp. 122-123.

${ }^{96}$ Pierre-Martial Côté, fils de J.-O Côté (notaire qui avait été greffier du 
Le soir est propice aux épanchements, et monsieur Côté avoua, dès sa première phrase, être sous le coup d'une émotion profonde. Il la coula si bien dans son texte qu'il la communiqua à tous ses auditeurs. Ceux-ci eurent donc droit, ce soir-là, à un discours ${ }^{97}$ de style romantique comme on les aimait encore en ce début du $\mathrm{XX}^{\mathrm{e}}$ siècle.

Son état d'âme dévoilép8, l'orateur invite ses compatriotes à remonter avec lui aux sources glorieuses de leur histoire pour y goûter de doux souvenirs et $y$ puiser le courage de lutter. Rythmant son débit par la répétition de "je me souviens», il évoque les grandes figures du passé, de Champlain à Mercier, et célèbre surtout les mérites de ceux, tels Lafontaine et Morin, qui ont «obtenu le gouvernement responsable avec tous ses bienfaits et ses libertés» et suscité "l'entente cordiale» dans le pays. Il fait aussi la louange des mères canadiennes; c'est grâce à elles que les Canadiens français sont maintenant quatre fois plus nombreux en Ontario qu'ils ne l'étaient cent cinquante ans auparavant dans tout le Canada, et, conséquemment, qu'ils sont installés dans cette province "pour y vivre, pour y grandir et pour y mourir". L'orateur termine son anamnèse ${ }^{99}$ par une phrase de conquérant, qui lui permet de passer de l'autrefois au présent et de fonder celui-ci sur celui-là: «Maintenant que nous nous sommes emparés de notre part

Consell privé du Canada), avocat, président de la Commission scolaire d'Ottawa de 1908 à 1910 [voir Noël-E. Lanolx, dir., Les Biographies françaises d'Amérique, Montréal, Les Journalistes associés, éditeurs, 1942, p. 24]. Il fut le père de Louis Côté (1890-1943), avocat et homme politlque [voir P.-F. Sylvestre, Nos parlementaires, p. 90; DAF, pp. 105-106].

${ }^{97}$ «Discours de M. P. M. Côté», dans CÉCFO, pp. 135-143.

98 Ibid., p. 135.

${ }^{99}$ Ibid., pp. 135-138. 
du sol, il nous faut réclamer et obtenir notre part de l'instruction publique et de l'éducation."

Monsieur Côté se montre optimiste dans la seconde partie de son discours ${ }^{100}$. Il croit, d'une part, que l'État ne peut rester sourd aux demandes de gens qui réclament le droit et les moyens de «faire pousser des hommes instruits» qui contribueront au prestige de la nation. D'autre part, il voit dans l'arrivée «à pleins paquebots" d'immigrants européens de petite condition une occasion à saisir par ses compatriotes; il exprime sa vision dans des termes qui montrent bien que le dominé n'a tout naturellement de cesse qu'il ne domine à son tour et pareillement: "À nous, dit-il, de donner (à ces immigrants) toute place au rang inférieur, et nous, montons, élevons-nous par l'éducation, afin qu'étant les maîtres dans notre propre maison, nous en fassions nos serviteurs." Pour s'élever, les Canadiens français devront sortir de leur indifférence et de leur apathie, mettre de côté leur égoïsme et la jalousie qu'ils ont les uns pour les autres, prendre conscience de leur situation et de leurs besoins. Il faudra, de plus, qu'ils fassent comprendre à leurs concitoyens anglophones, qui «craignent (leur) accroissement présent et redoutent peut-être (leur) suprématie future" qu'ils n'ont pas l'intention d'apprendre le français pour délaisser l'anglais, puisque la connaissance parfaite de cette langue s'impose pour réussir dans la province, et qu'ils ne seront pas moins patriotes non plus. Les préjugés finiront par disparaître, mais le «bien national le plus naturel et le plus fort» qu'est la langue, les Canadiens français ne le conserveront qu'à la condition de rester unis et d'être loyaux les uns envers les

${ }^{100}$ Ibid., pp. 138-143. 
autres comme le sont leurs concitoyens de langue anglaise. Et l'orateur de terminer en citant la dernière strophe du poème le plus célèbre de William Chapman, "Notre langue ${ }^{101 »:}$

Brille donc à jamais sous le regard de Dieu,

Ô langue des anciens! Combats et civilise,

Et sois toujours pour nous la colonne de feu

Qui guidait les Hébreux vers la Terre promise!

M. Côté lut ensuite le rapport du Comité ${ }^{102}$. C'est un texte substantiel, bien composé et rédigé dans une langue claire. Il se divise en quatre parties qui s'enchaînent logiquement: 1) une description succincte du système scolaire ontarien qui satisfait pleinement les Canadiens de langue anglaise, mais ne donne que peu de place à l'enseignement de la langue française; 2) une énumération, du point de vue des Canadiens français, des dix lacunes principales de ce système; 3 ) une liste des dix considérations sur lesquelles les Canadiens français s'appuient pour réclamer les réformes qui s'imposent et auxquelles, «en loyaux sujets de la grande nation dont (ils ont) reconnu la suzeraineté», ils affirment avoir droit; 4) une liste de dix-huit demandes.

La lecture du rapport terminée, $M$. Côté proposa, précédée de dix-huit attendus, une liste de dix-sept mesures qui serait envoyée au premier Ministre de la

${ }^{101}$ Publié pour la première fois dans le Monde illustré du 26 avril 1890 (p. 411), ce poème a été remanié à plusieurs reprises par son auteur entre cette date et 1901 . Jean Ménard en a donné une bonne version critique dans William Chapman, coll. "Classiques canadiens", 36, Montréal, Fides, 1968, pp. 41-44; nous avons reproduit cette version dans notre Anthologie de la poésie franco-ontarienne, des origines d̀ nos jours, Sudbury, Prise de parole, 1991, pp. 24-26.

102 "Rapport du Comité d'éducation", dans CÉCFO, pp. 144-153. 
province ${ }^{103}$. Le père Louis Le Jeune ${ }^{104}$, oblat venu de France treize ans plus tôt et professeur à l'Université d'Ottawa, appuya la proposition par un discours ampoulé sur l'éducation nationale ${ }^{105}$.

\section{L'ÉDUCATTON DE LA VOLONTÉ FATT L'HOMME}

Dans un premier point très bref ${ }^{106}$, intitulé «l'Éducation en général», il note que l'éducation "s'entend de l'action de former l'enfance et la jeunesse», puis il en distingue le champ: «la culture de la sensibilité, de la raison, de la volonté, c'est-à-dire de l'âme toute [sic] entière, de sa manifestation extérieure par le langage, par la conduite privée et publique», de celui de l'instruction: «la culture de l'esprit, (le) développement de l'intelligence et de ses opérations, [...] la conquête de la science».

Le second point, beaucoup plus long que le premier, a pour titre «l'Éducation morale»; il se divise en deux parties. Dans la première ${ }^{107}$, rythmée par la phrase suivante: "Les enfants d'aujourd'hui seront les hommes et les femmes de demain.", le Père fait l'éloge des mères canadiennes-françaises qui ont formé dès l'enfance les âmes fortes et les caractères vigoureux des ancêtres. Elles ont su éduquer, dit-il,

\footnotetext{
${ }^{103}$ Dans CÉCFO, pp. 153-159.

${ }^{104}$ Louis Le Jeune (1857-1935), né à Pleybert-Christ (Finistère, France), entre chez les Oblats de Marie-Immaculée à Nancy (France) en 1877, étudie en France et en Irlande, enseigne en France (1883-1891), en Hollande (1893-1896) et à l'Université d'Ottawa (1897-1913), publie plusieurs ouvrages en France et au Canada. Voir Gaston Carrière, Dictionnaire biographique des Oblats de Marie-Immaculée au Canada, tome 2, Ottawa, Éditions de l'Université d'Ottawa, 1977, pp. 306-307; DALFAN, pp. 859-860.

105 «Discours du R. P. L. Le Jeune, O.M.I.», dans CÉCFO, pp. 159-167. ${ }^{106}$ Ibid., p. 160.

${ }^{107}$ Ibid., pp. 160-164.
} 
parce qu'elles "ont compris que le "plaisir" est dans la privation des aises et des goûts; [...] le respect et la dépendance envers l'autorité; [...] le travail obscur et monotone, [...] l'abnégation de soi et le dévouement aux autres», et qu'il «résulte toujours de l'activité, consciencieusement et valeureusement déployée». Ces mères ont compris également qu'elles devaient faire accepter à leurs enfants le fait que «le labeur qu'impose le devoir, que les sacrifices qu'exige la vertu, sont [...] la source intarissable du vrai bonheur et de l'honneur». Aussi ont-elles donné à leur progéniture «le fécond enseignement de la "douleur", douleur physique et morale, double élément de l'héroïsme patriotique et religieux, de la prospérité domestique et nationale». Pour ces femmes instruites par le malheur, «la souffrance était un "avertissement", qui signale à l'enfant le mal par la crainte et le remords, [...] un "frein", qui arrête l'enfant sur le bord du vice et du déshonneur, [...] qui aiguillonne l'activité des jeunes, plus puissamment encore que la volupté..." Et l'oblat de s'écrier, sans doute avec beaucoup de regret dans la voix: «Quelle leçon, si on voulait l'entendre, de nos jours!... Car c'est en vertu de la douleur que la jeunesse devient travaillante et industrieuse, inventive et hardie, entreprenante et invincible.» C'est cette éducation qui explique le succès et l'héroïsme des hommes et des femmes d'autrefois et garantit la survie du catholicisme.

Dans la seconde partie ${ }^{108}$ de son second point, le Père invite les parents ainsi que les maîtres et mâ̂tresses à former les jeunes uaux bonnes manières, aux habitudes de politesse, de bienséance et de distinction", qui sont "la marque caractéristique de la

${ }^{108}$ Ibid., pp. 164-165. 
nation canadienne-française». Enfin, il leur rappelle que c'est «l'éducation de la volonté qui fait l'homme».

Dans sa conclusion ${ }^{109}$, l'orateur, bien formé à la rhétorique persuasive de son époque, s'efforce d'enlever l'adhésion finale de ses auditeurs en les forçant à s'interroger à répétition sur l'avenir de la jeunesse canadienne-française de l'Ontario. À cet effet, il pose quatre questions qui débutent de façon similaire, anaphorique: «Sera-t-il vrai, messieurs, que, dans le cours du vingtième siècle, la jeunesse canadiennefrançaise aura sa part d'influence dans» le gouvernement fédéral et provincial, l'Église du Canada, la vie économique et financière, les différentes professions, le commerce, l'industrie et l'agriculture. $\grave{A}$ chacune, il donne la même réponse pressante: «Oui, si ce Congrès d'éducation aboutit à nous garantir des hommes de volonté et de caractère, aux fortes convictions patriotiques et religieuses.» Optimiste, il prévoit que, dans cent ans, les 200000 Canadiens français de la province seront devenus vingt millions.

\section{L'ENSEIGNEMENT PROFESSIONNEL}

C'est un curé, l'abbé Joseph-Alfred Myrand"10 de Sainte-Anne d'Ottawa, qui monte ensuite à la tribune. Ses prédécesseurs ont parlé de l'enseignement académique; lui, il parlera de l'enseignement professionnel.

\footnotetext{
${ }^{109}$ Ibid., pp. 165-167.

110 Joseph-Alfred Myrand (1866-1949), né à Ottawa, prêtre en 1892, vicaire à la paroisse Sainte-Anne d'Ottawa (1892-1894), curé de SaintThomas-d'Aquin de Billing's-Bridge (1894-1902), vicaire à la cathédrale d'Ottawa (1902), curé de Sainte-Anne d'Ottawa (1903-1942). Voir DAF, pp. 254-255.
} 
Son discours ${ }^{111}$, bref, se fonde sur une observation concrète: un grand nombre d'écoliers sont destinés à être des travailleurs manuels, parce qu'ils quittent l'école très tôt, leurs parents n'ayant pas les moyens de les y maintenir. Jeunes, sans maturité suffisante et sans formation professionnelle, ces jeunes de douze à seize ans trouvent difficilement des emplois stables et suffisamment rémunérateurs; et quand ils en trouvent, il arrive souvent que les employeurs abusent de leurs forces et ne se soucient guère de leur apprendre les secrets du métier. Beaucoup de ces jeunes se découragent, "prennent des habitudes de vagabondage, d'intempérance et de fainéantise. Ils deviennent inutiles, encombrants, parfois même dangereux pour la société.»

La solution à ce problème serait la présence d'écoles d'arts et métiers dans les principaux centres canadiensfrançais. Lieux de transition entre l'école et l'atelier, ces écoles formeraient des apprentis que les employeurs engageraient volontiers et traiteraient mieux. L'enseignement, à la fois technologique et technique, serait diversifié de façon à ce que les élèves, guidés par leurs maîtres, puissent choisir le métier qui leur conviendrait le plus. Cet enseignement devrait être gratuit dans la mesure du possible et les directeurs et amis de ces institutions aideraient les finissants à trouver des emplois convenables.

Ce projet serait-il réalisable? Oui, si l'on pouvait obtenir la collaboration à la fois des autorités civiles qui auraient à installer et outiller les ateliers, d'un personnel compétent et dévoué et d'un comité de patronage qui choisirait le directeur, recruterait les élèves et recueillerait les fonds nécessaires à leur

111 «Discours de M. le Curé J. A. Myrand», dans CÉCFO, pp. 167-1 72. 
entretien et au fonctionnement de l'école. Les auditeurs de l'abbé Myrand convinrent avec lui de la possibilité d'une telle collaboration et de l'intérêt national du projet en approuvant sa proposition, appuyée par le père Le Jeune, à l'effet que «le projet de la fondation d'écoles d'arts et de métiers soit renvoyé au Comité des intérêts généraux, afin qu'il s'occupe sans retard de sa réalisation».

La deuxième journée du congrès commence avec le rapport ${ }^{112}$ du Comité des intérêts généraux. Études faites des questions qui lui ont été soumises, le Comité exprime deux vœux: que le Congrès fasse des démarches auprès des autorités, pour obtenir plus de représentants dans la magistrature, et auprès du gouvernement, pour que soit nommé un second sénateur canadien-français; il est recommandé, de plus et surtout, que les délégués fassent appel à leurs compatriotes afin que soient établies et soutenues, "même au prix des plus grands sacrifices", le plus grand nombre possible d'écoles séparées, car c'est dans ces écoles que les enfants recevront le plus librement la culture intégrale qui correspond au caractère national. Le Comité donne ensuite la liste des rapporteurs qui présenteront ses positions sur les questions suivantes: la fondation d'un journal français, catholique et indépendant des partis politiques; les chantiers et la colonisation; l'enseignement agricole; l'intempérance; la nécessité et les moyens de "rallier de façon permanente» les Canadiens français de la province.

${ }^{112}$ "Rapport du Comité des intérêts généraux", dans CÉCFO, pp. 173175. 
ÉCOLE SÉPARÉE ET ÉCOLE PUBLIQUE

Le Comité avait choisi l'abbé Sylvio Corbeil ${ }^{113}$, nommé peu auparavant principal de l'École normale de Hull, pour présenter ses vues sur l'école catholique. Ce fut l'un des meilleurs discours ${ }^{114}$ du congrès.

L'introduction ${ }^{115}$ est faite tout entière d'une précaution oratoire bien formulée. L'orateur assure les délégués que, en lançant un appel en faveur des. écoles séparées, le Comité n'a pas eu l'intention de blâmer ni de censurer les Canadiens français qui utilisent l'école publique, car il suppose que, patriotes, ils ont certainement de bonnes raisons d'agir ainsi. Le Comité, dans un geste patriotique, a simplement voulu rappeler que l'école publique, c'est un mal, et l'école séparée un idéal que les Canadiens français doivent rechercher pour deux motifs que l'abbé fait valoir dans un discours en trois points.

L'école publique est d'abord un mal parce qu'elle enferme les enfants - pâte malléable - de diverses

${ }^{113}$ Sylvio Corbeil (1860-1949), neveu, par sa mère, de Mgr Onésime Routhier et de sir Adolphe-Basile Routhier, né à Sainte-Scholastique (Québec), études au Petit Séminaire de Sainte-Thérèse, puis à Rome et a Paris, prêtre en 1884, professeur au Petit Séminaire de SainteThérèse (1885-1902), vicaire à la cathédrale d'Ottawa (1902-1909), premier principal de l'École normale de Hull (1909-1928), directeur du Grand Séminaire d'Ottawa (1928-1942). Selon Juliette LalondeRémillard, «il fut le directeur de conscience de Groulx quil le considérait comme son "père spirituel" [...]. Groulx admirait en lui le dynamisme, la pédagogie et le labeur intelligent." Voir Lionel Groulx, Journal, 1895-1911, édition critique par Giselle Huot et Réjean Bergeron, sous la direction de Benoît Lacrolx, Serge Lusignan et JeanPierre Wallot, blochronologie, notices blographiques et index thématique [par] Juliette Lalonde-Rémillard, préface [de] Benoît Lacroix, tome 2, Montréal, les Presses de l'Université de Montréal, 1984, p. 976; id., Mes Mémoires, tome 1, Montréal, Fides, 1970, pp. 68-72, passim (volr index, p. 417).

114 «Discours de M. l'Abbé S. Corbeil», dans CECFO, pp. 175-183.

115 Ibid., pp. 175-176. 
origines et diverses fois dans un moule commun qui tend à faire disparaître leurs caractères religieux particuliers. Les premiers auteurs de la législation scolaire ontarienne n'eurent pas ce but en tête, mais l'école neutre s'imposa à eux par suite des divisions qui existaient entre les divers groupes protestants. Or, cette école déforme l'être humain en ne le considérant que comme un être raisonnable et social alors qu'il est aussi un être religieux. Dans les faits, s'il se trouve que, dans maintes écoles publiques françaises, les élèves et les enseignants sont catholiques, il n'en reste pas moins que c'est malgré la loi et à la faveur de tolérances, de tromperies ou de complaisances que l'on y enseigne la religion catholique romaine. L'orateur termine son premier point ${ }^{116}$ en lançant un appel à la "fierté de race» des délégués: «Consentiriez-vous, Canadiens-Français, [...], pour l'amour de quelques piastres, à prendre des postures de suppliants pour mendier des tolérances quand la Constitution de 1867 vous permet d'ouvrir des écoles séparées et de vous tenir là, debout, dans votre dignité d'hommes libres?»

Il y a plus - c'est le deuxième point ${ }^{117}$ - : cette déformation humaine qu'engendre l'école publique est particulièrement néfaste dans le cas des Canadiens français, car elle entraîne une déformation nationale en mutilant l'âme de la nation «dans l'une de ses essentielles caractéristiques». C'est l'une des principales raisons sur lesquelles s'appuie le Comité des intérêts généraux pour justifier ses réclamations scolaires: «La valeur ethnologique du CanadienFrançais, dit-il, dépend directement de sa foi et de sa langue maternelle. Le Canadien-Français ne saurait

${ }^{116}$ Ibid., pp. 176-1 78.

${ }^{117}$ Ibid., pp. 178-180. 
abandonner ni l'une ni l'autre sans que sa mentalité en soit profondément modifiée au détriment de la société en général.» L'abbé Corbeil termine son point par un ordre: «Évacuez l'école publique: c'est le lieu de déformation nationale, Canadiens-Français; bâtissez, multipliez l'école séparée, c'est le lieu d'une culture complète et nationale.»

Le troisième point ${ }^{118}$ fait valoir un second motif en faveur de l'école séparée: le devoir de transmettre c'était le serment que l'adolescent de la Grèce antique prêtait au moment où il s'inscrivait sur la liste des citoyens - le patrimoine national intégralement, d'une génération à l'autre. L'école séparée fait partie de l'héritage des Canadiens français. Elle lui a été accordée en Ontario au début de l'Union des deux Canadas grâce aux rudes lutteurs politiques que furent La Fontaine, Parent, Taché et bien d'autres ${ }^{119}$, puis les pères de la Confédération l'ont mise sous la garde de la Constitution de 1867. «Compatriotes, lâcherons-nous cet héritage? [...] Renverserons-nous ce monument d'une longue et sainte bataille? Non, non [...].» Il faut y tenir d'autant plus que les AngloOntariens ont montré l'estime qu'ils avaient, eux aussi, pour l'école séparée en menant la lutte pour sa création et sa conservation. Bien plus, Ryerson, le père du système scolaire ontarien, n'a-t-il pas dit

${ }^{118}$ Ibid., pp. 180-183.

119 Parlant de ces grands Canadiens dont la voix et l'attitude ferme firent «fléchir le fanatisme qui sévissait dans Ontario», l'abbé Corbeil en vient à exprimer le sentiment de supériorité ethnique que ressentalent plus d'un Canadien français de l'époque: «Ces hommes d'État ne voulurent point permettre que les fils de leur race, passés dans cette province-ci, fussent frustrés de la culture catholique et française, car le sang (ils l'ont cru, ces immortels génies!)[,] le sang, dis-je, qui coule dans nos veines, la langue qui vibre sur nos lèvres, la foi qui ouvre à nos yeux de divins horizons, font de nous une race supérieure aux races aux hochets d'or." (Ibid., p. 180.) 
qu'elle était «l'élargissement de la pierre angulaire sur laquelle (il voulait) fonder l'instruction publique dans le Haut-Canada»?

L'abbé Corbeil admet que des raisons justifient provisoirement le maintien d'écoles publiques, mais l'argent ne peut en être une quand on sait que les catholiques de France et les Canadiens français des États-Unis, qui "payent intégralement les taxes des écoles publiques, [..] ne laissent pas de bâtir leurs écoles paroissiales». Ce serait une honte si les Canadiens français de l'Ontario délaissaient le précieux héritage qu'est l'école séparée: prolongement et élargissement du foyer familial et de l'église paroissiale, elle est aussi le lieu par excellence de la culture catholique et française.

Du discours ${ }^{120}$ de l'orateur suivant, monsieur Solomon White ${ }^{121}$, un avocat de Cobalt, les actes du congrès ne renferment qu'un bref résumé, dont les lignes suivantes sont les plus importantes: «Il affirme que les droits des Canadiens-Français à leurs écoles, à leur langue, à tous les privilèges qu'ils revendiquent, sont imprescriptibles, remontent à une lointaine et indiscutable origine. Il insiste sur la nécessité de réclamer nos droits et tous nos droits», en hommes libres et non en mendiants."

Chargé par le Comité des intérêts généraux de traiter de la nécessité de fonder un journal, monsieur $C$.

120 «Discours de M. S. White», dans CÉCFO, p. 183.

${ }^{121}$ Solomon White, né d'une mère canadienne-françalse, Angélique Fortier, a Anderdon (Essex), avocat en 1865, homme politique, maire de Cobalt en 1911. Voir H. J. Morgan, The Canadian Men and Women of the Time: A Handbook of Canadian Biography of Living Characters, second edition, p. 1160; G. M. Rose, Ed., A Cyclopadia of Canadian Biography: Being Chiefly Men of the Time, 1886, p. 265. 
S. O. Boudreault ${ }^{122}$, inspecteur général de l'Union Saint-Joseph du Canada, fit un bref discours ${ }^{123}$ que l'on peut résumer comme suit. Étant donné que le manque d'union a empêché les Canadiens français de l'Ontario de faire reconnaître leurs droits et que l'on ne peut obtenir la justice que lorsqu'on est capable de la réclamer, il importe de fonder un journal qui créera une "communauté d'idées et de sentiments". Mais ce journal, «organe officiel de l'élément français de l'Ontario», ne pourra être qu'un hebdomadaire - un quotidien ne serait pas viable -; «sa direction reposera entre les mains de l'Exécutif du Congrès» et son rédacteur sera "un journaliste aux principes sains et vigoureux». Le journal aura pour mission d'éduquer les Canadiens français de l'Ontario: «Il relèvera leurs aspirations nationales, stimulera leurs efforts sur le terrain économique, leur inculquera de saines notions de vie sociale, les mettra en garde contre les pièges tendus à la morale et à la foi.»

\section{LA LUTTE CONTRE L'INTEMPÉRANCE}

La première partie de l'après-midi du 19 janvier fut consacrée à la tempérance. Le juge Constantineau

${ }^{122}$ C.S.O. Boudreault (1856 ou 1857-1923) était «arrivé à Ottawa vers 1866 " avec sa famille. "Conservateur en politique, il tâta de la polltique municipale, fut échevin, se présenta comme maire, sans succès. Il s'occupa activement, entre autres, de la S[ain]t-Jean-Baptiste (président général), [de] l'Union St-Joseph, du Monument national (directeur)[,] de l'ACFÉO (président), des Forestiers catholiques [...], et du journal "Le Droit". Il était imprimeur de son métier et ses huit fils furent plus ou moins impliqués dans les activités de l'Ottawa Printing Co. dont C.S.O. était propriétaire, grosse entreprise qui eut à un certain moment une centaine d'employés.» G. Lamoureux, Histoire d'Ottawa, tome 4: Ottawa, 1900-1926, et sa population canadiennefrançaise, Ottawa, G. Lamoureux, 1984, pp. 234-235.

${ }^{123}$ «Rapport de M. C. S. O. Boudreault», dans CÉCFO, pp. 183-185. 
définit rapidement les visées du Congrès: 1) «réglementation de la vente des boissons enivrantes», 2) "réduction du nombre des débits de boissons", 3) "triomphe de la vertu de tempérance, et non de la prohibition». Suivirent deux discours, l'un par le curé Joseph Leclerc ${ }^{124}$ de Chute-à-Blondeau, l'autre par l'avocat J. B. T. Caron ${ }^{125}$, d'Ottawa. Seul le premier a été publié dans les actes du Congrès.

L'abbé Leclerc, à qui le Comité des intérêts généraux a demandé de "faire connaître les meilleurs moyens de rendre le peuple tempérant», rappelle que la tempérance, qui relève de la morale et de la religion, concerne aussi l'ordre social et l'économie et que l'alcoolisme est un vieux fléau auquel les Canadiens français de l'Ontario n'ont pas échappé. Les moyens à prendre pour l'enrayer étant de trois ordres: intellectuel, moral et religieux, le discours ${ }^{126}$ se divisera en autant de parties.

Le moyen intellectuel, c'est l'enseignement ${ }^{127}$. Il doit commencer dans la famille, mais le mauvais exemple de beaucoup de parents et l'insouciance de d'autres obligent l'école à mettre les enfants en garde

\footnotetext{
${ }^{124}$ L'abbé Joseph Leclerc était curé de Chute-à-Blondeau depuis 1894; né à Cap-Santé (Portneuf, Québec) le 15 juin 1866, il était devenu prêtre en 1892, puis avait été vicaire à Buckingham (1890-1893), Thurso (1893), Montcerf (1893-1894) et Mayo (1894). (D'après J.-B.A. Allaire, Dictionnaire biographique du clergé canadien-français, vol. 2: les Contemporains, p. 371.)

${ }^{125}$ Jean-Baptiste-Thomas Caron (1869-1944), né à Sainte-Perpétue (L'Islet, Québec), études au Collège Bourget, à l'Université Laval et à Osgoode Hall, avocat en 1898, greffier à la Chambre des communes (1896-1904), commissaire au bureau des licences à Ottawa (19041905), député libéral du comté fédéral d'Ottawa (1907-1908), juge pour le district de Cochrane (1923-1939). Voir I.-Y. Pelletier, Nos magistrats, pp. 82-83; P.-F. Sylvestre, Nos parlementaires, p. 85.

126 "Discours de M. le Curé Joseph Leclerc», dans CÉCFO, pp. 186-194. ${ }^{127}$ Ibid., Pp. 187-190.
} 
contre l'alcoolisme. Quant aux adultes, il faut essayer de les rejoindre par la conférence, «leçon familière» qui est à la mode, et par des tracts, les revues et les journaux, qui sont "le véhicule ordinaire de la pensée». L'orateur décrit ensuite quelques-uns des maux que l'alcoolisme cause aux individus et à leurs familles.

L'intempérance nuit à la santé publique et à l'ordre social, mais la faiblesse humaine est telle qu'il est nécessaire d'avoir des lois pour protéger la société. L'abbé Leclerc suggère deux moyens d'ordre moral ${ }^{128}$ : 1) que les autorités gouvernementales voient à la police des cabarets et des débits de boisson, qu'elles en diminuent le nombre, répriment les fraudes et réglementent la vente des alcools; 2) que l'on organise des ligues ou sociétés de tempérance comme on l'a fait avec succès dès 1809 en Angleterre et dans le nord de l'Europe, puis peu après 1840 au Québec.

Les moyens d'ordre religieux ${ }^{129}$ sont les prédications et les retraites, qui ont été fructueuses en Grande-Bretagne, et les prières et les sacrements qui procurent l'aide de Dieu. C'est par la prédication que le capucin irlandais Theobald Mathew ${ }^{130}$ a combattu l'intempérance avec succès, comme ses concitoyens l'ont reconnu en inscrivant l'épitaphe suivante sur la

${ }^{228}$ Ibid., pp. 190-192.

129 Ibid., pp. 192-195.

${ }^{130} \mathrm{C}^{\prime} e s t$ en Irlande, au début du XIX $\mathrm{X}^{\mathrm{e}}$ siècle, que les premières sociétés de tempérance européennes virent le jour. Theobald Mathew (17901856) adhéra à l'une d'entre elles en 1838 et prêcha la tempérance à travers l'Irlande jusqu'en 1842. En 1841, l'Irlande comptait plus de 4 millions et demi d'abstinents et, en trois ans, la consommation d'alcool diminua d'environ 50 pour cent; on attribua une grande partie de cette diminution aux effets de la prédication du père Mathew. Ce dernier alla prêcher en Angleterre en 1843 et aux États-Unis en 1849. (D'après the New Encyclopedia Britannica, Vol. 6, p. 688, et the New Columbia Encyclopedia, p. 1722.) 
statue qu'ils lui ont élevée à Cork: «À Mathew, l'apôtre de la tempérance, tout un peuple reconnaissant.» En terminant, le curé Leclerc invite ses auditeurs à prendre «un soin raisonnable» de leur corps, mais sans oublier leur âme ni leur intelligence, ni «leurs immortelles destinées».

\section{LES FRANCOPHONES DE L'EST ONTARIEN}

Le rapport du Comité des statistiques devait suivre. Malheureusement, les renseignements demandés par son long questionnaire du $1^{\text {er }}$ septembre 1909 étant encore incomplets, le Comité avait résolu de ne faire part au Congrès que «des faits contenus dans les rapports" du père $G$. Lebel et de messieurs $O$. A. Rocque et $S$. Ducharme, puis de recommander que «le tout soit référé au Comité Général Exécutif, afin que celui-ci avise aux moyens de faire continuer ces recherches ${ }^{131}$ ».

Le Comité d'éducation ayant fait voir "la nécessité de l'enseignement bilingue, les lacunes dans le système actuel et les réformes à y faire», monsieur $\mathrm{O}$. A. Rocque, d'Orléans, n'a plus qu'à «démontrer le besoin de cette éducation nationale». Il le fait en donnant des statistiques sur la population francophone et la situation de la langue française dans les paroisses, les écoles et la fonction publique de l'est de l'Ontario qu'il a divisé en trois parties pour les fins de son rapport: 1) les comtés de Russell, Prescott, Carleton et la ville d'Ottawa; 2 ) les comtés de Stormont et de Glengarry; 3) les villes de Cornwall et d'Alexandria. C'est dans ces deux villes que les Canadiens français sont le plus mal traités; la situation n'est guère

${ }^{131}$ CÉCFO, p. 194. 
meilleure dans Stormont et Glengarry, qui attirent de plus en plus de francophones. Dans les autres comtés de la région, et principalement dans celui de Prescott, les francophones sont mieux servis. Il n'en reste pas moins que leurs droits sont loin d'être respectés comme ils le devraient. Tous doivent s'unir pour améliorer la situation; ils n'y arriveront qu'en sortant de leur apathie, en se faisant plus vigilants et plus confiants en eux-mêmes, en participant davantage à la vie publique et en abandonnant leurs jalousies personnelles ${ }^{132}$.

\section{LES FRANCOPHONES DU NOUVEL ONTARIO}

Rapporteur sur le Nouvel Ontario, le père Guillaume Lebel ${ }^{133}$ a considéré six districts ${ }^{134}$ : Parry

132 "Rapport de M. O. A. Rocque», dans CÉCFO, pp. 195-207.

${ }^{133}$ Guillaume Lebel (1849-1925), né à Cacouna, fait ses études classiques au Collège Sainte-Marie (Montréal) à compter de 1862, puis il étudie le génie civil durant deux ans et pratique sa profession durant six ans avant de devenir jésuite le 6 avril 1881. Son noviciat terminé, il étudie la philosophie durant trois ans à Stonyhurst (Angleterre), enseigne les mathématiques au Collège de Saint-Boniface durant trois ans, étudie la théologie (1889-1893) à Milton Park (près de Dublin, Irlande), devient prêtre le 31 juillet 1893 , puis complète sa formation spirituelle (1893-1894) au Sault-au-Récollet (Montréal). Il enseigne ensuite les mathématiques au Collège de Saint-Boniface (1894-1903), avant d'exercer son ministère sacerdotal pendant une année dans les environs de Steelton et durant dix ans dans les hameaux de la région de Sudbury. De 1915 à 1919, il est procureur au Collège d'Edmonton; atteint d'une maladie grave, il revient à Montréal où il occupe diverses fonctions en divers lieux, dont Caughnawaga, puis décède le 23 mars 1925. [ $D$ 'après une notice biographique anonyme (le père Joseph Fortier?) - rédigée en latin - conservée aux Archives de la Compagnie de Jésus (province du Canada français) à Saint-Jérôme (Terrebonne, Québec). - Les mêmes archives conservent aussi une lettre du 11 avril 1925, adressée au père Joseph Fortier par monsieur Edmond Cloutier, secrétaire de l'ACFÉO; cette lettre de deux pages contient une évaluation louangeuse des services que le père Lebel a rendus à l'Association ainsi que de son dévouement auprès des Franco-Ontariens du Nouvel Ontario.]

134 «Rapport du Rév. Père G. Lebel, S.J., sur le Nouvel-Ontario», dans 
Sound, Nipissing, Sudbury, Algoma, Thunder Bay et Rainy River. Il présente les statisques démographiques de quarante paroisses situées dans quatre diocèses et un vicariat apostolique. De leurs 161050 habitants, 57835 sont catholiques, dont 38530 de langue française. Dans les 208 écoles élémentaires, on compte 6607 francophones. Le père Lebel note que, dans les centres agricoles, la population canadienne-française augmente plus rapidement que celle des autres nationalités. Il rend hommage à «l'habitant qui conserve, répand sa foi, sa langue, son caractère national», mais déplore le fait que beaucoup de Canadiens français ont perdu ou sont en train de perdre leur langue et, partant, leur foi dans le Nouvel Ontario. Il faut que dans toutes les institutions scolaires, $y$ compris les universités, «le français ait sa place légitime, ne serait-ce que pour apprendre plus facilement et mieux la langue de nos voisins, nos amis, nos concitoyens, l'anglais». À cette fin, les francophones sont en droit d'obtenir du ministère de l'Éducation que soient bilingues les inspecteurs, les livres scolaires, les écoles normales, les maîtres et maîtresses, et qu'il y ait, pour les institutions et les écoles bilingues, des allocations gouvernementales, des taxes et des octrois municipaux. «Nous réussirons», affirme-t-il.

LE DROIT À UNE ÉDUCATION CANADIENNE-FRANÇAISE COMPLĖTE

Le soir du 19 janvier, le Conseil municipal d'Ottawa recevait officiellement les délégués au théâtre Russell. Devant le premier ministre Wilfrid Laurier, une vingtaine de personnalités religieuses et politiques et

CÉCFO, pp. 207-214. 
2000 auditeurs, le maire Charles Hopewell ${ }^{135}$, après avoir salué les délégués, cita Ottawa et le Canada en exemple «de l'entente et de l'harmonie qui doivent exister entre deux races différentes», puis il fit valoir la nécessité de ne rien négliger pour promouvoir les bonnes relations et, l'éducation primant tout le reste, le besoin de "s'instruire et [de] travailler d'un commun accord pour le plus grand bien du pays ${ }^{136}$ ".

Le sénateur Napoléon-Antoine Belcourt, président du congrès, remercia en anglais le Maire et le Conseil de ville; il s'adressa ensuite à l'assemblée avec une éloquence toute française ${ }^{137}$.

Son texte porte essentiellement sur le but principal du congrès: la reconnaissance officielle et l'exercice concret du droit à une éducation canadiennefrançaise complète en tout domaine et à tout niveau dans des écoles bilingues soutenues par l'État.

En Ontario, le gouvernement a bien compris le devoir social qui lui incombe d'aider les parents à remplir l'obligation qu'ils ont d'éduquer leurs enfants: les citoyens anglophones de cette province "jouissent de tous les avantages connus en matière d'enseignement». Tel n'est pas le cas des francophones qui sont venus du Québec; ils se multiplient en Ontario, mais n'ont pas encore les institutions scolaires dont ils ont besoin pour leur développement physique, moral et intellectuel. Différents de leurs compatriotes anglophones non seulement par la langue et par la foi, mais aussi par «la mentalité, le

135 Cet entrepreneur d'Ottawa fut membre du premier Bureau des commissaires en 1908 et maire de 1909 a 1912 .

${ }^{136}$ Dans CECFO, p. 216.

137 "Discours de L'honorable N. A. Belcourt", dans CECFO, pp. 216 228. 
tempérament, les aptitudes, les tendances et les goûts intellectuels», ils exigent un enseignement qui respecte, en plus de leur foi, leur langue et leurs particularités nationales. Le gouvernement ontarien reconnaît en principe et en pratique le droit de chaque groupe spécifique à un mode d'enseignement qui lui convienne, puisqu'il existe officiellement dans la province des écoles confessionnelles et des écoles particulières (agricoles, industrielles, techniques) soutenues par l'État; le même gouvernement reconnaît même, «au moins virtuellement, l'établissement d'écoles ou [de] classes bilingues dans certaines parties de l'Ontario".

Les Canadiens français savent gré au gouvernement de ce qu'il a fait, mais ils demandent davantage: une reconnaissance explicite de l'école bilingue et l'aide requise pour assurer un «enseignement efficace dans les deux langues et dans les différents cours, tant pour l'éducation scolaire que pour l'entraînement pédagogique». Des modifications au système scolaire ont été proposées et des demandes ont été faites pour atteindre ces objectifs. On les a refusées parce que, venant de différents groupes, elles «manquaient d'harmonie et de précision», mais on a laissé entendre que, si elles avaient possédé ces qualités et avaient été présentées par l'ensemble de la minorité française, l'accueil aurait été bienveillant. Le moment est donc venu de réunir tous les Canadiens français de l'Ontario pour identifier les lacunes du système scolaire et proposer des réformes qui le rendront conforme aux désirs, aux aptitudes et aux besoins du groupe, "plus particulièrement en ce qui concerne l'enseignement dans les deux langues». Le congrès est l'occasion de fonder une association permanente qui s'occupera d'améliorer «la vie maté- 
rielle, morale et intellectuelle de la population française de l'Ontario". Le sénateur fait entrevoir le vaste champ d'activités de cette association en énumérant quelques-uns des moyens qu'elle devra prendre pour atteindre le but; elle $y$ arrivera

en encourageant le développement des forces physiques, en répandant les saines notions d'hygiène et de santé publique, en démontrant les maux causés par l'intempérance et en préconisant constamment la tempérance et la sobriété, en encourageant la culture des arts et des sciences, en aidant à l'établissement d'écoles agricoles ou techniques, en aidant à la fondation de clubs littéraires et athlétiques. Une telle association pourrait devenir un facteur important dans l'éducation civique des nôtres, en insistant sur le respect des lois et de l'autorité, en répandant de saines notions politiques, en inculquant une meilleure conception d'économie domestique et des obligations comme des droits du citoyen, et en inspirant à tous, et surtout à ceux qui sont mieux doués par la fortune et par l'intelligence, plus de dévouement à la cause publique, en combattant l'apathie et l'abstention d'un grand nombre pour les choses de la vie publique ${ }^{138}$.

Pour mieux faire comprendre le but du congrès et, partant, celui de l'association, l'honorable Belcourt dit que celle-ci, tout comme le congrès, ne sera ni un mouvement politique ou influencé par un parti politique, ni un groupement purement national (il sera ouvert aux sympathisants de tout lieu et de toute origine), ni un groupe hostile aux autres nationalités; il ne s'occupera pas non plus de questions religieuses. Ce que les organisateurs du congrès ont voulu, c'est «créer une saine émulation et une coopération féconde pour perfectionner les nôtres par l'éducation, l'instruction et l'enseignement, et, par ce moyen, leur permettre de se rendre plus utiles à euxmêmes et à la société». Ce que les francophones de ${ }^{138}$ Ibid., pp. 221-222. 
l'Ontario réclament, c'est le droit de se servir de la langue française pour éduquer leurs enfants, car c'est par la langue maternelle qu'on atteint le mieux et le plus l'intelligence et le cour. Il ne faut pas voir dans cette demande un rejet de la langue anglaise:

Je l'ai déjà dit et je le répète nous n'entretenons aucun préjugé contre la langue de la grande majorité du peuple canadien; nous ne sommes pas assez aveugles pour ne pas voir toute l'importance, toute la nécessité pour nous et pour les nôtres, de bien connaître et de bien parler la langue anglaise, ni assez préjugés pour entretenir la moindre objection à son maintien et à sa propagation. Elle est et sera en toute probabilité toujours la langue de la grande majorité au Canada. Tous les Canadiens-français de l'Ontario l'ont apprise et tous nos enfants l'apprendront. De l'aveu même de nos concitoyens anglais, nous la parlons quelquefois aussi bien, sinon mieux qu'euxmêmes. Nous lui accordons, dans nos relations d'affaires, une place pour le moins égale à la langue française, et il n'entre nullement dans nos desseins d'essayer à lui substituer cette dernière ${ }^{139}$.

La connaissance de la langue française n'a jamais empêché le Canadien d'être un bon et loyal citoyen; celle de la langue anglaise lui a été d'une aide précieuse dans l'accomplissement de ses tâches et, geste patriotique, dans le maintien de relations cordiales avec son entourage anglophone. "Doublement instruit», le Canadien français est "mieux armé pour les luttes de la vie et l'accomplissement de ses devoirs envers les siens, ses concitoyens et la société». Fautil rappeler que la langue française n'est ni une «étrangère" ni une "intruse» en Amérique et, surtout, en Ontario où elle est présente depuis le XVII ${ }^{e}$ siècle. Le gouvernement britannique, puis le gouvernement canadien en ont fait une langue officielle comme l'anglaise. C'est un héritage national dont la majorité ${ }^{139}$ Ibid., p. 224. 
des Canadiens anglais ne désirent pas la disparition. Son avenir en Ontario dépend des efforts que les Canadiens français voudront bien faire pour la parler et la conserver. Il importe donc que, misant sur l'esprit de justice des anglophones de la province, ils se mettent à l'œuvre pour réclamer avec fermeté et modération ce à quoi ils ont droit et dont ils ont besoin dans le domaine de l'éducation.

Sir Wilfrid Laurier ${ }^{140}$ prit ensuite la parole ${ }^{141}$, mais en tant que citoyen d'Ontario qui avait bien l'intention d'y finir ses jours. Les actes du congrès ne contiennent qu'un résumé de son discours. En écoutant son ami Belcourt, le Premier Ministre s'était rendu compte de l'importance du congrès. Il encourageait les délégués à continuer leur travail pour maintenir et améliorer les écoles bilingues et pour obtenir de la majorité ontarienne les droits que la majorité québécoise accordait à la minorité anglophone.

Mgr Joseph-Onésime Routhier fut bref; son texte tient en une page et demie ${ }^{142}$. Il rappela qu'il avait fallu lutter pour obtenir des écoles séparées, mais qu'on en avait reconnu le bien-fondé par la suite. Il en irait de même pour la place qu'on finirait par accorder à l'enseignement de la langue française; en octroyant à celle-ci la même liberté que l'on a donnée à la foi religieuse, on compléterait l'œuvre scolaire

\footnotetext{
${ }^{140}$ Wilfrid Laurier (1841-1919), né à Saint-Lin-des-Laurentides (L'Assomption, Québec), études classiques au Collège de L'Assomption, études de droit à l'Université McGill, avocat et journaliste, député libéral à l'Assemblée législative du Québec (1871-1874), puis à la Chambre des communes (1874-1919), chef du parti libéral (18871919), premier ministre (1896-1911). Voir L. Le Jeune, DGC, vol. 2, pp. 99-101; Réal Bélanger, «Laurier, sir Wilfrid», dans l'Encyclopédie du Canada, tome 2, pp. 1082-1083.

141 «Discours de Sir Wilfrid Laurier», dans CÉCFO, pp. 229-230.

142 «Discours de Mgr Routhier», dans CECFO, pp. 230-232.
} 
commencée un demi-siècle auparavant, mais négligée depuis.

L'orateur suivant, l'honorable Francis Cochrane ${ }^{143}$, ministre de la Colonisation et des Mines, représentait le gouvernement du premier ministre Whitney ${ }^{144}$; il parla en anglais, mais c'est un résumé en français que l'on trouve dans les actes du congrès ${ }^{145}$. Il assura les congressistes qu'ils pouvaient compter sur lui et que le gouvernement «ne cessera(it) de travailler de toutes ses forces à l'amélioration des écoles de la province, de manière à répondre de plus en plus aux besoins et aux aspirations de la population anglaise et française».

C'est en une page que l'on a résumé le discours de l'honorable Rodolphe Lemieux ${ }^{146}$, ministre des

143 Francis Cochrane (1852-1919), né à Clarenceville (Missisquoi, Québec), marchand, maire de Sudbury à plusieurs reprises, député conservateur de Nipissing est en 1905, de Sudbury en 1908, ministre de la Colonisation et des Mines [nom changé par la suite en celui de ministre des Terres et Forêts et des Mines] dans le cabinet Whitney en 1905, des Chemins de fer et des Canaux dans le cabinet Borden en 1911. Voir H. J. Morgan, Ed., The Canadian Men and Women of the Time: A Handbook of Canadian Biography of Living Characters, second edition, p. 244; Jesse Edgar Middleton [and] W. Scott Downs, Editors, National Encyclopedia of Canadian Biography, Toronto, The Dominion Publishing Company, 1935, pp. 134-136.

144 James Pliny Whitney (1843-1914), né à Williamsburg (Ontario) d'une "famille appartena(nt) au groupe des Loyalistes américains", avocat en 1876, député conservateur de Dundas à l'Assemblée législative de l'Ontario (1888-1914), leader de l'opposition conservatrice (1896-1905), premier ministre (1905-1914). C'est sous son gouvernement que fut publié le Règlement 17 . Volr L. Le Jeune, DGC, vol. 2, p. 814; H. J. Morgan, Ed., The Canadian Men and Women of the Time: A Handbook of Canadian Biography of Living Characters, second edition, p. 1164; Charles W. Humphries, "Whitney, Sir James Pliny», in The Canadian Encyclopedia, Vol. 4, p. 2302.

145 «Discours de l'honorable Frank Cochrane", dans CECFO, p. 232. ${ }^{146}$ Rodolphe Lemieux (1866-1937), né a Montréal, avocat, député à la Chambre des communes (1896-1930), professeur de droit international et d'histoire du droit canadien à l'Université de Montréal (1896- 
Postes dans le cabinet Laurier ${ }^{147}$. Comme son chef, le ministre se considère citoyen ontarien: il a son domicile dans la capitale fédérale et il a étudié à l'Université d'Ottawa. Les Canadiens français sont chez eux en Ontario comme dans les autres provinces canadiennes; s'ils veulent que l'on compte avec eux, il faut qu'ils s'aident eux-mêmes et qu'ils aient des écoles où ils recevront une éducation pratique comme il s'en donne dans les high schools.

Si l'on en juge par les résumés de sept et quatre lignes que l'on a publiés de leurs discours, les deux derniers orateurs de la soirée furent brefs. L'honorable Adam Beck ${ }^{148}$, ministre dans le cabinet Whitney, se dit fier de son origine allemande, mais heureux de vivre dans un pays où tous ont des droits égaux. Comme son collègue, l'honorable Francis Cochrane, il affirme que le gouvernement accueillera toujours favorablement les demandes des Canadiens français ${ }^{149}$. Le secrétaire d'État Charles Murphy ${ }^{150}$ estime que les congressistes ont un but «digne de louanges» et il leur souhaite de l'atteindre ${ }^{151}$.

1929), sénateur (1930-1937). Voir L. Le Jeune, DGC, vol. 2, pp. 136137.

${ }^{147}$ "Discours de l'honorable Rodolphe Lemieux", dans CÉCFO, p. 233. 148 Adam Beck (1857-1925), né à Baden (Ontario), "manufacturer, politician, power-authority commissioner [...]. Feared and revered as an empire builder, Beck dominated Ontario politics for a generation as he built and expanded the Hydro-Electric Power Commission of Ontario into the largest publicly owned power authority in the world.» $\mathrm{H}$. V[ivian] Nelles, «Beck, Sir Adam», in The Canadian Encyclopedia, Vol. 1, p. 193; voir aussi J. E. Middleton [and] W. S. Downs, Editors, National Encyclopedia of Canadian Biography, pp. 28-29.

${ }^{149}$ Dans CÉCFO, p. 233.

${ }^{150}$ Charles Murphy (1863-1925), né à Ottawa, avocat, député libéral de Russell a la Chambre des communes (1908-1925), secrétaire d'État (1908-1911), ministre des Postes (1922-1925), sénateur (1925).

${ }^{151}$ Dans CECFO, pp. 233-234. 
LES FRANCOPHONES DE L'OUEST ONTARIEN

Le matin du 20 janvier, troisième et dernière journée du congrès, monsieur Séverin Ducharme ${ }^{152}$, de Belle-Rivière, lit le troisième rapport du Comité de la statistique $^{153}$. Il donne les chiffres de la population francophone de cinq comtés et le nombre de familles que comptent les dix-huit paroisses francophones de l'Ouest ontarien. Il note que les Canadiens français sont en majorité parmi les catholiques du diocèse de London et que leur nombre augmente plus rapidement que celui de la population anglophone; la plupart des paroisses sont desservies par des prêtres canadiens-français, mais il y a plusieurs exceptions. L'étude du français est "négligée dans les écoles», on compte peu de francophones parmi les fonctionnaires publics et il existe un certain nombre de francophones apathiques ou indifférents. L'annonce du congrès a provoqué un réveil et l'on s'apprête à réclamer une éducation bilingue et à jouer un plus grand rôle dans le domaine public.

\section{LA MUTUALITE, UN REMEDE}

Le Comité des intérêts généraux avait chargé monsieur G. W. Séguin, président de l'Union Saint-Joseph

\footnotetext{
${ }^{152}$ Séverin Ducharme (1866-19??), né à Saint-Félix-de-Valois (Québec), il sera "cultivateur, notaire, banquier, greffier" de canton et "préfet" de village à Belle-Rivière (Essex) et député libéral d'Essex-Nord à l'Assemblée législative de l'Ontario (1914-1919). Voir P.-F. Sylvestre, Nos parlementaires, p. 91.

153 «Discours de M. S. Ducharme», dans CÉCFO, pp. 237-240.
} 
du Canada ${ }^{154}$, de parler de la mutualité ${ }^{155}$ qui est en progrès au Canada. Il la présente comme un perfectionnement de l'assurance-vie, puis en fait valoir, dans un long discours en quatre parties, les avantages économiques, sociaux, religieux et nationaux ${ }^{156}$.

Au point de vue économique ${ }^{157}$, la mutualité protège contre les revers de fortune, la maladie et la mort qui jettent dans la misère. Elle ne peut jouer ce rôle, cependant, que si elle rassemble un nombre considérable de membres. C'est donc l'union qui fait sa force. La mutualité s'adapte aux besoins de chacun

154 «Société mutuelle, catholique, canadienne française [sic], pour assurance d'adulte et infantile, bénéfices de maladie et d'invalidité. L'institution a pris naissance à Ottawa, en 1863, par le groupement de modestes ouvriers. Lancée d'abord à titre d'essai ou d'expérience, avec de rudimentaires ressources de coopération mutuelle, elle a lentement progressé $[\ldots]$.

Ainsi, par pénibles étapes et en dépit de la multiple concurrence, l'Union a réussi à aboutir à l'assurance-vie, appuyée sur des bases scientifiques du calcul des probabilités et garantissant une solvabilité parfaite. $[$...]

C'est le mérite de l'Union d'avoir donné naissance à l'Association d'éducation de l'Ontario.» L. Le Jeune, DGC, vol. 2, pp. 746-747. Incorporée en 1864 sous le nom d'Union Saint-Joseph d'Ottawa, cette société mutuelle sera connue sous ce nom jusqu'en 1905, puis sous celui d'Union Saint-Joseph du Canada jusqu'en 1959, année où elle adopte son nom actuel: Union du Canada. (D'après DAF, p. 373.) 155 «Forme de prévoyance volontaire fondée sur un système d'engagements synallagmatiques [i.e. qui comportent des obligations réciproques entre les parties] par lequel les membres d'un groupe, moyennant le seul payement d'une cotisation, s'assurent réciproquement contre certains risques (maladies, blessures, infirmités, chômage) ou se promettent certaines prestations (frais funéraires, secours aux ascendants, veuves, orphelins), en se garantissant les mêmes avantages sans autre distinction que celle qui résulte des cotisations fournies et en excluant toute idée de bénéfice.» Henri Capitant, "Mutualité», Vocabulaire juridique, rédigé par des professeurs de droit, des magistrats et des jurisconsultes sous la direction de Henri Capitant, Paris, Presses universitaires de France, 1936, p. 342.

${ }_{156}$ "Discours de Monsieur G. W. Séguin», dans CECFO, pp. 240-249. ${ }^{157}$ Ibid., pp. 24 1-243. 
et elle est une caisse d'épargne parfaite, car ses opérations «sont soumises aux lois de l'État et reposent sur les calculs les plus judicieux». Son bureau de direction est élu par les membres, ce qui en fait une institution "essentiellement démocratique" où la charité chrétienne a aussi sa place.

La mutualité se présente aussi comme une «solution pratique, pacifique, patriotique» aux problèmes sociaux ${ }^{158}$. L'ordre social n'a pas encore été bouleversé au Canada, mais on peut se demander si la vague socialiste qui désagrège l'Europe n'y déferlera pas, étant donné la pauvreté de la classe ouvrière. Les retraites ouvrières ne sont pas un remède, le socialisme non plus: les deux ont failli en NouvelleZélande et en d'autres pays.

Sur le plan religieux ${ }^{159}$, la mutualité rassemble les forces pour la défense de la foi et la sauvegarde des bonnes mœurs. Le sociétaire de la mutualité remplit ses devoirs non seulement envers Dieu en pratiquant le précepte "Aide-toi et le ciel t'aidera", mais aussi envers son prochain parce qu'il contribue au soulagement des malheureux et protège sa famille, et envers lui-même puisqu'il s'engage à suivre des règlements qui le gardent dans la voie droite, entre autres ceux qui défendent l'abus de l'alcool et privent les désœuvrés de leurs droits acquis. Le sociétaire protège aussi sa foi en se liant à une société catholique plutôt qu'à une société neutre.

Enfin, au point de vue national ${ }^{160}$, la mutualité, en rassemblant les énergies d'un peuple, est un puis-

158 Ibid., pp. 243-245.

${ }^{159}$ Ibid., pp. 245-247.

${ }^{160}$ Ibid., pp. 247-249. 
sant moyen pour en préserver les caractères distinctifs, c'est-à-dire la nationalité, son bien le plus sacré. C'est en concentrant leurs forces dans des institutions propres et en défendant leur droit à l'existence que les Canadiens français de l'Ontario pourront survivre comme nation, et non pas, sous prétexte de travailler à l'harmonie du pays, en faisant partie de sociétés anglo-saxonnes: il ne peut y avoir de bonne entente qu'entre des groupes égaux et distincts. L'heure est grave: «Langue, religion, mœurs, traditions, aspirations, tels sont les éléments constitutifs d'une nation. Or, ces éléments ont perdu leur pureté primitive chez les Canadiens-Français d'Ontario. Le remède à la situation réside dans la Mutualité catholique et canadienne-française.»

\section{LA NECESSITE DE FONDER UNE ASSOCIATION NATIONALE}

L'orateur suivant ${ }^{161}$, l'abbé Alexandre Beausoleil, vice-président du Comité général et l'un des principaux instigateurs du congrès, avait été invité par le Comité des intérêts généraux à traiter du "[re]groupement compact, solide et permanent de tous nos compatriotes d'Ontario en un bloc national, qui nous permette de résister à toutes les tentations d'anglicisation, d'assurer notre résistance comme race dans la province». Après avoir noté qu'un sociologue aurait été plus qualifié que lui pour traiter ce sujet, le curé de Fournierville avoua que, après avoir milité publiquement pendant des mois pour la tenue du congrès, il s'était senti obligé d'accepter l'invitation ${ }^{162}$.

Dans la première partie de son discours ${ }^{163}$, il décrit

161 "Discours du curé Beausolell", dans CÉCFO, pp. 249-260.

${ }^{162}$ Ibid., pp. 249-250.

${ }^{163}$ Ibid., pp. 250-255. 
les conditions sociales des 200000 francophones qui forment un dixième de la population de l'Ontario. Ils se sentent chez eux dans Prescott et Russell et ils le seront bientôt, si un réveil national se produit, dans Glengarry et Stormont; dans les autres régions de la province, ils résistent dans des conditions difficiles, mais il se trouve aussi que, en certains endroits, le poids de leur nombre se fait sentir. Leur répartition sur un vaste territoire ne favorise pas l'union; cependant, le secret de leur faiblesse ne réside pas seulement dans l'éparpillement géographique. Les orateurs de la Saint-Jean-Baptiste peuvent bien chanter la geste glorieuse des ancêtres, il n'en reste pas moins que le groupe canadien-français est loin d'être parfait. Ses travers mis de côté, ce peuple souffre de trois grands défauts socialement ravageurs, que n'excuse pas le fait qu'ils ne lui sont pas propres. Ce sont "l'abus des liqueurs, le blasphème et la jalousie». L'économie sociale souffre, en plus, d'un "quatrième vice»: l'esprit de parti, qui oblitère la clairvoyance de l'opinion publique et engendre des querelles et des divisions ruineuses jusque dans les conseils scolaires et municipaux. Il faudrait plutôt avoir l'esprit de corps à l'exemple d'une autre race pourtant plus nombreuse. Et l'orateur de charger aveuglants et aveuglés:

Tous nos grands hommes du jour, quand ils sont reçus à Toronto, ne manquent jamais d'exhiber un certificat de loyalisme qu'on ne leur demande pas d'ailleurs, et d'asssurer leurs hôtes que le dernier coup de canon tiré sur le vieux rocher de Québec, pour la défense du drapeau britannique, sera l'œuvre d'un Canadien-Français. Imaginez donc!

Et dire que ceux qui vident leurs coupes de champagne au bruit pompeux de ces gargarismes oratoires, n'ont pas encore songé à donner à l'enseignement du français la place officielle qu'il doit occuper dans la législation pro- 
vinciale. La langue de Champlain et de Montcalm, de Lafontaine, de Papineau et de Cartier, de... Laurier, est regardée dans Ontario comme une langue étrangère et mise sur le même pied que l'allemand, le russe et le chinois.

Cet état de choses est en réalité déplorable et humiliant pour nous. Mais, de grâce, n'allez pas en jeter la responsabilité sur les seuls chefs que vous vous êtes donnés. Vous les avez honorés de votre confiance; vous les avez chargés de vous représenter dans les législatures; mais, dites-moi, messieurs, quand leur avez-vous tracé une ligne à suivre au renouvellement d'un mandat? Ceux qui sollicitent vos suffrages déploient, avec force discours, le programme de leurs fermes résolutions et de leurs bons propos; mais jamais vous n'avez songé, un seul instant, à leur imposer vos vues, pour la bonne raison que chez les nôtres l'opinion publique est nulle.

Vous votez rouge ou bleu sur tout et partout, sans vous douter que ces luttes et ces divisions, souvent inexplicables, anéantissent votre prestige et font le jeu de ceux qui arrivent, qui se casent et vivent à vos dépens.

Ce mal dont nous souffrons est plus grand et plus désastreux que vous ne le pensez, et je puis vous assurer que ce ne sont pas les hommes politiques qui s'empresseront d'y porter remède. Il n'est rien qu'ils redoutent tant qu'un réveil de l'opinion publique, qu'ils s'étudient d'ailleurs à endormir avec un luxe infini de précautions vraiment touchantes; jamais une classe d'hommes n'a mieux compris la sagesse du vieil axiome machiavélique: «Diviser pour régner ${ }^{164} . »$

Que les Canadiens français de l'Ontario se débarrassent de leurs défauts, vices et travers ainsi que de leurs préjugés et qu'ils réalisent l'union pour laquelle ils sont accourus des quatre coins de la province; ils pourront alors «regarder l'avenir avec confiance, car les peuples unis ne meurent pas».

${ }^{164}$ Ibid., pp. 254-255. 
Monsieur Séguin a déjà donné un moyen à prendre pour réaliser cette union en parlant de la mutualité. Un deuxième s'impose: la fondation d'un journal; il fera l'objet du deuxième point de l'orateur ${ }^{165}$. La presse joue dans la vie des nations modernes un rôle militant qui dépasse même celui des grandes armées. Les Canadiens français de l'Ontario doivent se servir de cette arme. Il leur faut un organe de publicité reconnu comme leur porte-parole, défenseur de leurs droits et capable d'influencer l'opinion publique. Le Comité des intérêts généraux a étudié la question. Il est d'autant plus convaincu que ce besoin est grand qu'il a pu se rendre compte de l'efficacité d'un simple journal régional comme le Moniteur de Hawkesbury lorsqu'il s'est agi de lancer l'idée du congrès, mais il s'est heurté à des difficultés financières et le temps lui a manqué pour bien préparer un tel projet. Il reste toujours la possibilité d'appuyer les journaux français qui existent et de les amener à défendre les intérêts réels de la nation. Favoriser leurs compatriotes et leurs entreprises, n'est-ce pas d'ailleurs ce que les Canadiens français devraient faire en tout domaine?

Dans la troisième partie de son discours ${ }^{166}$, le curé Beausoleil présente un troisième moyen d'union: la permanence du Bureau du congrès. Ce Bureau doit demeurer «un foyer actif», être le point de convergence de «l'ensemble» des "œuvres nationales", «diriger» et "canaliser" avec sagesse et prudence efforts, ressources et énergies pour un même et fructueux service de la cause nationale. C'est "la base d'un édifice [...] destiné à abriter les nobles aspirations et les

\footnotetext{
${ }^{165}$ Ibid., pp. 256-258.
}

${ }^{166}$ Ibid., pp. 258-260. 
libertés des générations futures» et l'on peut avoir confiance en lui, car c'est un mouvement populaire comme les nombreux congrès qui ont bien servi les Acadiens et les Canadiens français des États-Unis.

Le curé Beausoleil conclut son discours en invitant ses auditeurs à prendre comme devise une phrase d'Honoré Mercier: "Cessons nos luttes fratricides, sachons rester unis ${ }^{167}$."

\section{L'ACCÈS AUX CHARGES PUBLIQUES}

Monsieur Aurélien Bélanger, inspecteur des écoles bilingues, prit ensuite la parole. Il traita de la question des écoles et donna quelques conseils. Puis, monsieur Emmanuel Tassé ${ }^{168}$ présenta les résolutions du Comité des intérêts généraux. Les actes du congrès contiennent "la substance» de son discours ${ }^{169}$.

Le texte porte principalement sur la distribution des charges publiques. L'étude menée par le Comité montre bien que les Canadiens français de l'Ontario n'ont pas la part qui leur revient de droit dans «les charges élevées de l'État, sur le banc ou dans les conseils de la nation", et même dans les diocèses, celui d'Ottawa y compris. Il invite donc les délégués

\footnotetext{
${ }^{167}$ Cette phrase est tirée d'un discours prononcé par Honoré Mercier en la fête de la Saint-Jean-Baptiste du 24 juin 1889.

${ }^{168}$ Emmanuel Tassé, né à Trois-Rivières en 1850 , zouave pontifical en 1868 , homme d'affaires, promoteur des compagnies Temiscamingue Colonization (1886) et Lake Temiscamingue Railway (1890), journaliste, propriétaire du journal le Canada (1894), fondateur de la Compagnie d'imprimerie le Canada (1894), amateur de sport et de musique. Voir H. J. Morgan, The Canadian Men and Women of the Time: $A$ Handbook of Canadian Blography of Living Characters, second edition, 1912 , p. 1085.

169 «Discours de M. Emmanuel Tassé», dans CÉCFO, pp. 260-266.
} 
à voter en faveur de la résolution qu'il propose au nom du Comité. Précédée de cinq considérants qui font état des injustices dont est victime la minorité francophone et des droits de ce groupe de par son nombre et la jurisprudence britannique, la proposition se lit comme suit: «confiant dans la justice de sa présente recommandation, le Congrès d'Éducation des Canadiens-Français d'Ontario demande respectueusement et instamment la nomination d'un sénateur, d'un juge de la cour supérieure et de juges de la cour de comté, choisis parmi les Canadiens-Français de cette province». La résolution sera envoyée au Premier Ministre du Canada et à qui de droit.

L'après-midi du $\mathbf{2 0}$ janvier, le Congrès approuva sans changement, mais avec une addition à l'article 5, les «Statuts de l'Association Canadienne-Française d'Éducation de l'Ontario ${ }^{170} "$, puis on procéda à l'élection du Comité exécutif ${ }^{171}$.

\section{LE MAL DES CHANTIERS}

Le père André Paquet ${ }^{172}$, oblat d'Ottawa, chargé de traiter de la question des chantiers, présenta son

\footnotetext{
${ }^{170}$ Voir CÉCFO, pp. 267-273.

${ }^{171}$ Voir ibid., pp. 273-276.

${ }^{172}$ André Paquet (1878-1920), né à Sainte-Jeanne de Neuville [PontRouge], études au Juniorat du Sacré-Cœur [Ottawa] (1894-1899), oblat en 1899, prêtre en 1905, économe au Scolasticat Saint-Joseph [Ottawa] (1904-1905), professeur à l'Université d'Ottawa (1905-1911), vicaire à Mattawa (1911-1912), Hull (1912-1913), Stanton [Texas] (1913-1914), Maniwaki (1914-1915), au sanctuaire de Notre-Damedu-Cap [Cap-de-la-Madeleine] (1915-1916), à Saint-Pierre-Apôtre [Montréal] (1916-1917). (D'après Gaston Carrière, Dictionnaire biographique des Oblats de Marie-Immaculée au Canada, vol. 3, Ottawa, Éditions de l'Université d'Ottawa, 1979, pp. 37-38.) Pour le rôle qu'il aurait joué en faveur de la langue française à l'Université d'Ottawa, voir R. Guindon, Coexistence menacée. La Dualité linguistique d l'Université d'Ottawa, vol. 2: 1898-1936, pp. 62, 64, 202.
} 
étude. Il l'avait menée sur les plans politique, économique, social, religieux et national. Son texte ${ }^{173}$ se divisait en deux parties: 1) les dangers, 2) les préservatifs.

La première partie ${ }^{174}$ débute par des statistiques. Il y aurait en Ontario plus de vingt mille familles dont le chef ou au moins un membre travaille dans les chantiers, ce qui fait dépendre des chantiers environ 50000 personnes, soit un quart de la population francophone. Ces forestiers n'ont pas la possibilité de voter, sauf quand leur maître - «qui n'est pas des (n)ôtres» - y trouve avantage; l'influence des francophones s'en trouve diminuée au moment des élections. Dès sept ou huit ans, les enfants rêvent de la vie des chantiers et sont portés à délaisser l'école; à douze ans, ils en sont retirés parce que la famille a besoin de leur salaire. La société canadiennefrançaise souffre de ce manque d'éducation d'autant plus fortement que les hommes de chantier non seulement ne s'enrichissent pas, mais délaissent la culture de la terre et la vie ordonnée qui pourrait leur apporter le bien-être et l'aisance. Bien plus, ils ruinent leur santé et apportent la misère à leur famille. La forêt n'est source d'enrichissement que pour les patrons et la plupart ne sont pas Canadiens. Éloigné tôt de la paroisse, le jeune homme prend aussi ses distances avec les traditions religieuses et nationales; il dépense sa vie et ruine «son domaine national pour le premier étranger venu».

Les préservatifs ${ }^{175}$ contre le mal des chantiers sont de divers ordres. Il revient à l'enseignant, au prêtre

${ }_{173}$ «Discours du R. P. A. Paquet, O.M.I.», dans CÉCFO, pp. 276-284.

${ }^{174}$ Ibid., pp. 277-282.

${ }^{175}$ Ibid., pp. 282-284. 
et aux paroissiens influents de renseigner les jeunes sur les dangers de la vie des chantiers. Une loi qui empêcherait l'embauche des jeunes de moins de dixhuit ans aiderait aussi. Il faudrait en arriver à pouvoir lancer ces jeunes dans les industries nationales, dans l'industrie forestière pour leur propre compte et surtout dans un mouvement de colonisation:

Soit par l'achat de nos voisins, soit par la création de paroisses nouvelles, réalisons la devise des plus grands patriotes: «Emparons-nous du sol.» À la ville et au chantier, nous servons; mais à la campagne, dans les champs, nous régnons. Les richesses se dissipent, les mines s'épuisent; mais le sol reste toujours plus précieux ${ }^{176}$.

\section{LE BANQUET DE CLÓTURE}

Le congrès se termina par un grand banquet (plus de 250 convives) à l'hôtel Russell le soir du 20 janvier. Onze personnalités, dont le premier ministre du Canada et le chef de l'opposition, l'honorable Robert Borden $^{177}$, y prirent la parole. Les actes du congrès reproduisent intégralement les textes de trois d'entre eux $^{178}$.

Mgr J. O. Routhier, portant un toast au Gouverneur général, évoqua les enseignements de respect pour le roi reçus de sa mère dont le frère, condamné à mort pour avoir participé aux troubles de Saint-

\footnotetext{
${ }^{176}$ Ibid., pp. 283-284.

${ }^{177}$ Robert Laird Borden (1854-1937), né à Grand-Pré (Nouvelle-Écosse), avocat en 1878, député conservateur à la Chambre des communes (1896-1920), chef de l'opposition (1901-1911), premier ministre (19111920). Voir L. Le Jeune, DGC, vol. 1, pp. 207-208; Robert Craig Brown, «Borden, Sir Robert Laird», in The Canadian Encyclopedia, Vol. 1, p. 252.

${ }^{178}$ Les discours des autres orateurs sont résumés en quelques lignes, sauf ceux de Sir Wilfrid Laurier (dans CECFO, pp. 290-291) et de l'honorable Robert Borden (ibid., pp. 291-292).
} 
Eustache, avait tenu sa grâce de la reine Victoria ${ }^{179}$. M. Georges Pharand ${ }^{180}$, député provincial de Prescott, exprima les sentiments de ses compatriotes ${ }^{181}$ :

[...], qui n'admirerait le spectacle de toute une race se levant comme un seul homme? Se levant, non pour provoquer qui que ce soit, non pour blesser les sentiments de ceux qui nous entourent, mais bien pour s'affirmer. Se levant pour montrer qu'elle n'a pas dégénéré, qu'elle est digne de ses ancêtres, de ceux qui ont été les premiers explorateurs et les premiers missionnaires de notre belle et grande province d'Ontario.

[...] Nous sommes fiers d'être sujets britanniques, de jouir de tous les droits, de tous les privilèges que comporte ce titre. Nous voulons nous en montrer dignes, en assumant toutes les obligations et les responsabilités. Nous voulons nous en montrer dignes par la pratique des vertus qui font les bons citoyens et les bons chrétiens.

Le père William Murphy ${ }^{182}$, o.m.i., recteur de l'Université d'Ottawa, loua les efforts du Congrès et demanda «pour tout homme la connaissance courante des deux langues et la culture soignée de sa langue maternelle». Le bilinguisme, qui facilite les relations

179 «Discours de Mgr J. O. Routhier», dans CÉCFO, pp. 287-288.

${ }^{180}$ Georges-Hector Pharand (1868-19??), né à Saint-Clet (Soulanges, Québec), "marchand et agent du CPR», député conservateur du comté de Prescott à l'Assemblée législative de l'Ontario (1908-1911). Voir Paul-François Sylvestre, Nos parlementaires, p. 110.

181 «Discours de M. Pharand», dans CÉCFO, pp. 289-290.

182 William Murphy (1865-1915), né à Williams Lake (ColombieBritannique), oblat de Marie-Immaculée en 1885, prêtre en 1892 , professeur à l'Université d'Ottawa (1887-1911), curé de la paroisse Saint-Joseph [Ottawa] (1901-1915), recteur de l'Université d'Ottawa (1905-1911). "Le Père fut toujours reconnu comme un esprit droit, conciliant et pacificateur dans les luttes raciales qui existaient alors dans la capitale canadienne.» Gaston Carrière, Dictionnaire biographique des Oblats de Marie-Immaculée au Canada. t. 2, pp. 418-419. Voir aussi Roger Guindon, Coexistence menacée. La Dualité linguistique d̀ l'Université d'Ottawa, vol. 2: 1898-1936, pp. 47-65: «Un recteur irlandais ramène le calme (1905-1911)». 
sociales et la «fusion des esprits», permet aussi de «doubler» influence et fortune. C'est dans leur langue maternelle que se sont exprimés les grands esprits de chaque nation, et «la langue de Bossuet est assez belle pour justifier l'orgueil et la ténacité de ceux qui disent: "Nous la parlons et nous la parlerons toujours [...]".» C'est une langue utile à cause de son caractère universel, de sa souplesse et de sa clarté. "Aussi est-elle enseignée dans tous les collèges et toutes les académies de l'Empire britannique, et l'Allemagne elle-même en impose l'étude dans ses gymnases et ses universités. [...] dans toutes les contrées de l'Europe, les hommes instruits s'honorent de parler aisément la langue française." Le recteur de l'Université d'Ottawa venait de donner une petite leçon qu'il conclut, dernier orateur de la soirée, par un appel à l'hommage: «Donc, Messieurs, honneur aux Canadiens-Français qui se glorifient de leur langue! Succès au Congrès d'Éducation des CanadiensFrançais d'Ontario ${ }^{183 ! »}$

\section{LES FRANCOPHONES DE LA RÉGION DE PEMBROKE}

Les actes du congrès contiennent en appendice un rapport ${ }^{184} \mathrm{du}$ père Charles Charlebois ${ }^{185}$, oblat d'Ottawa,

183 «Discours du Rév. Père W. Murphy, O.M.I.», dans CÉCFO, pp. 292294.

184 «Rapport du Rév. Père C. Charlebois, O. M. I. Recensement de Pembroke», dans CÉCFO, pp. 298-304.

${ }^{185}$ Charles Charlebois (1871-1945), né à Sainte-Marguerite-du-LacMasson, oblat en 1889, prêtre en 1895, curé de Mattawa [Ontario] (1897-1898), de Saint-Paul-des-Métis [Alberta] (1899-1901), curéfondateur de Sainte-Famille [Ottawa] (1901-1917), directeurfondateur du journal le Droit (1913-1930), supérieur du scolasticat oblat de Sainte-Agathe-des-Monts (1934-1945). Voir DAF, p. 82; $\mathrm{R}$. Choquette, La Foi gardienne de la langue en Ontario, 1900-1950, pp. $210-213$ [Choquette cite (p. 210 , note 2) une lettre dans laquelle le père Charlebois écrit que sa nomination à Sainte-Famille prit fin le 
sur la région de Pembroke. Le Comité de la statistique lui avait demandé de faire le recensement de la population canadienne-française et de tenir des réunions d'information sur le congrès en préparation.

Le Père a été bien accueilli par une population avide de l'entendre. Il n'a trouvé qu'une seule école bilingue dans la partie du diocèse qu'il a recensée. Dans certaines écoles anglaises, on enseigne le français quelques heures par semaine. Il faudrait, pour le bien des deux groupes, diviser les écoles ou les classes selon la langue. Les francophones de la région délaissent ou négligent malheureusement l'agriculture pour les chantiers alors que ceux-ci ne devraient être qu'un moyen d'amasser l'argent nécessaire à l'achat d'une terre. Il est regrettable aussi que, la tranquillité une fois trouvée, les Canadiens français ne s'occupent plus des affaires publiques. Il existe des «conseils florissants» de l'Union Saint-Joseph du Canada et quelques bibliothèques où l'on trouve des livres français. Les Canadiens français sont fidèles à leur foi et sont desservis par des prêtres de leur langue dans plusieurs paroisses, mais pas dans toutes. Le père Charlebois termine son rapport en citant l'archevêque Quigley ${ }^{186}$, qui s'était adressé à ses diocésains francophones de Chicago dans les termes suivants:

Avant tout, Canadiens-Français, conservez vos traditions, vos institutions, propagez votre langue. C'est parce que

30 mars 1913]; Gaston Carrière, Dictionnaire biographique des Oblats de Marie-Immaculée au Canada, tome 1, Ottawa, Éditions de l'Université d'Ottawa, 1976, pp. 184-185 [Carrière avait fait du père Charlebois un vicaire à Mattawa, un économe a Saint-Paul-des-Métis et le curé de Sainte-Famille jusqu'en 1917].

186 James Edward Quigley (1854-1911), né à Ottawa; à Buffalo en 1859, évêque de Buffalo en 1897, archevêque de Chicago en 1903. 
vous avez gardé votre langue et vos traditions que vous êtes restés, en Amérique, un peuple distinct et que vous avez conquis l'admiration de tous. Et c'est en conservant votre langue et vos traditions que vous pourrez remplir votre mission, qui est celle de donner à l'Amérique tout ce que la vieille France avait d'admirable et que vous avez si bien conservé. (Semaine religieuse de Montréal, $1^{\mathrm{er}}$ août 1904.)

Le recueil des actes du Congrès contient quatre autres appendices qui ne manquent pas d'intérêt: la liste des souscriptions reçues (6 188,21 \$) pour l'administration du Congrès (elle inclut les noms des donateurs - individus ou personnes morales - et de leurs paroisses, à quelques exceptions près ${ }^{187}$ ); le compte rendu des recettes (6 188,21 \$) et des dépenses administratives ( $1728,46 \$$ ), qui affiche une balance en banque $(4459,75 \$)^{188}$; la liste des délégués et le lieu de résidence de chacun ${ }^{189}$; la réponse du roi Édouard VII au câblogramme que lui avaient adressé les membres du Congrès ${ }^{190}$; des "échos de la presse", dont la présence avait été assurée par les correspondants d'une vingtaine de journaux anglais ou français $^{191}$.

\section{1910: Le Congrès de fondation de l'ACFÉ.}

UNE PIÈCE D'WENTIE

Pour les congressistes et l'ensemble de leurs compatriotes qui ont suivi les travaux de leurs représen-

\footnotetext{
187 «Souscriptions pour le Congrès d'Éducation des CanadiensFrançais d'Ontario», dans CÉCFO, pp. 305-310.

188 «Administration», ibid., pp. 311-312.

189 «Liste des Délégués au Congrès d'Éducation des CanadiensFrançais d'Ontario», ibid., pp. 313-344.

190 «Réponse au Câblogramme adressé par les Membres du Congrès à Sa Majesté Édouard VII», ibid., p. 345.

191 «Échos de la Presse», ibid., pp. 356-359.
} 
tants par l'intermédiaire du médium de l'époque, les journaux, la vie du Congrès de 1910 ne s'éteint pas le soir du 20 janvier; elle se continue à travers l'Association canadienne-française d'éducation de l'Ontario que les quelque 1200 élus du peuple viennent de créer pour rassembler tous les francophones de l'Ontario en un groupe d'action démocratique qui prendra dorénavant en charge, avec la force que donne l'union, la défense des intérêts et des ambitions légitimes de la communauté franco-ontarienne. Pour le lecteur d'aujourd'hui, les actes que nous venons de présenter s'affichent comme une pièce d'identité communautaire, en ce sens qu'ils officialisent, de par la prise de conscience collective qu'ils expriment à la suite d'un processus démocratique, l'existence d'un groupe qui, en prenant la parole, se démarque des autres groupes canadiens-français par divers traits, intérêts ou attitudes spécifiques. Ce sont ces marques que nous allons relever et comparer, pour mieux les faire voir, à celles que nous trouvons dans les actes d'autres conventions nationales canadiennes-françaises.

\section{UNE CONVENTION TARDINE}

Il importe d'abord de noter que les FrancoOntariens ont beaucoup tardé à tenir une convention nationale. Les Franco-Américains l'avaient fait les premiers, dès 1865, à New York, à l'instigation des fondateurs de la Société Saint-Jean-Baptiste de cette ville, puis ils s'étaient réunis annuellement presque toujours en des lieux différents - jusqu'en 1874 , et à tous les deux ans par la suite, mais les Conventions des Sociétés de secours mutuels avaient 
continué de se tenir chaque année et des Conventions régionales existaient dans plusieurs États ${ }^{192}$.

Au Québec, le 23 juin 1874, la Société Saint-JeanBaptiste de Montréal fut la première «à réunir, dans une même fête, des envoyés de tous les groupes canadiens [canadiens-français]»; le lendemain, elle inaugura dans cette province «l'ère des conventions nationales, à l'instar des conventions nationales des États-Unis». Ce devait être, en ce quarantième anniversaire de la fondation de la Société, une «assemblée générale des différentes sociétés nationales françaises du Canada et des États-Unis ${ }^{193}$ ". En fait, les 18000 Franco-Américains qui y étaient venus dans plus de deux cent cinquante wagons de chemin de fer, s'y trouvèrent en plus grand nombre que les Canadiens ${ }^{194}$. Parmi les orateurs qui s'adressèrent aux quatre cents délégués que la Convention réunit, Robert Rumilly n'a signalé, qui soit d'Ottawa, que Joseph Tassé (qui était accompagné d'un vieil ami outaouais), et dans le Comité d'organisation du projet de fédération des sociétés Saint-Jean-Baptiste d'Amérique ( «Union nationale canadienne-française de l'Amérique»), qui comprenait des «FrancoAméricains, des Acadiens, des Franco-Manitobains et des Canadiens français de la province de Québec», on ne reconnaît qu'un seul Outaouais, Stanislas Drapeau, et pas plus que Joseph Tassé, il n'est signalé comme tel; il faut mentionner, toutefois, qu'aucun des quatre et seuls délégués de la Saint-Jean-Baptiste

${ }^{192}$ Voir H.-J.-J.-B. Chouinard, FNCF, pp. 241-243.

${ }^{193}$ Ibid., pp. 42-43.

${ }^{194}$ Ibid., pp. 44, 124; Robert Rumilly, Histoire de la Société Saint-JeanBaptiste de Montréal. Des Patriotes au fleurdelysé, 1834-1948, Montréal, L'Aurore, 1975, p. 103; id., Histoire des Franco-Américains, Montréal, édité par l'Auteur, sous les auspices de l'Union Saint-IeanBaptiste d'Amérique, 1958, pp. 66-75. 
de Québec ne fait partie dudit comité ${ }^{195}$. Doit-on en conclure que cette première convention nationale fut plutôt montréalaise et franco-américaine que largement canadienne-française?

Quoi qu'il en ait été de leur participation, les quatre délégués de Québec, «enthousiasmés» quand même, semèrent, à leur retour de Montréal, l'idée d'une convention semblable dans la Vieille Capitale ${ }^{196}$. Mais conflits, frictions et bouderie entre les deux villes en retardèrent la réalisation pendant six ans ${ }^{197}$. Les Québécois tinrent leur première convention nationale à Québec les 25 et 26 juin $1880^{198}$ (après une grandiose célébration de la Saint-Jean-Baptiste le 24). Trois Franco-Américains y firent des discours sur la situation et le rôle des Canadiens français aux États-Unis ${ }^{199}$ et deux Acadiens, sur la situation et l'avenir des Acadiens ${ }^{200}$. Personne ne discourut sur les Canadiens français de l'Ontario; pas même les Franco-Ontariens présents: Joseph Tassé, membre de la cinquième commission ( $«$ Sciences. Lettres. Beaux-Arts») traita de l'émigration canadienne aux États-Unis ${ }^{201}$; Benjamin Sulte, membre de la même commission, fit rapport sur les lettres ${ }^{202}$, et le député fédéral Wilfrid Laurier parla de «notre langue ${ }^{203}$ ». Les deux rapporteurs de la sixième commission («Des Canadiens des États-Unis et de [sic] Manitoba»)

195 Ibid., pp. 104-106; H.-I.-J.-B. Chouinard, FNCF, p, 47.

196 Ibid., p. 93.

197 R. Rumilly, Histoire de la Société Saint-Jean-Baptiste de Montréal. Des Patriotes au fleurdelysé, 1834-1948, pp. 120-121.

198 H.-J.-J.-B. Chouinard, FNCF, pp. 241-484.

199 Ibid., pp. 302-309 et 314-326; voir aussi R. Rumilly, Histoire des Franco-Américains, pp. 90-94.

${ }^{200}$ H.-J.-J.-B. Chouinard, FNCF, pp. 296-301 et 336-346.

${ }^{201}$ Ibid., pp. 359-374.

202 Ibid., pp. 414-416.

${ }^{203}$ Ibid., pp. 334-336. 
furent un Franco-Américain et un FrancoManitobain ${ }^{204}$; ceux de la septième commission («Des Acadiens»), un Acadien et un Québécois (qui parla des Acadiens du Québec) ${ }^{205}$. On n'avait pas prévu de commission pour faire rapport sur les Canadiens français de l'Ontario. Officiellement, en sa qualité de président de la Société Saint-Jean-Baptiste d'Ottawa, le docteur F.-X. Valade, était l'un des huit viceprésidents de la convention ${ }^{206}$, tandis que messieurs Alphonse Lusignan et Stanislas Drapeau faisaient partie de la cinquième commission ${ }^{207}$. Quand on consulte la liste des délégués ${ }^{208}$ qui se sont fait connaître aux organisateurs de la convention, on compte cinquantetrois Franco-Américains, quarante-deux Acadiens ${ }^{209}$, deux Franco-Manitobains et seulement neuf FrancoOntariens auxquels s'ajoutent quatre délégués de la Société Saint-Jean-Baptiste de Hull dits (par erreur?) de l'Ontario et deux Québécois inscrits (par erreur?) comme délégués des Sociétés Saint-Jean-Baptiste et Saint-Pierre d'Ottawa ${ }^{210}$.

\footnotetext{
${ }^{204}$ Ibid., Pp. 440-444.

205 Ibid., Pp. 446-475.

${ }^{206}$ Ibid., pp. 245 et 606.

${ }^{207}$ Ibid., p. 255. Messieurs Joseph Marmette et Alfred-Duclos De Celles étaient aussi membres de cette commission, mais le premier n'habitait pas encore Ottawa et le second, qui s'y est installé cette année-là, n'y habitait pas encore ou que depuis peu.

${ }^{208}$ Ibid., pp. 477-481.

${ }^{209}$ Ibid., p. 477; la liste de la page 445 n'en compte cependant que quarante et un. - Marguerite Maillet a regroupé leurs photos individuelles à la page 61 de son Histoire de la littérature acadienne. De rêve en rêve, coll. "Universitaire», Moncton, Éditions d'Acadie, 1983; ils sont quarante-quatre. - Robert Rumilly (Histoire des Acadiens, II, Montréal, [s.é.], 1955, p. 780) affirme que soixante-dix délégués acadiens auraient participé à la célébration de la Saint-Jean-Baptiste le 24 juin 1880. Il note aussi (p. 779) que «les Acadiens n'avaient pas de sociétés nationales, lors du ralliement montréalais de 1874 " et qu' «ils n'en ont pas encore en 1880".

${ }^{210}$ Selon Chad Gaffield (Schooling and Cultural Conflict: The Origins of
} 
Bien meilleure, et plus exaltante, fut la participation des Acadiens! Certains d'entre eux ont même vu dans les travaux de leur commission (la septième, composée de vingt-quatre membres acadiens ${ }^{211}$ ) une sorte de congrès national: pour la première fois, des délégués de toutes les régions des provinces Maritimes se réunissaient; ils auraient été plus d'une centaine à célébrer le 24 juin à Québec ${ }^{212}$. La plupart ne se connaissaient même pas. Quand ils se séparèrent, ils avaient non seulement retrouvé des frères dans les Canadiens français, mais décidé de réunir

the French-Language Controversy in Ontario, p. 139), plusieurs organisateurs qui avaient participé à la célébration de la Saint-Jean-Baptiste à L'Orignal le 21 juin [qui était un lundi en 1880 , et non pas un samedi comme l'indique l'auteur], auraient quitté dès la célébration terminée afin d'aller célébrer à Québec; il est impossible d'ajouter ces personnes au nombre des délégués, car il n'est pas dit qu'elles avaient été invitées a la convention et, ne connaissant pas leurs noms, nous ne pouvons vérifier si elles se trouvent parmi les inscrits. Il faut cependant ajouter à la liste au moins deux membres de la Société Saint-Jean-Baptiste de Toronto: E. G. Lemaître, président, et C. Levasseur, secrétaire; en effet, d'après le télégramme de félicitations qu'ils ont adressé au président de la Société Saint-Jean-Baptiste de Québec le soir du 25 juin (voir le texte dans $F N C F$, p. 240), ils n'avaient quitté Québec que le soir de ce jour après avoir (supposons-nous) participé à la première journée de la convention et aux célébrations de la journée précédente. - Il importe aussi de noter que les Sociétés de bienfaisance canadiennesfrançaises avaient tenu leur convention ce même jour à Saint-Sauveur de Québec (voir le compte rendu dans FNCF, pp. 234-238) et que quatre unions d'Ottawa (Saint-Thomas, Saint-Pierre, Saint-Joseph, des Secours mutuels des Franco-Canadiens), y comptaient, chacune, trois représentants, soit un total de douze (dont l'un était J.-C. Taché) parmi les quatre-vingt-dix-sept qui avaient été délégués (voir la liste, ibid., p. 593) par vingt-huit associations (voir ibid., p. 235).

211 Pascal Poirier, "Introduction», dans Conventions nationales des Acadiens [désormais: CNA ], recueil des travaux et délibérations des six premières conventions, compilé par Ferdinand-J. Robidoux, avocat, vol. 1: Memramcook - Miscouche - Pointe de l'église [sic], 1881 1884 -1890, Shédiac, N.-B., Imprimerie du «Moniteur Acadien», 1907, pp. xili-xiv.

212 Ibid., p. ix, xiil et xxviil. 
une première convention nationale des Acadiens à Memramcook l'année suivante ${ }^{213}$.

Comment expliquer l'absence, à la convention nationale de Québec, d'une commission qui aurait fait rapport sur la situation des Canadiens français de l'Ontario, le si petit nombre de délégués francoontariens, et le fait que Joseph Tassé et Benjamin Sulte n'aient pas cru bon de parler de leurs compatriotes ontariens? Y aurait-il eu conflit entre la Société Saint-Jean-Baptiste de Québec, organisatrice de la convention, et celle d'Ottawa, qui n'y aurait envoyé, en plus de son président, qu'un délégué (et québécois en plus...)? Y aurait-il eu défaut d'organisation ou difficulté de relations entre les différentes sociétés Saint-Jean-Baptiste de l'Ontario? Les ressources auraient-elles manqué? Les Franco-Ontariens auraient-ils été plus pauvres que les Acadiens des Maritimes ou les Franco-Américains des États de l'Ouest? Y aurait-il eu absence d'information? Pourtant, sept mille exemplaires du manifeste d'invitation avaient été distribués au Canada et aux États-Unis et l'invitation avait été faite à tous, par l'intermédiaire des sociétés Saint-Jean-Baptiste, de venir célébrer la fête nationale à Québec ${ }^{214}$.

Quoi qu'il en soit, la quasi-absence des FrancoOntariens de la Convention nationale de Québec, et non pas de la célébration de la Saint-Jean-Baptiste ${ }^{215}$,

${ }^{213}$ Ibid., p. xxii.

${ }^{214}$ H.-J.-J.-B. Chouinard, FNCF, pp. 93-106.

${ }^{215}$ En effet, selon H.-J.-J.-B. Chouinard (ibid., p. 192), le 24 juin, les vingt-huitième, vingt-neuvième et trentième divisions de la procession comprenaient les «délégués de la Société Typographique d'Ottawa»; la trente et unième, "les élèves de l'Université d'Ottawa, avec corps de musique»; la trente-deuxième, la «Société Saint-Jean-Baptiste d'Ottawa» et la «Société Salnt-Jean-Baptiste de Amherstburg, Onta- 
ne nous incite pas seulement à poser des questions; elle nous force à émettre des hypothèses sur la situation des Sociétés Saint-Jean-Baptiste à ce moment-là en Ontario français. Nous sommes porté à croire que, en 1880 , ces Sociétés n'étaient ni assez bien installées ni assez nanties dans l'ensemble de l'Ontario pour rassembler une commission qui aurait participé aux travaux de la convention de Québec. Nous le croyons d'autant plus que, vingt-six ans plus tard, leur projet - dont nous avons parlé plus haut - d'une «Fédération catholique et nationale des Canadiens-Français de la province d'Ontario» n'aboutit pas et, après examen, ne fut pas repris par les organisateurs du congrès de 1910 . De plus, en 1880, les Franco-Ontariens de l'Est et de l'Outaouais étaient encore plus proches de leurs origines québécoises que des autres groupes francophones du grand Ontario. Quant au Nord, il commençait à peine à se développer ${ }^{216}$ et les quelque 20000 francophones du lointain Sud-Ouest s'organisaient assez bien par eux-mêmes, mais faisaient cavalier seul, presque

rio». - Dans la description (ibid., pp. 485-516) des «chars allégoriques, drapeaux et bannières qui ont figuré dans la procession du 24 juin", on trouve minutieusement décrite (ibid., pp. 505-506), à son rang du défilé, la bannière que les Sœurs du Bon Pasteur avaient créée en 1874 pour la section Saint-Joseph de la Société Saint-Jean-Baptiste d'Ottawa; suit une description du drapeau qui avait été exécuté en 1866 pour la même section par les Sœurs Grises d'Ottawa.

${ }^{216}$ Voir Gaétan Gervais, "L'Ontario français (1821-1910)», dans C. Jaenen, Les Franco-Ontariens, pp. 82-94: "L'Expansion vers le Nord (1880-1910)»; Fernand Ouellet, "L'Évolution de la présence francophone en Ontario. Une perspective économique et sociale», ibid., pp. 175-188: "Le Nord. Croissance et déclin»; Roger Bernard, Le Travail et l'espoir. Migrations, développements économiques et mobilité sociale, Québec / Ontario, 1900-1985, Hearst, Le Nordir, 1991, pp. 39-67: «Le Sentier migratoire Québec / Hearst», et pp. 121-148: «Peuplement du nord de l'Ontario". 
inconnus des autres groupes canadiens-français ${ }^{217}$. Des onze délégués franco-ontariens dont nous avons pu repérer la présence à la convention de Québec, quatre venaient du comté d'Essex. Ils n'avaient pas fait le voyage inutilement. On peut penser, en effet, que c'est à Québec, ou peu après leur retour, qu'ils eurent l'idée de la convention régionale du 25 juin 1883 à Windsor; réussie, elle les révéla à leurs compatriotes du Nord et de l'Est. Ceux-ci s'en souvinrent en 1908, mais ce sont surtout, comme nous le verrons plus loin, les conventions nationales des FrancoAméricains et des Acadiens ${ }^{218}$, plus que celle de Québec, qui leur servirent de modèles. Toutefois, ces modèles n'avaient pu, à eux seuls, amener les FrancoOntariens à se rassembler. Il avait fallu que, dans toutes les régions de la province et surtout dans le château fort de l'Est, ils se sentent menacés dans leur quiétude canadienne-française par la restriction progressive de leurs droits linguistiques. Alors seulement, c'est-à-dire à partir de la décennie de 1880 , ils avaient été amenés à prendre conscience peu à peu que, au milieu des Canadiens français, ils formaient, à l'intérieur des limites de la province canadienne d'Ontario, une collectivité qui avait des problèmes

\footnotetext{
217 «Le 25 juin 1883, une éclatante manifestation franco-canadienne, à l'extrémité ouest de la province d'Ontario, venait révéler à notre esprit étonné et ravi l'existence d'un groupe important et compact, peu connu jusqu'alors, de Canadiens-Français. M. Rameau les avait découverts lors de son premier voyage au Canada, mais bien peu de personnes, parmi nous, savaient que plus de 20,000 de nos compatriotes, fermement attachés à leur religion et à la langue des ancêtres, s'étaient solidement implantés dans les comtés d'Essex et de Kent et y avaient conquis cette influence prépondérante qui devait bientôt leur assurer le choix du premier sénateur canadien-français d'Ottawa, dans la personne de l'honorable docteur C. E. Casgrain.» H.-J.-J.-B. Chouinard, cité dans CÉCFO, pp. 40-41.

${ }^{218}$ Voir CÉCFO, pp. 57, 59, 86, 259.
} 
spécifiques qu'il leur incombait de résoudre de façon particulière avec leurs concitoyens anglo-ontariens ${ }^{219}$.

\section{UNE CONVENTION FRANCO-ONTARIENNE}

C'est pour cette raison que le congrès des Canadiens français de l'Ontario, même s'il eut lieu après maintes conventions nationales qui en donnèrent l'idée à ses organisateurs et les inspirèrent dans une certaine mesure, est une convention nationale originale à la fois par son organisation, ses buts, ses thèmes et sa parole. Nous définirons cette originalité en comparant, sous divers aspects, le congrès de 1910 aux conventions nationales des Canadiens français des États-Unis, du Québec et de l'Acadie. Il en ressortira, nous l'espérons, des traits distinctifs de la collectivité franco-ontarienne.

\section{UNE CONVENTION DÉMOCRATIQUE}

Nous avons déjà signalé l'aspect très démocratique du congrès d'Ottawa. L'idée de cette convention nationale est venue d'individus de divers milieux qui ont fait part à la communauté de leur intention, puis se sont constitués en comités. Ceux-ci ont alerté les francophones de toutes les parties de la province et ont fait des études sur la situation de leurs compatriotes dans chacune des régions, non seulement en déléguant des enquêteurs, mais aussi en consultant les simples citoyens des diverses paroisses avec l'aide de leurs curés. Puis, ils ont laissé aux paroissiens le

\footnotetext{
${ }^{219}$ Au sujet de cette prise de conscience ( «the rise of francophone consciousness) dans l'est de l'Ontario, voir C. Gaffield, Language, Schooling, and Cultural Conflict: The Origins of the French-Language Controversy in Ontario, pp. 131-152: "Quatre Fantômes et la foule: The Politics of Cultural Conflict».
} 
soin de choisir eux-mêmes leurs délégués (sans imposer de limites à leur nombre) lors d'assemblées populaires. Ainsi, ils ont rejoint la base de la communauté et ce sont les 1200 représentants de celle-ci qui se sont présentés à Ottawa pour approuver les travaux et les résolutions des comités ainsi que les statuts d'une Association nationale qui a survécu jusqu'à nos jours.

Les Conventions nationales acadiennes avaient été organisées de la même façon démocratique, à peu de différences près. Comme nous l'avons vu plus haut, à Québec, aussitôt la décision prise de tenir la première en 1881, les membres de la Commission acadienne avaient formé un comité exécutif «chargé de convoquer une assemblée plénière de tous les Acadiens des Provinces Maritimes, à Memramcook, au mois de juillet suivant ${ }^{220} »$. Dans la proposition qui avait entraîné la création de ce comité, ils avaient précisé que cette convention serait «composée de délégués nommés par les Acadiens de l'île-du-PrinceÉdouard, de la Nouvelle-Écosse et du NouveauBrunswick ${ }^{221} »$. Le 10 mai suivant, cinq des six membres du comité se réunirent à Shédiac; ils s'adjoignirent dix-sept autres membres laïcs et invitèrent les curés présents dans la ville à «honorer le comité de leur présence et à lui prêter le concours de leurs lumières pour la transaction des affaires». Ils résolurent aussi que «les membres du clergé ayant charge de paroisses acadiennes s(eraient) instamment et respectueusement priés de prêter leur puissant et

${ }^{220}$ Pascal Poirier, «Introduction», dans CNA, pp. xxi et xxii. Le texte de la proposition se trouve aussi dans H.-J.-J.-B. Chouinard, FNCF, pp. 444-445, et F.-J. Robidoux, CNA, p. 1.

${ }^{221}$ H.-J.-J.-B. Chouinard, FNCF, p. 444; F.-J. Robidoux, CNA, p. 1. 
indispensable concours à l'organisation de la Convention et de se mettre à la tête du mouvement que ce comité (était) chargé de mener à bonne fin ${ }^{222} \%$. Ce même jour, le Comité lança un "manifeste» dans lequel les Acadiens des diverses régions étaient incités à choisir sans tarder les délégués qu'ils enverraient à Memramcook le 20 juillet. Deux membres du comité furent chargés de faire une tournée de promotion dans les centres acadiens de l'île-duPrince-Édouard et de la Nouvelle-Écosse. Les 20 et 21 juillet, quatre-vingt-treize délégués de vingt-six villes ou paroisses se présentèrent à Memramcook et l'on estima que 5000 personnes de l'extérieur y passèrent une journée ou deux ${ }^{223}$. Des conventions semblables eurent lieu avec une assistance aussi nombreuse et un nombre plus considérable de délégués (cinq au lieu de trois par paroisse) à Miscouche $(1884)^{224}$ et à Pointe-de-l'Église (1890) ${ }^{225}$.

La Convention nationale de Québec avait été organisée d'une façon bien différente par la Société Saint-Iean-Baptiste de cette ville. L'idée était venue de la tête de l'institution et non de la communauté urbaine, dont on gagna le concours en lui exposant le projet pour ratification lors d'une assemblée publique tenue à cet effet le 26 octobre 1879. Le nombre des membres ayant beaucoup diminué à la suite de rivalités politiques, les dirigeants avaient voulu donner un élan nouveau à la Société en organisant une célébration extraordinaire de la fête nationale du 24

\footnotetext{
${ }^{222}$ F.-J. Robidoux, CNA, p. 3.

${ }^{223}$ Ibid., pp. 13-17. La liste des délégués est donnée aux pages 13 à 15 .

${ }^{224}$ Ibid., pp. 145-196.

225 Ibid., pp. 199-277. - D'autres conventions nationales eurent lieu par la suite; les plus importantes avant 1910 se tinrent à Arichat (1900), à Caraquet (1905) et à Saint-Basile (1908). Voir R. Rumilly, Histoire des Acadiens, II, pp. 832-834, 853-856, 865-868.
} 
juin 1880 à laquelle ils inviteraient les Canadiens français de l'Amérique du Nord ${ }^{226}$. Ils la feraient suivre d'une convention nationale dont les participants, en nombre limité ${ }^{227}$, seraient choisis par les Sociétés parmi leurs membres; les membres du clergé ne pourraient être invités que "pour des raisons exceptionnelles ${ }^{228}$ ». La Convention de Québec fut donc, dans une bonne mesure, une convention nationale des Sociétés Saint-Jean-Baptiste et de leurs dirigeants ou représentants plutôt qu'une convention nationale du peuple entier comme le seraient les premières conventions acadiennes et le congrès francoontarien de 1910.

${ }^{226}$ Voir H.-J.-J.-B. Chouinard, FNCF, pp. 106-1 10 .
${ }^{227}$ Le programme soumis par H.-J.-J.-B. Chouinard, secrétaire du Co-
mité général, prévoyait que «toutes les sociétés canadiennes françai-
ses [sic] du Canada et des États-Unis» seraient invitées «à prendre
part aux travaux de cette convention et à s'y faire représenter par leurs
présidents respectifs, et en outre chacune par un délégué choisi par
elles en assemblée régulière convoquée à cette fin, et dâment fondé de
pouvoirs suivant procuration dûment scellée et certifiée par leurs offi-
ciers». H.-J.-J.-B. Chouinard, FNCF, p. 244 .
Le Comité décida par la suite que seraient admis comme membres de
la Convention:
"1. Les présidents et les officiers de toutes les sociétés canadiennes-
françaises du Canada et des États-Unis et les personnes invitées à y
prendre part. Dans les soclétés composées de plusieurs sections,
chaque section sera considérée comme une société indépendante. 2. Les délégués choisis par les dites [sic] sociétés.

3. Les personnes munies d'une carte d'admission. Chaque président recevra en outre pour les membres de sa société, trois cartes de membres de la Convention.

4. Les membres du clergé sont de droit membres de la Convention et seront admis sans cartes à toutes les séances de la Convention et aux séances des Commissions.» (Ibid., p. 250.) Ce quatrième paragraphe fut ajouté tardivement et l'on supprima, pour des raisons de préséance, un article du programme qui plaçait la Convention sous le patronage du lieutenant-gouverneur du Manitoba, des archevêques de Québec et de Saint-Boniface et des évêques des provinces de Québec et du Manitoba. Ibid., pp. 259-260.

228 Ibid., p. 260. 
UNE CONVENTION PROVINCIALE

Les conventions nationales de Montréal et de Québec avaient eu, en plus de leur caractère national, fondé sur des liens linguistiques, culturels et religieux, un visage international, car elles rassemblaient des résidants, voire des citoyens de deux pays: le Canada et les États-Unis, et c'est à différents États ou régions de ces pays qu'appartenaient les conférenciers. Les premières conventions acadiennes eurent, au contraire, un caractère régional; elles ne réunirent que les Acadiens des Maritimes et, à deux exceptions près - Sir Hector Langevin, qui discourut de façon fort paternaliste à Memramcook ${ }^{229}$ et envoya à Pointe-de-l'Église une lettre qui fut lue ${ }^{230}$, et M. J.-P. Rhéaume, président de la Société SaintJean-Baptiste de Québec, que l'on avait invité à Memramcook parce qu'il avait accueilli les Acadiens à la convention de Québec l'année précédente ${ }^{231}$-, n'y prirent la parole que des gens de ces provinces ${ }^{232}$. Le Congrès de 1910 à Ottawa fut provincial: les conférenciers tout comme les membres des comités et les délégués étaient de l'Ontario.

\footnotetext{
${ }^{229}$ F.-J. Robidoux, CNA, pp. 35-39.

230 Ibid., pp. 209-211.

${ }^{231}$ Ibid., pp. 39-43.

${ }^{232}$ Lors de la première convention, on avait invité le Français Edme Rameau que les Acadiens chérissaient comme un protecteur depuis qu'il avait parlé d'eux dans la France aux colonies (Paris, A. Jouby, 1859) et qu'il leur avait rendu visite en 1860. L'invitation lui parvint trop tard. Le 10 août 1881 , dans une lettre au secrétaire de la convention (F.-J. Robidoux, CNA, pp. 1401-42), il expliquait son absence et suggérait que les Acadiens du Maine et ceux de la frontière québécoise soient invités aux conventions suivantes. Il semble bien que l'on ne suivit pas son conseil, car la liste des membres du comité exécutif et celle des délégués a la convention de Miscouche ne comprend que des Acadiens des Maritimes (ibid., pp. 159-161).
} 
UNE CONVENTION NATIONALE

Tous ces rassemblements étaient nés d'une idée commune: «l'union fait la force», et d'un besoin d'affirmer et de défendre une nationalité ou une communauté spécifique. Chacun d'eux mit donc au monde une association propre à l'identifier et à agir en son nom: la convention de Québec créa «l'Union canadienne-française de l'Amérique du Nord ${ }^{233}$ "), dont les Montréalais avaient eu l'idée en $1874^{234}$, celle de Memramcook, «la Société nationale l'Assomption ${ }^{235}$ ", et le Congrès d'Ottawa, «l'Association canadiennefrançaise d'éducation de l'Ontario". Pour mieux se faire connaître et reconnaître collectivement, l'Union canadienne-française de l'Amérique du Nord se choisit un drapeau et un chant national. Les Québécois avaient proposé le drapeau tricolore et «la Marseillaise», mais les Franco-Américains demandèrent et firent accepter le drapeau blanc aux fleurs de lys, en rappel de Carillon et de la Nouvelle-France, et «Vive la Canadienne ${ }^{236}$ ».

233 Voir H.-J.-J.-B. Chouinard, FNCF, pp. 312, 393-395; R. Rumilly, Histoire de la Société Saint-Jean-Baptiste de Montréal, p. 123; id., Histoire des Franco-Américains, p. 94. - Des sept grandes divisions territoriales de l'association, trois sont canadiennes: la province de Québec, les provinces Maritimes, les provinces de l'Ouest; dans FNCF, il n'y a aucun indice que l'on ait même songé à faire de l'Ontario une division. ${ }^{234}$ R. Rumilly, Histoire de la Société Saint-Jean-Baptiste de Montréal, p. 104.

235 "En 1957, le nom fut changé en "Société nationale des Acadiens" afin d'éviter toute confusion avec la Compagnie d'assurance l'Assomption puis, en 1992, en "Société nationale de l'Acadie"». Léon Thériault, "L'Acadie de 1763 à 1990. Synthèse historique», dans l'Acadie des Maritimes. Études thématiques des débuts d̀ nos jours [désormais: ADM], Moncton, Chaire d'études acadiennes, Université de Moncton, 1993, p. 67 , note 98 .

${ }^{236}$ Voir H.-J.-J.-B. Chouinard, FNCF, p. 312 . - Le soir du 24 juin, on avait chanté pour la première fois, sur la musique de Calixa Lavallée, le poème du juge Adolphe Routhier, "Ô Canada", qui allait s'imposer comme hymne national des Canadiens français avant de devenir offi- 
Les Acadiens firent davantage. La première préoccupation de la Convention de Memramcook fut de choisir «une fête nationale générale pour les Acadiens des provinces maritimes". La question fut longuement débattue. Certains auraient préféré la SaintJean-Baptiste. Mais la très grande majorité des membres du comité spécial (douze sur 16) s'opposa et l'assemblée approuva leur choix du 15 août, fête de l'Assomption de la Vierge Marie, qui était la fête nationale de la France au temps des fondateurs de l'Acadie. Les arguments des gagnants avaient pour fondements l'identité acadienne et la dévotion traditionnelle des Acadiens à Marie. Les passages suivants, extraits de trois des douze discours publiés dans les actes de la convention ${ }^{237}$, expriment clairement la volonté des Acadiens de se voir reconnaître comme une nation distincte:

$[\ldots]$, un caractère national très distinct peut se former à la longue en dépit d'une identité de langue, de religion et d'origine.

[...] le petit peuple acadien se distingue de tous les peuples de la terre, sans même excepter le peuple canadien $[. .$.$] parce que les circonstances qui se rattachent à$ son origine et qui ont entouré son existence sont différentes de celles qui ont formé le caractère national des autres peuples.

[...] En choisissant une fête que nous pourrons dire nôtre, nous voulons affirmer notre existence comme peuple distinct, ce que nous sommes en réalité. C'est pour fêter notre nationalité $[\ldots]^{238}$.

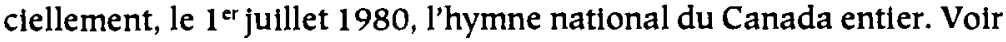
ibid., pp. 140-I 41, 200; Gilles Potvin, «Lavallée, Calixa (baptisé Callixte)", dans $D B C$, vol. 12 , p. 579.

${ }^{237}$ F.-J. Robidoux, CNA, pp. 45-79.

${ }^{238}$ «Discours du Rév. S. J. Doucet», ibid., pp. 47-48. - StanislasJoseph Doucet (1847-1925), né à Bathurst, études à Chatham et à Montréal, prêtre en 1870, vicalre à Tracadie [N.-B.] (1870-1871), curé 
[...] le patron qu'il nous faut au ciel est un patron bien à nous, qui nous soit propre, qui ait des rapports de convenance avec notre histoire. La fête nationale des Acadiens ne doit pas être, si nous voulons rester fidèles à notre passé, celle des Écossais, des Irlandais, ni même des Canadiens-Français; [...]. Chacune de ces nationalités a sa fête nationale, sa fête de famille. Pourquoi les Acadiens n'auraient-ils pas aussi la leur?

[...] Avec la Saint-Jean-Baptiste pour fête nationale, on ne nous distinguera pas des Canadiens [Canadiens français]. Or, n'est-ce pas que nous voulons non seulement rester ce que nous sommes, mais qu'on sache qui nous sommes?

[...] (L'Assomption), nous voulons en faire l'emblême de notre réveil national ${ }^{239}$.

[...]; nous sommes convoqués ici par les organisateurs de cette convention acadienne pour "affirmer notre existence comme peuple" et prendre les moyens de conserver notre nationalité. $[\ldots]$

Les Canadiens ayant choisi Saint Jean-Baptiste pour patron, il me semble qu'à moins de vouloir confondre notre

de Shippagan (1871-1872), de Saint-Charles-d'Aldouane (1872-1878), de Pokemouche-en-bas (1878-1888), de Shippagan (1888-1898), de Grande-Anse (1898-1925). (D'après J.-B.-A. Allaire, Dictionnaire biographique du clergé canadien-français, vol. 2, pp. 188-189, et DAF, p. 125.) Voir Éloi DeGrâce, Monseigneur Stanislas-J. Doucet, p.d., 18471925, Shippagan (N.-B.), [chez l'Auteur], 1977, $160 \mathrm{p}$.

${ }^{239}$ "Discours de M. Pascal Poirier", ibid., pp. 55-57. - Pascal Poirier (1852-1933), né à Shédiac (N.-B.), études au Collège Saint-Joseph de Memramcook, maître de poste à la Chambre des communes (18721885 ), écrivain, avocat (au barreau du Québec en 1873, du NouveauBrunswick en 1883), sénateur (1885-1933), membre du Club des Dix (Ottawa), président-fondateur de la Société nationale l'Assomption (1881-1904, 1913-1921), membre de l'Institut canadien-français d'Ottawa (à partir de 1873?, président en 1882-1883), membre de la Soclété royale du Canada (1899-1933), décédé à Ottawa. Voir DAF, p. 287; M. Maillet, Histoire de la littérature acadienne. De rêve en rêve, pp. 72-79; id., Bibliographie des publications d'Acadie, 1609-1990. Sources premières et sources secondes, coll. «Balises», 2, Moncton, Chaire d'études acadiennes [Université de Moncton], 1992, pp. 236-238; Gérard Beaulieu, «Pascal Poirier, premier sénateur acadien, 1852-1933", thèse de maîtrise ès arts, Université d'Ottawa, 1971, $107 \mathrm{f}$. 
nationalité dans la leur il est urgent pour les Acadiens de se choisir une fête particulière. Il est bon de remarquer que nous ne sommes pas les descendants des Canadiens, mais de la France, et par conséquent je ne vois aucune raison qui nous engage à nous faire adopter la Saint-JeanBaptiste comme notre fête nationale. À l'exemple des Anglais, des Irlandais, des Écossais, des Allemands, nous devons tâcher de nous choisir une fête qui nous rappelle nos origines. J'ose même affirmer que la fête de l'Assomption a toujours été et doit être toujours la fête nationale des Acadiens, descendants de la race française ${ }^{240}$.

Dès leur deuxième convention, à Miscouche, les Acadiens se choisirent un drapeau national. Ils optèrent à l'unanimité pour le tricolore français qui leur rappellerait leurs origines, mais, pour bien marquer leur nationalité distincte, ils en chargèrent la partie bleue d'une "étoile aux couleurs papales» (jaune), figure de Marie, Stella Maris, étoile de la mer, qui les identifierait comme peuple différent et

${ }^{240}$ «Discours du Révd. M. F. Richard», ibid., pp. 58 et 62. - MarcelFrançois Richard (1847-1915), né à Saint-Louis de Kent (N.-B.), études au Collège Saint-Dunstan (Î.-P.-É.), puis au Grand Séminaire de Montréal, prêtre en 1870 , curé de sa paroisse natale, fondateur du Collège Saint-Louis (1870-1882), chargé de la mission de Rogersville en 1885. Voir DAF, p. 310-311; Fr. M. Gildas, Mgr M.-F. Richard, prélat domestique. Sa vie et ses œuvres, Moncton, L'Imprimerie nationale ltée, 1940, 159 p.; Camille-A. Doucet, Une étoile s'est levée en Acadie. Marcel-François Richard, [Charlesbourg-Est, les Éditions du Renouveau, 1973], 312 p. - "Tour à tour et simultanément fondateur de paroisses, bâtisseur d'églises, de monastères, de collège, de couvent, d'écoles, apôtre de la colonisation, orateur de congrès, ce curécolonisateur-patriote fut, pendant plus de quarante ans, de toutes les causes comme de toutes les luttes religieuses et nationales en Acadie. L'on dit que ses discours bien structurés, "sa parole enflammée" [Fr. M. Gildas, op. cit., p. 93], sa stature imposante produisaient sur son auditoire une très vive impression. Nul, certainement, ne songerait à nier que son intervention fut prépondérante dans le choix d'une fête nationale distincte de celle des Canadiens français. Tous reconnaissent, également, que l'Acadie lui doit le tricolore étoilé comme drapeau et l'Ave Maris Stella comme hymne national.» M. Maillet, Histoire de la littérature acadienne. De rêve en rêve, p. 69. 
désireux de le rester, en même temps qu'attaché à l'Église catholique romaine ${ }^{241}$. La commission du drapeau fit aussi adopter un insigne qui serait porté «à la boutonnière aux jours de fête":

une bandelette de soie bleue sur laquelle sera frappée une étoile entourée de rayons. Au-dessous un vaisseau voguant à pleines voiles avec le mot Acadie écrit sur son pavillon. La devise au bas sera: "L'union fait la force." Le tout couronné d'une rosette en ruban rouge et blanc ${ }^{242}$.

On compléta le choix des emblèmes en adoptant à l'unanimité comme hymne national «l'Ave Maris Stella du chant grégorien, avec des paroles françaises». Ce fut un moment plein d'émotion, selon le reporteur du Moniteur acadien:

La scène qui accompagne l'adoption du drapeau et le chant de l'Ave Maris Stella était solennelle et touchante: un grand nombre pleuraient. C'est qu'au lieu de la mort nationale, le peuple acadien saluait dans son drapeau l'emblême de la vie nationale, se levant sur lui pour la première fois depuis $1713^{243}$.

Les organisateurs et les délégués du Congrès d'Ottawa n'expriment pas le désir d'afficher aussi ostensiblement leur identité: ils ne se choisiront ni fête nationale ni hymne national propres, et c'est aussi tard que le 25 septembre 1975 qu'ils déploieront un drapeau national ${ }^{244}$. En 1910 , cependant, ils sont déjà conscients de former une communauté différente de la québécoise. Ils l'ont démontré, comme nous l'avons vu plus haut, en n'invitant que des con-

\footnotetext{
${ }^{241}$ Voir F.-J. Robidoux, CNA, pp. 156, 172, 177-178.

${ }^{242}$ Ibid., p. 178.

${ }^{243}$ Ibid., p. 156; voir aussi pp. 162-163.

${ }^{244}$ CEuvre de Gaétan Gervais, professeur d'histoire à l'Université Laurentienne, et de Michel Dupuis, son élève, il flotta dès ce jour-là à l'un des mâts de l'Université de Sudbury, mais ne fut reconnu que deux ans plus tard par l'ACFO.
} 
férenciers d'un territoire bien déterminé: l'Ontario, et, bien plus encore, en se présentant constamment comme «Canadiens-Français d'Ontario ${ }^{245}$ ». Il est incontestable qu'ils le faisaient consciemment pour se distinguer des Canadiens français des autres provinces, tout comme les conférenciers des conventions acadiennes allaient jusqu'à se dire «AcadiensFrançais», lorsqu'ils voulaient affirmer très fortement leur spécificité par rapport aux Canadiens français, qu'ils appelaient tout simplement les Canadiens ${ }^{246}$. Ils se démarquaient de ceux-ci par leurs origines, ce que ne pouvaient faire les Canadiens français de l'Ontario, car la plupart d'entre eux étaient issus de Québécois.

Les Canadiens français de l'Ontario ne se définissent pas moins comme un groupe distinct des autres groupes canadiens-français et des Acadiens lorsqu'ils utilisent le mot "national». Lorsque l'abbé Beausoleil, dans le Moniteur du 18 décembre 1908,

\footnotetext{
${ }^{245}$ Cette appellation n'était pas nouvelle en 1910: «Indeed, the Prescott county example supports the conclusion that the phrase «French Canadians in Ontarion was consistently employed throughout the nineteenth century.» Chad Gaffield, Language, Schooling, and Cultural Conflict: The Origins of the French-Language Controversy in Ontario, p. xv. Gaffield voit aussi avec raison une marque d'identité dans cette appellation; Il ne nous semble pas possible, cependant, d'affirmer, à partir du seul exemple de cette région, que cette identité était sentie collectivement ou nationalement spécifique par tous les Canadiens français de l'Ontario en 1880; elle ne le sera, selon nous, qu'à partir du moment où tous ces Canadiens français, ou la grande majorité d'entre eux, feront front ensemble en vue d'une action commune ou se réuniront en une association ou un regroupement, au moins provisoire, d'associations canadiennes-françaises de l'Ontario.

${ }^{246}$ Il n'est pas sans intérêt de signaler que les Canadiens français de la fin du XIX ${ }^{\mathrm{c}}$ siècle et du début du XXe utilisaient aussi le terme "francocanadien» pour s'identifier. Voir H.-J.-J.-B. Chouinard, FNCF, p. 264 (Pierre-Joseph-Olivier Chauveau) et passim; aussi CÉCFO, p. 264 (Emmanuel Tassé, qui emploie également franco-catholique à la page 261).
} 
fait valoir la nécessité de tenir un congrès des Canadiens français de l'Ontario, c'est un «Congrès National» qu'il veut, et ce qu'il entend par ces mots, ce sont des «assises nationales» comme celles qu'ont tenues les Franco-Américains et les Acadiens, c'està-dire un congrès qui «étudiera les conditions sociales des Canadiens-Français d'Ontario" qu'il voit comme formant un "bloc" de 235000 personnes établies «sur le sol d'Ontario [...] pour y rester» et "pour y vivre ${ }^{247}$ ». Bien plus, lorsque le sénateur Belcourt affirme «que le Congrès n'est pas et ne sera pas non plus purement un groupement national ${ }^{248}$, ce n'est pas pour y admettre des Canadiens français d'ailleurs, mais des Ontariens d'autres origines qui offriraient leur aide. Quand les organisateurs et les conférenciers du congrès d'Ottawa répètent que "l'union fait la force», ils proposent cette devise à la seule collectivité franco-ontarienne et non pas, comme les organisateurs et les conférenciers de la convention nationale de Québec, à tous les groupes francophones de l'Amérique du Nord. C'est cette même communauté francophone de l'Ontario que l'abbé Léon-Calixte Raymond considère comme un "peuple» lorsqu'il rappelle à ses auditeurs de la messe d'ouverture que «le but du Congrès est d'arriver à développer jusqu'à l'épanouissement» les «trois qualités [...] nécessaires pour constituer un peuple: l'unité de la foi, l'uniformité des mœurs, la communauté de langage $^{249}$ ». Pour G. W. Séguin ces trois qualités sont, avec les traditions et les aspirations de la collectivité, les cinq «éléments constitutifs d'une nation ${ }^{250}$ ».

\footnotetext{
${ }^{247}$ Dans CÉCFO, pp. 50-51.

${ }^{248}$ Ibid., p. 222.

${ }^{249}$ Ibid., p. 111.

250 Ibid. , pp. 248-249.
} 
La principale aspiration des Franco-Ontariens, c'est à une éducation française à tous les niveaux d'enseignement ${ }^{251}$ y compris au niveau supérieur ${ }^{252}$, afin de sauvegarder non seulement leur langue et leur culture, mais aussi leur foi catholique. Ils n'en excluent pas pour autant l'apprentissage de la langue anglaise, car "c'est une nécessité dans notre province de savoir les deux langues, mais n'allons pas conclure de là que c'est la langue anglaise qui doit être la seule apprise; non, c'est la langue française qu'il faut d'abord apprendre très bien, puis, ensuite, comme perfectionnement, la langue anglaise ${ }^{253} \|$. Les Acadiens réclament pareillement des institutions scolaires bilingues dans lesquelles la langue française aura la préséance, car «rien ne saurait faire obstacle à l'avancement des Acadiens comme le défaut d'instruction dans leur propre langue ${ }^{254} »$. Cependant, ils «doivent aussi apprendre la langue anglaise», afin de «faire une concurrence effective aux autres nationalités environnantes ${ }^{255}$. Acadiens et FrancoOntariens se distinguent done des Québécois qui, dans l'ensemble, ne se soucient pas d'apprendre l'anglais ou l'apprennent peu et ne traitent pas ce sujet à leur convention de 1880 . Il n'empêche que le Québécois Hector Langevin, homme politique qui connaît le Canada pour l'avoir parcouru, n'hésite pas, lui, à encourager le bilinguisme chez les Acadiens:

${ }^{251}$ Voir ibid., 39, 89, 111.

252 Voir ibid., pp. 89, 102, 120.

${ }^{253}$ Ibid., pp. 47-48.

${ }^{254}$ Dans F.-J. Robidoux, CNA, p. 104.

${ }^{255}$ Hubert Girroir, ibid., p. 111 . - Hubert Girroir (1825-1884), né à Tracadie (N.-É.), études théologiques au Séminaire de Québec, prêtre en 1853, vicaire puis curé de la cathédrale d'Arichat et professeur puis supérieur du collège de l'endroit (1853-1863), curé de Little [West] Arichat (1863-1868), de Chéticamp (1868-1875), de Havre-Boucher (1875-1884). (D'après DAF, p. 167.) 
Répandez parmi vous l'instruction, l'instruction française, afin de ne pas oublier votre langue; car vous ne formerez une race à part, vous ne serez le peuple acadien, qu'en autant que vous resterez français et catholiques. Mais en apprenant le français il faut aussi apprendre l'anglais. Pour le commerce, pour l'agriculture, pour la prédication religieuse, pour la pratique de la médecine, pour les fins politiques, au barreau, vous avez besoin de la langue anglaise ${ }^{256}$.

L'Acadien Pascal Poirier, qui réside à Ottawa et passe une bonne partie de son temps en Acadie ou avec ses compatriotes du Canada et des États-Unis, est conscient des dangers auxquels l'utilisation quotidienne de la langue anglaise expose la langue maternelle des francophones; aussi suggère-t-il, comme précaution à prendre, une ligne de conduite commune:

La connaissance de l'anglais nous est nécessaire, indispensable même; mais, si nous voulons perpétuer notre nationalité, et, je puis ajouter, conserver notre religion, il est de notre devoir essentiel de parler notre langue, lorsque nous sommes entre nous, et de la parler, avant toute autre et à l'exclusion de toute autre, au foyer, dans notre famille et à l'église. Prions et aimons en français. C'est là toute la loi et les prophètes de notre évangile acadien. Tant que la parole de Dieu nous sera prêchée en français et que nos jeunes gens se conteront leurs amours en français, la nationalité sera sauve. Hors de là, pas de salut national ${ }^{257}$.

\section{UNE CONVENTION LOYALE}

Acadiens et Franco-Ontariens insistent à la fois sur le fait que la connaissance des deux langues facilitent les relations avec les anglophones du Canada et sur la loyauté, que tout francophones qu'ils soient, ils n'ont de cesse de garder envers l'Angle-

${ }^{256}$ Dans F.-J. Robidoux, CNA, pp. 37-38.

${ }^{257}$ Ibid., p. 273. 
terre et ses souverains. Les Québécois affirment la même loyauté, mais ils le font de façon moins forte que les Acadiens, tandis que les Franco-Ontariens, eux, claironnent en quelque sorte leur fidélité. Ils se disent «fiers d'accomplir un devoir en priant (leur) auguste souverain d'accueillir (leurs) hommages» dans un câblogramme par lequel «le Congrès d'Éducation, représentant plus de 200,000 CanadiensFrançais d'Ontario, prie humblement Sa Majesté d'accepter le tribut de son inaltérable loyauté et l'hommage de son absolu dévouement à Sa Personne et à l'Empire ${ }^{258}$. Et le juge Constantineau, leur chef de file, de renchérir au nom de tous, comme nous l'avons vu plus haut, sur cette déclaration ${ }^{259}$. Ces gestes et ces paroles de soumission laissent voir jusqu'à quel point la collectivité franco-ontarienne vivait dans la crainte au moment du Congrès de 1910 et sentait le besoin de démolir la réputation de mauvais sujet qu'on lui avait bâtie au cours des deux décennies précédentes.

Les Acadiens sont plus libres et plus audacieux. Ils puisent leur fierté dans leur histoire, car ils en ont une en propre, bien vivante à travers une tradition orale qui a la puissance du mythe littéraire. Elle est tissée de misères et d'exils forcés, de retour au pays et de renaissance, voire de résurrection comme peuple dans la terre même d'où on les avait expulsés. Quand ils évoquent leur passé au cours des années 1880 , c'est d'une nation presque tricentenaire qu'ils parlent, et ils glorifient les générations qui les ont précédés dans une Acadie qu'ils n'ont jamais cessé, même en exil, de considérer comme leur pays. Telle n'est pas,

${ }^{258}$ Voir CECFO, pp. I 13-114.

259 Voir ibid., pp. 121-122. 
en 1910, la situation des Franco-Ontariens. Premiers occupants de l'Ontario, ils ont été débordés graduellement depuis la fin du XVIII ${ }^{e}$ siècle par l'arrivée d'immigrants anglophones dont le nombre a toujours dépassé de beaucoup celui des immigrants francophones. Lorsque les congressistes d'Ottawa, tel PierreMartial Côté, rappellent des gloires du passé - ce qu'ils font peu -, les noms qu'ils évoquent appartiennent à la Nouvelle-France et au Québec. Les Canadiens français de l'Ontario ont bien une histoire, mais ils n'en prendront conscience comme peuple que progressivement à partir de cette première prise de parole collective qu'est le Congrès et du premier tableau général que les rapporteurs dessinent de leur situation dans les différentes régions d'une province qu'ils considèrent déjà comme un pays, car ils expriment leur intention non seulement de continuer à l'habiter, mais encore d'y profiter de tous les droits, privilèges et avantages qui sont ceux de leurs concitoyens anglophones. C'est à travers les difficultés qu'ils rencontreront que s'inscrira dans le tissu du pays ontarien l'histoire de ce peuple qui commence à se situer dans son espace, mais n'a pas encore, tel le Canada français avant François-Xavier Garneau, récupéré son temps de vie ni relevé ses traces plus que séculaires en Ontario.

\section{UNE CONVENTION OPTIMISTE}

Les congressistes d'Ottawa ne manquent pas d'optimisme; cependant, ils ne fondent pas cet optimisme sur leur ontarianité, mais sur leur croissance démographique et sur le fait qu'ils font partie de la urace canadienne-française" qui doit maintenir «son action civilisatrice sur le monde" et accomplir «jusqu'à 
l'heure dernière, sa mission providentielle de misères et de combats d'abord, d'accroissement et de vitalité ensuite, de développement, d'expansion, d'évangélisation, de succès et de prospérité finalement ${ }^{260}$ ». Cette idée d'une mission providentielle des Canadiens français, que le sociologue Edme Rameau de Saint-Père avait prônée de façon convaincante dans la France aux colonies ${ }^{261}$ avait été répandue en abondance dans le Québec de la seconde moitié du $\mathrm{XIX}^{\mathrm{e}}$ siècle ${ }^{262}$ et même de la première moitié du $\mathrm{XX}^{\mathrm{e} 263}$. Lors de la convention nationale de 1880 à Québec, dans une lettre au président, Mgr Louis-François Laflèche ${ }^{264}$, évêque des Trois-Rivières, avait démontré pourquoi et comment

${ }^{260}$ «Discours de Son Honneur le Juge A. Constantineau», dans CÉCFO, p. 123.

${ }^{261}$ Chapitre XIV, pp. 249-275: «De l'avenir moral et intellectuel des Canadiens en Amérique».

${ }^{262}$ Voir, par exemple, «Discours de M. L. F. Laflèche, v.-g., prononcé lors de la fête de la Saint-Jean-Baptiste à "Ottawa", lundi le 25 juin, 1866", dans CEuvres de Mgr Louis-François Laflèche, évêque des TroisRivières, publiées par Arthur Savaète, Paris, Arthur Savaète, éditeur, [s.d.], pp. 49-62. - Nous avons reproduit ce texte en entier dans la Patrie littéraire, 1760-1895, vol. 2 de l'Anthologie de la littérature québécoise sous la direction de Gilles Marcotte, Montréal, La Presse, 1978, pp. 478-489; [ $2^{\mathrm{e}}$ éd. révisée], Montréal, L'Hexagone, 1994, vol. 1, t. 2, pp. 768-778.

${ }^{263}$ Voir, entre autres, Mgr L[ouis]-A[dolphe] Paquet, «Sermon sur la vocation de la race française en Amérique, prononcé près du monument Champlain à l'occasion des noces de diamant de la Société SaintJean-Baptiste de Québec, le 23 juin 1902», Discours et allocutions, Québec, Imprimerie franciscaine missionnaire, 1915, pp. 181-202; id., Bréviaire du patriote canadien-français, sermon du 23 juin 1902, commenté par le chanoine Émile Chartier, Montréal, Bibliothèque de l'Action française, 1925, pp. 49-59 (c'est le texte Intégral de cette édition que nous avons reproduit dans la Patrie littéraire, 1760-1895, pp. 500-508; [2éd. révisée], pp. 789-797); Le Comité permanent de la survivance française en Amérique, La Vocation de la race française en Amérique du Nord, Québec, le Comité permanent de la survivance française en Amérique, 1945, 199 p.

${ }^{264}$ Voir H.-J.-J.-B. Chouinard, FNCF, pp. 113-116. 
cette mission avait fait le salut des Canadiens, et quatre orateurs des plus influents lui avaient consacré une partie importante ou la quasi-totalité de leur discours: Mgr Antoine Racine ${ }^{265}$, évêque de Sherbrooke, l'honorable Pierre-Joseph-Olivier Chauveau $^{266}$, ex-premier ministre du Québec, l'honorable juge Adolphe-Basile Routhier ${ }^{267}$, le poète, conteur et romancier Pamphile Lemay ${ }^{268}$. Les FrancoAméricains croyaient qu'ils étaient destinés à accomplir la même tâche aux États-Unis ${ }^{269}$. Aucun Acadien ne discourut sur cette mission canadiennefrançaise; on trouve cependant une trace partielle

${ }^{265}$ Voir ibid., pp. 167-186. Le discours de Mgr Racine comprend trois parties qui sont autant de réponses dans l'ordre aux questions suivantes: "Quelle a été la vocation du peuple canadien-français?" (pp. 170174), "Le peuple canadien a-t-il été fidèle à sa vocation?" (pp. 174180), "Que devons-nous faire pour continuer cette alliance de la religion et de la patrie, pour suivre la voie que Dieu nous a tracée?» (pp. 180-186).

266 Voir ibid., pp. 277-279.

${ }^{267}$ Voir ibid., pp. 282-295: «Le Rôle de la race française en Amérique». - Deux phrases (p. 285) donnent une excellente idée du contenu et de l'orientation de ce discours: «Pour juger sainement de la mission d'une race, il faut nécessairement étudier son histoire et remonter jusqu'à son origine. Les seules lumières du passé peuvent éclairer l'avenir."

${ }^{268}$ Voir ibid., pp. 374-383: «La Littérature canadienne-française et sa mission". - Nous avons reproduit une grande partie de ce discours (pp. 375-376, 381-383) dans la Patrie littéraire, 1760-1895, pp. 368371 ; [ $2^{\mathrm{e}}$ éd. révisée], pp. 660-663.

${ }^{269}$ «Messieurs, je crois que ce n'est pas sans un dessein providentiel que les Canadiens sont comme irrésistiblement poussés vers tous les points de la vaste république américaine. $M$. le Président l'hon. $M$. Chauveau, vient d'exprimer cette vérité, et l'autorité de sa parole me confirme dans ma croyance. Le Canada, on l'a souvent répété, est appelé à jouer en Amérique le rôle de la France en Europe. Et nous, Canadiens des États-Unis, si nous sommes fidèles à notre vocation nationale, nous rendrons indubitablement service à la république qui nous donne asile et subsistance, en lui faisant connaître et apprécier, par nos œuvres et par toute notre conduite, le Dieu de notre amour et de nos adorations.» M. Pager, "Le Rôle des Canadiens-Français aux États-Unis", dans H.-J.-J.-B. Chouinard, FNCF, p. 306. 
de cette idée dans le discours du député GilbertAnselme Girouard, secrétaire de la convention de Memramcook: «[...] l'éducation est la sauvegarde des peuples; c'est par elle qu'une nation s'élève, grandit, et parvient au but que la providence lui a assigné $^{270} . »$ Il n'empêche que les discours des conventions acadiennes sont de tous les plus imprégnés de foi chrétienne; tout se passe comme si les Acadiens allaient tout simplement leur chemin, protégés et guidés par Dieu et Marie, leur patronne, sans intention de conversion ni de conquête, mais avec le désir de vivre en harmonie avec leurs concitoyens anglophones à qui ils croient devoir pardonner, en chrétiens charitables, même le crime que fut la déportation de 1755.

\section{$U_{\text {NE CONVENTION LITTÉRAIRE }}$}

À la Convention de Québec en 1880, il y avait eu place pour les lettres et les arts ${ }^{271}$. Tel ne fut pas le cas dans les Conventions acadiennes ni au Congrès de 1910. Pourtant, vivaient encore à Ottawa une dizaine d'écrivains, qui avaient publié au cours des années précédentes et le feraient encore dans les années suivantes, dont Benjamin Sulte, qui avait rédigé le rapport sur les lettres à la Convention de Québec, et d'autres qui avaient participé au colloque littéraire de l'Institut canadien-français en 1877.

\footnotetext{
${ }^{270}$ Voir F.-J. Robidoux, CNA, p. 99. - Gilbert-Anselme Girouard (18461885), né à Sainte-Marie-de-Kent (N.-B.), il y enseigne durant deux ans après avoir terminé ses études classiques en 1868 au Collège Saint-Joseph de Memramcook; en 1870, il est marchand général à Bouctouche; de 1878 à 1883 , il est député conservateur à la Chambre des communes; il avait été l'un des membres fondateurs de la Société nationale de l'Assomption. (D'après DAF, p. 167.)

${ }^{271}$ Voir H.-J.-J.-B. Chouinard, FNCF, pp. 347, 349, 41 4-4 16, 429-436.
} 
Le Congrès de 1910 fut littéraire pour une autre raison: les discours contenus dans les actes sont d'une très belle venue. La composition de la plupart d'entre eux est remarquable. L'écriture, à deux ou trois exceptions près, l'emporte par son classicisme et sa simplicité sur les textes parfois romantiques et un peu ronflants de la Convention de Québec. La plupart des conférenciers d'Ottawa vont droit au but: ils connaissent bien leur langue et ils n'ont cure que de transmettre leur message, à savoir que les FrancoOntariens doivent travailler ensemble à la revendication de leurs droits de citoyens canadiens, et principalement de ceux qui leur permettront d'obtenir et de gérer, à tous les niveaux d'enseignement, des établissements où la langue française tiendra le premier rang sans que soit exclu, cependant, l'apprentissage de l'anglais. Parlant avec leur cœur dans une situation où rien moins que la survivance linguistique et culturelle de leur communauté leur semble en jeu, ces éveilleurs et rassembleurs trouvent les mots qu'il faut pour communiquer le message à leurs auditeurs. Acclamés et approuvés par douze cents délégués populaires qui les transmettront à leurs électeurs ou coparoissiens, les discours de quelques-uns deviennent la première prise de parole collective de l'Ontario français, et le livre qui contient ces actes miroir et projet d'une communauté - , constitue un texte fondateur receleur d'identité. 